\title{
FLORA Y VEGETACIÓN DE LA ZONA DE ESPECIAL CONSERVACIÓN (ZEC) SIERRA DE CAMAROLOS (MÁLAGA, ESPAÑA)
}

\author{
Baltasar CABEZUDO, Federico CASIMIRO SORIGUER-SOLANAS, \\ José GARCÍA-SÁNCHEZ y Andrés V. PÉREZ LATORRE* \\ Dpto de Biología Vegetal. Facultad de Ciencia. Universidad de Málaga. 29071. Málaga \\ *Autor para correspondencia: avperez@uma.es
}

Recibido el 27 de septiembre de 2016, aceptado para su publicación el 15 de noviembre de 2016

RESUMEN. Flora y Vegetación de la Zona de Especial Conservación (ZEC) Sierra de Camarolos (Málaga, España). El objetivo de este trabajo es realizar un catálogo de la flora, de las comunidades vegetales y el estudio del dinamismo sucesional y del paisaje vegetal de la Zona de Especial Conservación (ZEC) Sierra de Camarolos (ES6170012), situada en la provincia de Málaga (Andalucía, España) con una superficie de $8.691 \mathrm{Ha}$. Presenta macrobioclima de tipo mediterráneo con termotipos meso y supramediterráneo y ombrotipos subhúmedo y húmedo. Está compuesta litológicamente de modo mayoritario por materiales calizo-dolomíticos, arcillosos y margo-yesíferos, con relieve kárstico y ondulado-escarpado y altitudes entre 500 y $1640 \mathrm{~m}$. Se encuentra en la provincia fitogeográfica Bética (región Mediterránea), sector Antequerano, subsector Antequerano (zonas margo-yesíferas) y subsector Torcalense (zonas calizodolomíticas). El catálogo florístico se compone de 879 taxones, destacando la presencia de numerosas especies amenazadas y/o legalmente protegidas a nivel autonómico como Narcissus pseudonarcissus subsp. nevadensis, Narcissus assoanus, Festuca elegans, Amelanchier ovalis, Prunus insititia, P. mahaleb, Sorbus aria, Hieracium texedense, Scrophularia viciosoi, Quercus faginea subsp. alpestris, Sarcocapnos baetica y Saxifraga biternata. Otras especies de interés son nuevas citas a nivel fitogeográfico y/o provincial. Se han catalogado 73 comunidades y asociaciones vegetales, entre las que destacan como novedades sintaxonómicas una nueva subalianza (Fumano hispidulae-Hippocrepidenion bourgaei suball. nova) y 5 nuevas asociaciones: la vegetación rupícola orófila sobre dolomías (Hieracietum baetici-texedensis ass. nova), los cardales verticícolas temporihigrófilos (Eryngio aquifolii-Cynaretum baeticae ass. nova), los majadales basófilos (Thrincio hispidae-Poetum bulbosae ass. nova), los albaidares gipsícolas (Hippocrepido bourgaei-Anthyllidetum cytisoidis ass. nova) y los piornales xeroacánticos supra-mesomediterráneos (Festuco segimonensis-Erinaceetum anthyllidis ass. nova). También se proponen 3 nuevas subasociaciones: espartal termófilo (Thymo gracilis-Stipetum tenacissimae thymetosum capitati subass. nova), vallicares (Gaudinio fragilis-Agrostietum castellanae festucetosum amplae subass. nova) y encinares mesomediterráneos termófilos (Paeonio coriaceae-Quercetum rotundifoliae pistacietosum lentisci subass. nova). El dinamismo sucesional se expresa en 8 series de vegetación. 3 series climatófilas: una mesomediterránea de Quercus rotundifolia, y 2 de Quercus faginea, respectivamente antequerana y torcalense. 3 series edafoxerófilas puntuales: una termófila subrupícola de Olea europaea subsp. sylvestris, otra karsticícola más ombrófila de Pistacia terebinthus y una gipsícola de Pinus halepensis. Existen también una serie edafohigrófila de 
fresnedas (Fraxinus angustifolia) y otra de adelfar (Nerium oleander). En los frecuentes hábitats rocosos y de gleras se describen 2 geopermaseries: una calcícola caracterizada por Saxifraga biternata, S. reuteriana y S. camposii y otra dolomitícola con Hieracium texedense e H. baeticum y, muy escaso, con Sarcocapnos baetica. Las geopermaseries dulceacuícolas lagunares están caracterizadas por $R$. peltatus subsp. saniculifolius y subsp. peltatus, Zannichellia palustris y Chara vulgaris subsp. crassicaulis. Finalmente la geopermaserie temporihigrófila de suelos vérticos se caracteriza por Eryngium caespitiferum, Phalaris caerulescens y Festuca ampla. En la ZEC existen 15 grandes unidades de paisaje zonopotencial, caracterizados en gran medida, y en el caso de los bosques, por la presencia de Quercus rotundifolia y $Q$. faginea, con diferencias entre el paisaje vegetal de los dos subsectores de la ZEC, Torcalense y Antequerano.

Palabras clave. Flora, Comunidades vegetales, Hábitats, Sierra de Camarolos, Málaga, Península Ibérica.

ABSTRACT. Flora and plant communities of the Zone of Special Conservation Sierra de Camarolos (Malaga, Spain). The objective of this work is to catalogue the flora and plant communities and studying the successional dynamism of the vegetation and the landscape of the Special Conservation Zone (ZEC) Sierra de Camarolos (ES6170012) which is located in the province of Malaga (Andalusia, Spain) with an area of $8.691 \mathrm{Ha}$. The macrobioclimate is Mediterranean with mesomediterranean and supramediterranean thermotypes (vegetation belts) and subhumid-humid ombrotypes. Geologically, dominant rocks are limestone and dolomite, clays and gypsum, with karstic and wavy-steep relief and altitudes between 500 and $1640 \mathrm{~m}$. The $\mathrm{ZEC}$ is placed in the Baetica phytogeographical province (Mediterranean Region) included in the Antequerano sector with differentiated areas: Antequerano subsector (clays-gypsum substrates) and Torcalense subsector (limestones and dolomites substrates). The floristic list consists of 879 taxa, emphasizing the presence of numerous threatened and / or legally protected species at the regional level such as Narcissus pseudonarcissus subsp. nevadensis, Narcissus assoanus, Festuca elegans, Amelanchier ovalis, Prunus insititia, P. mahaleb, Sorbus aria, Hieracium texedense, Scrophularia viciosoi, Quercus faginea subsp. alpestris, Sarcocapnos baetica and Saxifraga biternata. Other species of interest are new records at the phytogeographical and/ or provincial level. A total of 73 plant communities and associations have been catalogued, including syntaxonomic novelties as a new suballiance (Fumano hispidulae-Hippocrepidenion bourgaei subal. nova) and 5 new associations: rupicolous vegetation on dolomites (Hieracietum baetici-texedensis ass. nova), tall-herb nitrophilous vegetation on clay temporarily wet soils ((Eryngio aquifolii-Cynaretum baeticae ass. nova), basophyllous pastures (Thrincio hispidae-Poetum bulbosae ass. nova), gypsicolous shrublands (Hippocrepido bourgaei-Anthyllidetum cytisoidis ass. nova) and supra-mesomediterranean cushion shrublands (Festuco segimonensis-Erinaceetum anthyllidis ass. nova). Moreover, 3 new subassociations are proposed: thermophyllous graminoid perennial vegetation (Thymo gracilis-Stipetum tenacissimae thymetosum capitati subass. nova), wet meadows (Gaudinio fragilis-Agrostietum castellanae festucetosum amplae subass. nova) and low mesomediterranean oak forests (Paeonio coriaceae-Quercetum rotundifoliae pistacietosum lentisci subass. nova). Succesional dynamism of plant communities is expressed in 8 vegetation series. 3 series are climatophilous: one mesomediterranean of Quercus rotundifolia and two of Quercus faginea. 3 series are edaphoxerophilous: one thermophilic subrupicolous of Olea europaea subsp. sylvestris, one karstic ombrophile of Pistacia terebinthus and one on gypsum soils of Pinus halepensis. There are also 2 edaphohygrophyllous series: one of Fraxinus angustifolia and another one of Nerium oleander. In the frequent rocky and stony ground habitats, 2 geopermaseries are described: a calcicolous one, characterized by Saxifraga biternata, S. reuteriana and $S$. camposii and another dolomiticolous one, with Hieracium texedense and H. baeticum and, very scarce, with Sarcocapnos baetica. The freshwater ponds geopermaseries are characterized by Ranunculus peltatus, subsp. saniculifolius and subsp. peltatus, Zannichellia palustris and Chara vulgaris subsp. crassicaulis. Finally, the temporary hygrophilic geopermaserie of clay soils is characterized by Eryngium caespitiferum, Phalaris caerulescens and Festuca ampla. In the ZEC there are 15 large zonopotential landscape units, characterized to a great extent, and in the case of forests, by the presence of Quercus rotundifolia and Q. faginea, with differences between the vegetation landscape of the two subsectors of the ZEC, Torcalense and Antequerano.

Key words. Flora, plant communities, Habitats, Sierra de Camarolos, Malaga, Iberian Peninsula. 


\section{INTRODUCCIÓN Y OBJETIVOS}

La Sierra de Camarolos (Málaga, España) se incluyó en la lista de Lugares de Importancia Comunitaria (LIC) de la Región Biogeográfica Mediterránea (Directiva Hábitats y Ley 42/2007, de 13 de diciembre) por decisión de la Comisión Europea de 19 de julio de 2006 y fue declarada por la Consejería de Medio Ambiente y Ordenación del Territorio de la Junta de Andalucía Zona Especial de Conservación (ZEC) en el Decreto 110/2015, de 17 de marzo (Boletín Oficial de la Junta de Andalucía de 8 de Mayo de 2015). El 2 de junio de 2015 (BOJA 104:9) se publica la Orden de 11 de mayo de 2015 por la que se aprueba, entre otros, el Plan de Gestión de la ZEC Sierra de Camarolos (ES6170012) (Anexo VIII).
El objetivo de este trabajo se centra en destacar los valores botánicos de la ZEC de Sierra de Camarolos mediante el estudio de su flora vascular, caracterización de sus comunidades vegetales más significativas, las series de vegetación y el esquema sintaxonómico, cumpliendo de esta manera las medidas de alta prioridad que se contemplan en el referido Plan de Gestión.

\section{MATERIAL Y MÉTODOS}

\section{Localización geográfica}

La ZEC Sierra de Camarolos, situada en la zona nororiental de la provincia de Málaga (fig. 1), ocupa una superficie aproximada de 8.691 Ha, repartidas en siete términos municipales:

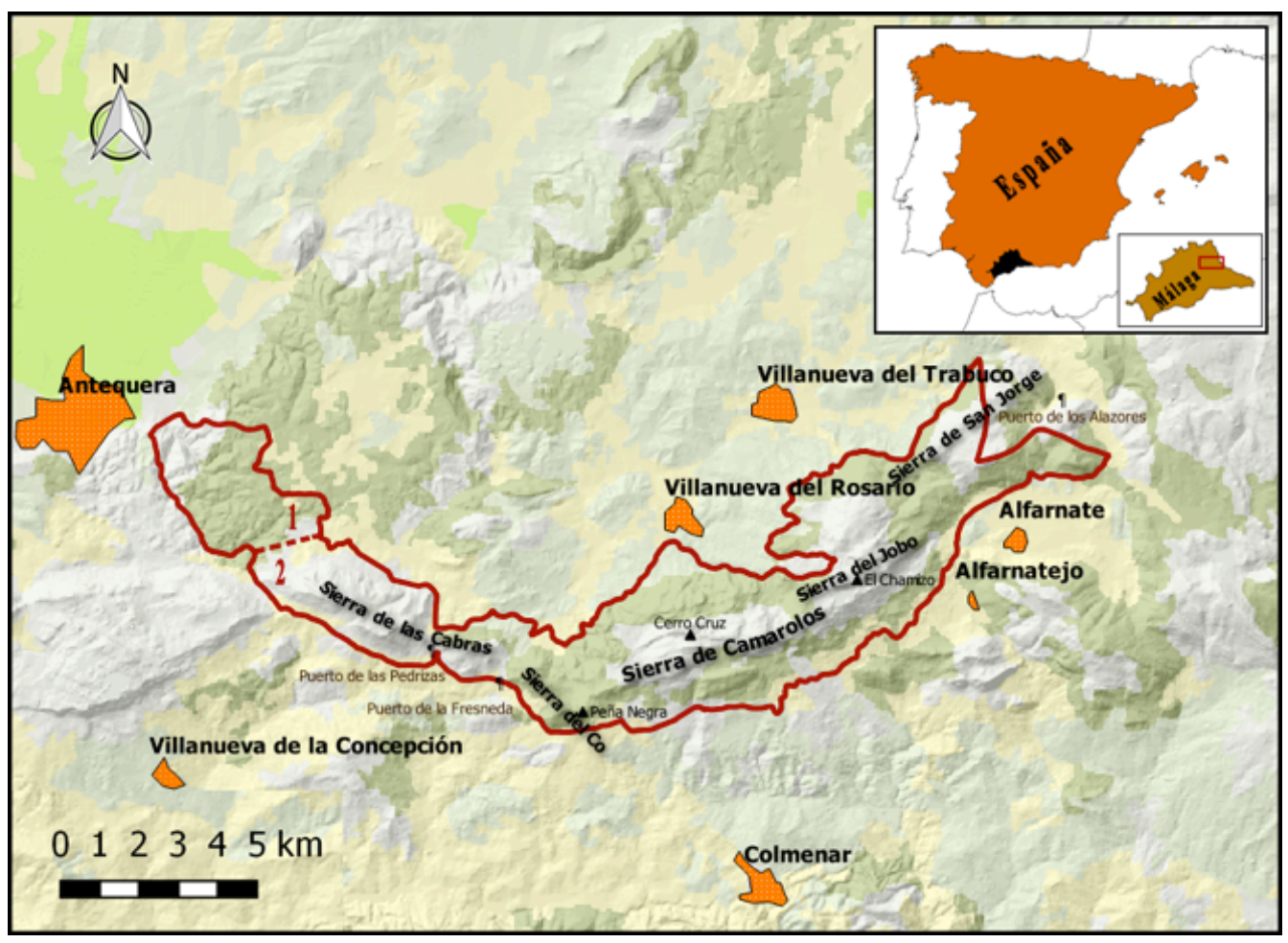

Figura 1. Localización de la ZEC Sierra de Camarolos (Málaga). Sectorización fitogeográfica: 1. Subsector Antequerano. 2. Subsector Torcalense. Location of the ZEC Sierra de Camarolos (Malaga). Phytogeographical units: 1. Antequerano subsector. 2. Torcalense subsector. 
Antequera, Villanueva del Trabuco, Villanueva del Rosario, Villanueva de la Concepción, Alfarnate, Alfarnatejo y Colmenar, ocupando el término de Antequera aproximadamente la mitad del territorio. A un nivel cartográfico amplio, la ZEC se encuadra en las siguientes cuadrículas UTM de 10x10 km: 30SUF69, 30SUF78, 30SUF79 y 30 SUF89.

El territorio engloba en su totalidad la zona oeste de la Cordillera Antequerana formada por una alineación de sierras que se extienden de oeste a este desde las proximidades de la ciudad de Antequera hasta la provincia de Granada. Las más significativas son: Sierra de las Cabras (1283 m), Sierra del Co (Peña Negra, 1353 m), Sierra de Camarolos (Cerro Cruz, 1444 m), Sierra del Jobo (El Chamizo, $1641 \mathrm{~m})$ y Sierra de San Jorge (1413 m). Todo este conjunto de sierras se imbrican a través de una serie de puertos de montaña como el Puerto de las Pedrizas, de la Fresneda, de los Tres Mojones, de los Perdigones, del Jobo, etc., presentando una pendiente media del $30 \%$, que supera el $45 \%$ en las zonas más elevadas, lo que unido a una litología formada mayoritariamente por calizas y dolomías, crea un abrupto paisaje donde abundan los cantiles, lapiaces, gleras, dolinas, etc. Penetra en su extremo noroccidental en las cercanías de Antequera, donde el territorio cambia de forma notable. Aquí el paisaje es menos abrupto con una altitud inferior a los $750 \mathrm{~m}$ y la litología es un mosaico de margas, yesos, areniscas y carniolas. También se ha incluido en la zona estudiada el extremo oriental de la Sierra de San Jorge, que quedó incomprensiblemente fuera de la ZEC, al pertenecer al municipio de Loja en la provincia de Granada.

La red hidrográfica dentro de la ZEC está poco desarrollada, aunque son destacables algunos nacimientos ubicados en los piedemontes de las sierras, ya en el límite de la zona estudiada, nacimientos como la Fuente de los 100 Caños o la del Arroyo del Cerezo. Dentro de los límites de la ZEC nace el río
Guadalmedina, en una serie de depresiones intramontañosas entre el Cerro Cruz y Sierra Prieta. A los pies de la Sierra de San Jorge nace el río Guadalhorce. En el extremo noroccidental es destacable el Arroyo de las Adelfas.

Respecto al uso del suelo predominan, con un $85 \%$ de la superficie del territorio, las áreas forestales y naturales. Estas áreas están dedicadas fundamentalmente a la ganadería (ovina-caprina y vacuna) y a la caza. Las zonas agrícolas dentro de la ZEC son marginales ocupando la zona basal de las sierras y menos frecuentemente algunas depresiones intramontañosas. También existe una explotación de áridos en el interior de la ZEC.

\section{Litología y Edafología}

La ZEC Sierra de Camarolos muestra una gran fragmentación litológica (IGME, 1978, 1983), aunque fundamentalmente, y como sustrato para la flora y vegetación, predominan los materiales básicos (calizas y dolomías), predominando por tanto las comunidades vegetales basófilas, calcícolas o dolomitícolas. Los materiales silíceos (areniscas y vulcanitas) quedan relegados a muy pequeños enclaves, al igual que los afloramientos de yesos (vegetación gipsícola). Son muy abundantes las litologías que generan suelos vérticos (arcillas y margas), donde va a aparecer un tipo de vegetación herbácea especial ligada a la humedad edáfica.

En base a la distribución litológica y la forma geográfica de la ZEC se han definido 4 zonas que van a coincidir con la sectorización fitogeográfica:

Zona1. Trías de Antequera: margas, areniscas silíceas, yesos y carniolas.

Zona 2. Parte Occidental, Sierra de las Cabras: calizas tableadas, oolíticas y brechoides, margas rojas y areniscas, dolomías y coladas de solifluxión y arcillas de descalcificación (zonas kársticas).

Zona 3. Parte Central, Sierra de los Camarolos: calizas oolíticas, margosas y con 
conglomerados, margas, margocalizas, brechas calizas, margoareniscas, dolomías y coladas de solifluxión (desprendimientos) y coluviones.

Zona 4. Parte Oriental, Sierra de San Jorge y Los Alazores: dolomías, vulcanitas, calizas blancas, nodulosas y oolíticas, arcillas y carniolas, margas rojas, calcarenitas con sílex, y rellenos de depresiones (zonas kársticas) y conos aluviales.

Los suelos que se encuentran en cada una de estas zonas litológico-geográficas son (Balsera, 1989):

Zona 1: a) Afloramientos de margas abigarradas y yesos: el suelo dominante es el cambisol cálcico, con deficiencias de drenaje, presencia de yeso y riesgo de erosión, en un relieve de ondulado a fuertemente ondulado con escarpes. Regosoles calcáreos (áreas erosionadas con cárcavas), litosoles (carniolas), cambisoles (vérticos), fluvisoles calcáreos (puntuales en vaguadas); b) Altiplanicies calcáreo-yesíferas: predominan los cambisoles cálcicos alternando con luvisoles crómicos relictos y más escasos regosoles calcáreos (zonas expuestas a erosión), en mesetas de topografía suavemente ondulada a inclinada con erosión moderada y expuestos a sequía estival severa.

Zonas 2, 3 y 4: c) Núcleo central de las Sierras: sobre calizas y dolomías de relieve accidentado, con elevada pedregosidad y pendientes escarpadas, con formas de disolución kárstica. Los litosoles dominan sobre todo en las cimas, rendsinas a media ladera en zona forestal lluviosa, luvisoles crómicos en piedemontes y valles. Sobre derrubios se desarrollan cambisoles; d) Zonas periféricas: suelos poco o moderadamente evolucionados, calcáreos en relieves ondulados con rendsinas y regosoles calcáreos y formaciones rocosas con litosoles y rendsinas, cambisoles cálcicos en las partes más bajas o menos erosionadas. Son suelos con pendiente, riesgo de erosión, acentuada sequía estival y alto porcentaje de caliza activa.

\section{Bioclimatología}

La caracterización bioclimática del área de estudio se ha basado en los conceptos de termotipo (piso bioclimático) y ombrotipo (Rivas Martínez, 2007). Los datos climatológicos se han obtenido de De León (1989) y los bioclimatológicos de Rivas Martínez (2007). La clasificación macrobioclimática y los índices bioclimáticos utilizados están basados en los conceptos de Rivas Martínez (op. cit.). Al no existir estaciones climatológicas al interior de la ZEC, se han utilizado también bioindicadores tanto florísticos como fitocenológicos para la estimación de los límites de los termotipos y ombrotipos (Nieto et al., 1998).

A la vista de las estaciones climatológicas existentes en las cercanías de la ZEC (tab. 1), el macrobioclima del territorio se puede definir como Mediterráneo pluviestacionaloceánico. Sin embargo existe variación de los

\begin{tabular}{|c|c|c|c|c|c|c|c|}
\hline Estación & altitud & $\mathbf{P}(\mathbf{m m})$ & $\mathrm{T}\left({ }^{\circ} \mathrm{C}\right)$ & Itc & Io & Ic & Termotipo/ombrotipo \\
\hline \multicolumn{8}{|c|}{ Subsector Antequerano } \\
\hline Antequera & 477 & 551 & 15,5 & 317 & 3 & 17,4 & Meso inf / Seco sup \\
\hline \multicolumn{8}{|c|}{ Subsector Torcalense } \\
\hline Alfarnate & 925 & 1013 & 13,3 & 262 & 6,4 & 16,1 & Meso sup/Subhum sup \\
\hline El Torcal & 1218 & 784 & 12,6 & 221 & 5,2 & 17 & Meso sup / Subhum sup \\
\hline
\end{tabular}

Tabla 1. Datos bioclimáticos de la zona estudiada. P: precipitación media anual. T: temperatura media anual. Itc: índice de termicidad compensado. Io: índice ombrotérmico. Ic: índice de continentalidad simple. Datos: www.globalbioclimatics.org. y De León (1989). Climatic data. P: average annual rainfall. T: average annual temperature. Itc: Balanced thermicity index. Io: ombrothermic index., Ic: single continentality index. Data: www.globalbioclimatics.org and De León (1989). 
principales índices bioclimáticos en función de una baja altitud y de la situación hacia el oeste (subsector Antequerano) y de elevadas cumbres y situación central y hacia el este (subsector Torcalense). Las temperaturas descienden en altitud, existiendo el rango desde el termotipo mesomediterráneo inferior a $477 \mathrm{~m}$. (Itc: 317) hasta el supramediterráneo superior (bioindicadores: Prunus prostrata, Rhamnus pumila) y las precipitaciones ascienden desde el oeste con ombrotipo seco superior (P: 551), hacia el este con ombrotipo húmedo (bioindicadores: Daphne laureola, Alliaria petiolata).

La zona de la ZEC correspondiente al subsector Antequerano presenta una diagnosis bioclimática mesomediterránea inferior seca superior con un Ic semicontinental. Sin embargo la presencia de quejigales de Quercus faginea nos hace presuponer la existencia del ombrotipo subhúmedo en las zonas más elevadas cercanas a $700 \mathrm{~m}$. Del mismo modo, la presencia de los matorrales termófilos de Genisto equisetiformisCytisetum fontanesii indican ese horizonte térmico del piso mesomediterráneo. La zona correspondiente al subsector Torcalense es algo más compleja. Estimamos que el piso mesomediterráneo ocupa la base de las sierras hasta unos $1300 \mathrm{~m}$. y a partir de ahí se extiende el piso supramediterráneo hasta los $1640 \mathrm{~m}$., apareciendo bioindicadores incluso del piso supramediterráneo superior (Ptilotrichum spinosum, Prunus prostrata) a partir de 1400 $\mathrm{m}$. y sobre todo en las umbrías, donde pueden descender. El ombrotipo pasa de subhúmedo en la zona occidental de Sierra de las Cabras y Puerto de las Pedrizas hacia el húmedo en Sierra de Camarolos y Puerto de los Alazores, donde se podría suponer, además, un aporte bastante potente de la criptoprecipitación y las precipitaciones son en forma de nieve al menos durante el invierno. La continentalidad desciende hacia el este con un Ic euoceánico. Es digno de reseñar un fenómeno geobotánico que hemos recogido hasta el momento solo en estas
Sierras Torcalenses (ya detectado en la Sierra de Huma: Pérez Latorre et al., 2014) y es la sustitución de los matorrales de Rosmarinetalia por los piornales xeroacánticos de Erinacetalia a altitudes mucho menores que en el resto de las sierras circundantes e incluso que en el resto de serranías Béticas, lo que podría ser objeto de estudio fitoclimático.

\section{Fitogeografía y vegetación}

La vegetación forestal de la zona fue estudiada por Ceballos \& Vicioso (1933) indicando en su cartografía las siguientes unidades de vegetación: a) matorrales (dominantes) encinares y encinares adehesados en el subsector Antequerano de la ZEC y b) matorrales (dominantes), encinares con quejigos y puntualmente acebuchales en el subsector Torcalense de la ZEC. Por otro lado, una consulta del mapa de series de vegetación de Valle \& Lorite (2005) a escala 1:400.000 para territorio de la ZEC indica: a/ en el subsector Antequerano la presencia de la serie Paeonio coriaceae-Querceto rotundifoliae $S$ en su modelo hispalense, que finalmente se ha confirmado en este trabajo; b/ en el subsector Torcalense la serie Paeonio coriaceae-Querceto rotundifoliae $S$ en su modelo anticariense (confirmada), la serie Berberido hispanicaeQuerceto rotundifoliae $S$ (ausente de la ZEC) y la serie Rhamno myrtifolii-Junipereto phoeniceae $S$ (ausente de la ZEC). Yus et al. (2007) realizan una aproximación a la vegetación de la zona.

Para realizar la sectorización fitogeográfica de la ZEC se han utilizado los trabajos de Nieto Caldera et al. (1998) y Pérez Latorre y Cabezudo (2002) para el nivel de la provincia política de Málaga, y el de Pérez Latorre et al. (2009) y Cabezudo et al. (2013) para el sector Antequerano. La sectorización a nivel superior al provincial ha seguido la propuesta de Galán de Mera et al. (2003). Las fronteras de las unidades fitogeográficas se han fijado en base a bioindicadores florísticos, 
comunidades, series de vegetación, paisaje vegetal, bioclimatología, geología y uso del territorio. La ZEC queda encuadrada en el siguiente esquema fitogeográfico:

\section{Reino Holártico}

Región Mediterránea. Subregión Mediterránea Occidental.

Superprovincia Iberomarroquí-Atlántica. Provincia Bética.

A. Sector Antequerano [p.p. Sector Rondeño, Subsector Rondeño sensu Rivas Martínez et al. (2007)]

A1. Subsector Antequerano [p.p. Distrito Anticariense sensu Rivas Martínez et al. (2007)]

Corresponde a toda la zona NW de la ZEC, constituido litológicamente por el Trías de Antequera. Algunos bioindicadores en el territorio: Campanula fastigiata, Avellinia festucoides, Hippocrepis bourgaei y Moricandia moricandioides subsp. giennensis; algunos sinfitoindicadores: Hippocrepido bourgaeiAnthyllidetum cytisoidis, ChaenorrhinoCampanuletum fastigiatae avellinietosum festucoidis y Genisto equisetiformis-Cytisetum fontanesii.

A2. Subsector Torcalense [Distrito Anticariense sensu Rivas Martínez et al. (2007)]

A2.1. Distrito de Las Pedrizas sensu Pérez Latorre et al. 2009. [Contacta con el distrito Zafarrayero, que ocuparía la zona más sudoriental de la Cordillera Torcalense y fue objeto de estudio y denominado como "unidad" fitogeográfica en Pérez Latorre et al. op. cit.]

Corresponde a la zona central y NE de la ZEC, constituido litológicamente y de forma mayoritaria por materiales básicos jurásicos del Subbético. Algunos bioindicadores en el territorio: Saxifraga reuteriana, Saxifraga biternata y Scrophularia viciosoi; algunos sinfitoindicadores: Linario anticariaeSaxifragetum biternatae, Genisto speciosaeUlicetum parviflorii, Vinco difformis-Quercetum fagineae y Satchydo officinalis-Eryngietum caespitiferi.

Gómez Mercado et al. (1994) reflexionan sobre la localización fitogeográfica de las cercanas Sierras Subbéticas del sur de Córdoba diciendo que existen elementos florísticos béticos pero prácticamente ninguno subbético y que sin embargo la presencia de elementos rondeños sensu lato (incluyendo antequeranos) como Linaria anticaria, Merendera androcymbioides, Saxifraga reuterana, etc. y la de elementos iberomagrebíes con distribución ibérica muy similar entre ambas zonas (Centaurea clementei, Biscutella frutescens) sugieren relación al menos florística. Creemos que un estudio comparado entre el subsector Torcalense y las subbéticas cordobesas podría dar como resultado la agrupación en una misma unidad fitogeográfica de ambos territorios, dentro del ámbito territorial del sector Antequerano y no del Subbético.

\section{METODOLOGÍA}

El trabajo de campo se ha realizado durante los años 2015 y 2016 en todo el territorio de la ZEC de Sierra de Camarolos. Se han herborizado 2.385 pliegos en todos los biotopos identificados y en todas las épocas del año. Se ha recolectado material vegetal de la mayor parte de las especies incluidas en los inventarios fitosociológicos y de otras especies de interés para la caracterización florística del territorio (endemismos, especies amenazadas, raras, singulares, etc.). Para la identificación del material recolectado, se han seguido básicamente las obras "Flora Vascular de Andalucía Oriental" (Blanca et al., 2011), "Flora Iberica" (Castroviejo et al., 1986-2015) y "Flora Vascular de Andalucía Occidental" (Valdes et al., 1987). Para casos concretos se han utilizado las monografías 
sobre gramíneas ibéricas (Romero-Zarco 2015), Agrostis (Romero-Garcia et al., 1988), Koeleria (Quintanar \& Castroviejo, 2013) y trabajos florísticos de otros territorios como Flora Europaea (Tutin 1964-80), Flora del Norte de Marruecos (Valdés et al., 2002) y Flora del Pirineo aragonés (Villar et al., 1997-2001 ). Para la nomenclatura hemos seguido preferentemente a Flora Iberica y en su defecto a Flora Vascular de Andalucía Oriental. Excepto para los generos Thrincia (Talavera, 2015) y Koeleria (Quintanar \& Castroviejo, 2013). Todos los pliegos recolectados, identificados, georreferenciados e informatizados, incluidos los de briófitos, se han depositado en el Herbario MGC de la Universidad de Málaga. Los datos de todo el material estudiado son accesibles desde la base de datos "MGC-Cormof" disponible a través del portal de datos de GBIF (Global Biodiversity Information Facility) mediante el siguiente enlace: http://doi.org/10.15468/2gfyxk

Con el fin de lograr un listado más detallado de la flora y vegetación de la ZEC, se realizaron consultas en todas las bases de datos de biodiversidad vegetal disponibles a través del Portal de Datos de GBIF (2015-2016). Para ello se buscaron todos los registros georreferenciados de plantas que se encuentran dentro de los límites cartográficos de la ZEC, así como los registros no georreferenciados cuya localidad coincide con los topónimos principales del área de estudio. Solamente se tuvieron en consideración bases de datos con pliegos de herbario como fuente de información, teniendo registros dentro de nuestra área de estudio las siguientes colecciones: BC, COA, EMMA, FCO, GDA, LEB, MA, MGC, PAMP, SALA, SEV y VIT. Además, se incluyó a la colección ANTHOS, ya que a pesar de estar considerada en GBIF como una colección con base de su información del tipo "observación humana", el origen de sus datos son referencias bibliográficas con información contrastada. Las especies localizadas en estas bases de datos y no confirmadas por nuestras recolecciones vienen reseñadas con un (*) en el Anexo I. Las especies que aparecen en los inventarios y que no tienen un pliego testigo vienen reseñadas en el Anexo I con el símbolo (\#). El listado final proviene de una depuración de los datos primigenios, revisando los pliegos dudosos.

Para la flora legalmente protegida y amenazada se ha consultado el Decreto 23/2012 de 14 de febrero de la Junta de Andalucía y la información que aparece en los libros (Blanca et al., 1999 y 2000; Bañares et al., 2004, 2010), listas rojas española (LRE) (Moreno, 2010) y de Andalucía (LRA) (Cabezudo \& Talavera, 2005) y floras de ámbito nacional (Castroviejo et al., 1986-2015; FIB) y autonómico (Blanca et al., 2011).

De todos los taxones que aparecen en el catálogo florístico del Anexo I hemos reseñado, en el apartado de flora, aquellos de interés especial para la zona y para los que hemos indicado todos los datos que aparecen en la etiqueta de los pliegos de referencia. Para los comentarios corológicos de estas especies nos hemos basado inicialmente en la distribución que indica Flora Vascular de Andalucía Oriental (FVAO) y Flora Iberica (FIB) para cada taxón, luego se ha realizado una búsqueda en GBIF para confirmar en lo posible que ese taxón no había sido previamente herborizado en la zona, para la que es indicado como novedad. Además se han consultado diversas publicaciones donde aparecen los territorios reseñados, publicaciones indicadas en cada caso.

Las unidades de vegetación se han descrito en base a la metodología fitosociológica de Braun-Blanquet (1979), Gehú \& Rivas Martínez (1981) y Schuhwerk (1990). Los inventarios 151 se encuentran georreferenciados en teselas ecológicamente homogéneas de tamaño estimado mediante el cálculo del área mínima. Las comunidades fragmentarias debidas a la antropización son descritas como comunidades 


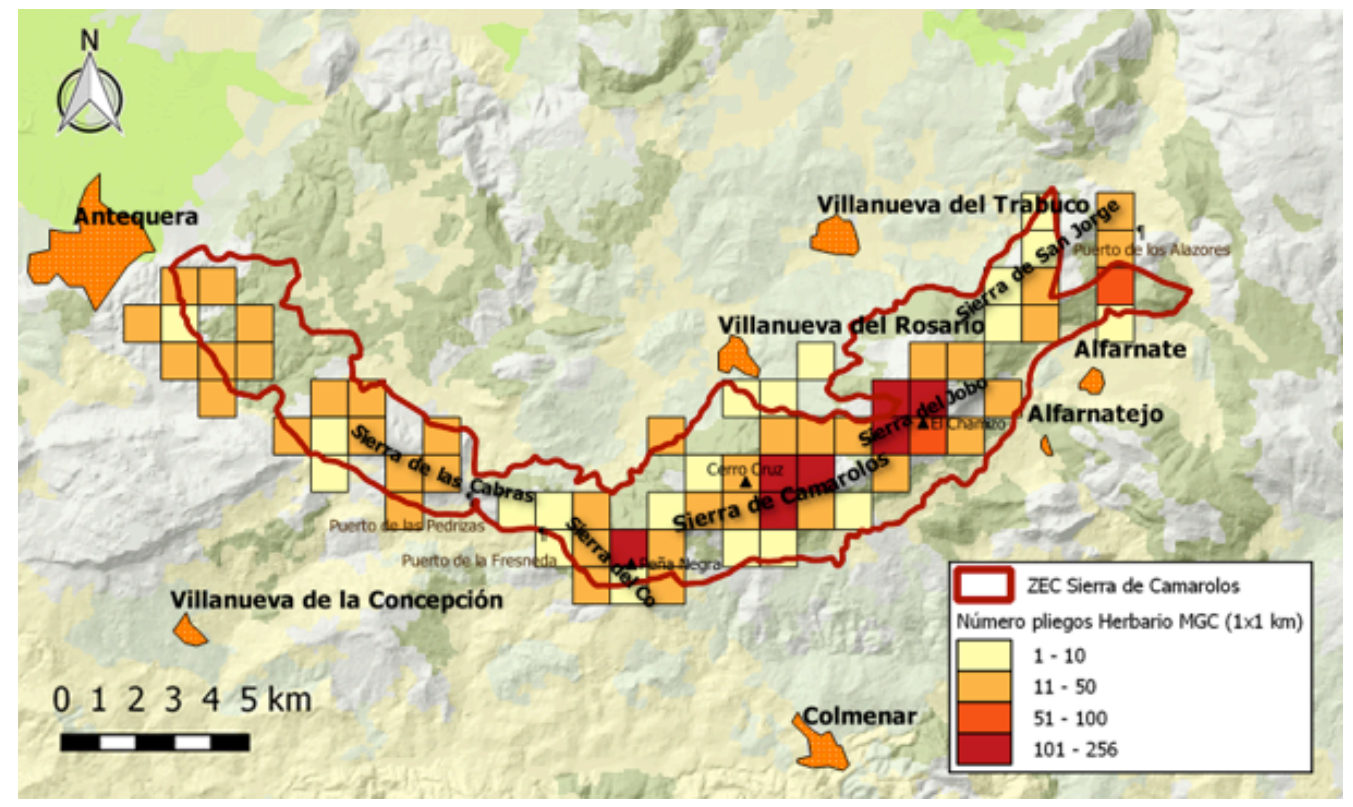

Figura 2.- Densidad de material recolectado en la ZEC de Camarolos (medido en número de pliegos de herbario por cuadrículas de $1 \mathrm{Km}^{2}$ ). Density of material collected in the ZEC of Camarolos (measured in number of herbarium plots per $\left.1 \mathrm{Km}^{2} \mathrm{grid}\right)$.

basales (BC) (Foucault, 1981; Dierschke, 1993). Los diferentes estadios dinámicos de la vegetación han sido analizados según la metodología sinfitosociológica bidireccional (Rivas Martínez, 2011), aunque existe también dinamismo horizontal "en red" (Pérez Latorre et al., 2012), sobre todo en las geopermaseries. Para el esquema sintaxonómico hemos seguido la propuesta de Rivas Martínez (2011), identificando sintaxones basándonos en el estudio de las especies características listadas en Rivas Martínez et al. (2002) salvo excepciones indicadas en las tablas de inventarios. Para las nuevas propuestas nomenclaturales sintaxonómicas se ha consultado el Código Internacional de Nomenclatura Botánica (Weber et al., 2000). Para las propuestas tipológicas de los complejos de vegetación (geopermaseries) seguimos a Rivas Martínez $(2007,2011)$ y respecto a la zonopotencialidad de los territorios y teselas y la vegetación criptoclimácica a Pérez Latorre et al. (2004, 2008). Para la nomenclatura geoecológica más precisa de las series y geopermaseries se utiliza la nomenclatura de Rivas Martínez (2011). Proponemos que se añada a dicha lista el adjetivo karsticícola, para series y subseries que se desarrollan en los hábitats kársticos y la vegetación atropógena mantenida como permanente por actuación humana constante.

\section{RESULTADOS Y DISCUSIÓN}

\section{Flora General}

El catálogo general de la flora vascular identificada en la zona de estudio se presenta en el Anexo I, con un total de 879 taxones pertenecientes a 76 familias. A nivel taxonómico las familias mejor representadas son Asteraceae (118), Poaceae (101), Fabaceae (89), Apiaceae (48), Brassicaceae (46) y Lamiaceae (44). En 
la figura 2 se representa en cuadriculas de un kilometro cuadrado la densidad de material recolectado en la ZEC.

\section{A. Especies legalmente protegidas (Legislación de Andalucía)}

Narcissus bugei (Fern. Casas) Fern. Casas

MÁLAGA. Colmenar. Sierra Prieta. 30SUF79, 1200 m s.n.m. 18/02/2007. Leg.: A. V. Pérez Latorre \& R. Yus Ramos. MGC 65056.

Especie Silvestre en Régimen de Protección Especial. Bajo el nombre de Narcissus bugei (Fern. Casas) Fern. Casas se considera especie Vulnerable (VU) en las listas rojas española y andaluza (LRE y LRA) y considerada como endemismo andaluz de los sectores Subbético y Rondeño. Estas poblaciones se engloban (FIB) en la especie N. pseudonarcissus subsp. nevadensis (Pugsley) A. Fern., con una distribución más amplia desde el sur de Albacete hasta el este de la provincia de Cádiz (Aedo, 2013).

Narcissus assoanus Dufour ex Schult. \& Schult. fil.

Especie Silvestre en Régimen de Protección Especial. La entidad legalmente protegida correspondería a lo descrito como $N$. fernandessi G. Pedro. El material recolectado en la ZEC, identificado como $N$. assoanus, se corresponde con las formas denominadas $N$. baeticus Fdez. Casas, que al igual que $N$. fernandessi está actualmente incluido dentro de $N$. assoanus (Aedo, 2013). Por tanto el $N$. assoanus de la zona no estaría legalmente protegido

\section{Festuca elegans Boiss.}

MÁLAGA. Alfarnate. Sierra del Jobo. Entre el Cortijo del Jobo y El Chamizo. 30SUF8495, 1180 m s.n.m. 05/07/2016. Quejigares con arces bien conservados. Calizas-arcillas. Leg.: B. Cabezudo, A. V. Pérez Latorre \& F. Soriguer. MGC 83892.

Especie Silvestre en Régimen de Protección Especial. Ampliamente distribuida en Andalucía Oriental (FVAO, Devesa et al., 2013). En la provincia de Málaga estaba citada solo para la Serranía de Ronda y Sierra Tejeda (Cabezudo et al., 1990).

\section{Amelanchier ovalis Medik.}

MÁLAGA. Villanueva del Rosario. Sierra del Jobo. Entre el Puerto de los Perdigones y el Tajo de la Magdalena. 30SUF8293, $1480 \mathrm{~m}$ s.n.m. 06/07/2016. Peñón dolomítico. Orientación Norte. Leg.: F. Soriguer \& J. García-Sánchez. MGC 83966; ibídem. Zona superior. Cercanías del Puerto de los Perdigones. 30SUF8293, $1425 \mathrm{~m}$ s.n.m. 03/06/2016. Peñón dolomítico. Orientación Norte. Leg.: B. Cabezudo, A. V. Pérez Latorre \& F. Soriguer. MGC 83135

Especie Silvestre en Régimen de Protección Especial. En Andalucía esta especie se conoce fundamentalmente de su mitad oriental (FIB) y de la Subbética Cordobesa (Valdés et al., 1987). En Málaga solo se conocía de Sierra Almijara (Cabezudo et al., 2005) y no estaba reseñada para el área natural de Ronda (FVAO). Incluida en la Lista Roja de la Flora Vascular de Andalucía (Cabezudo \& Talavera, 2005) como Casi Amenazado (NT).

\section{Prunus insititia L.}

MÁLAGA. Antequera. Finca La Fresneda. Sierra del Co. Tajo de los Machos. 30SUF7491, 850 m s.n.m. 08/06/2016. Quejigal con arces. Calizas-margas. Leg.: B. Cabezudo \& F. Soriguer. MGC 83342; Antequera. Sierra de Camarolos. Cara Norte del Cerro de la Cruz. Finca La Fresneda. 30SUF7992, 1200 m s.n.m. 30/06/2016. Quejigalaceral denso con pastoreo vacuno. Suelos arcillosos. Leg.: J. García-Sánchez \& F. Soriguer. MGC 83786; ibídem. Vertiente Noreste del Cerro Cruz. 30SUF7992, 1150 m s.n.m. 02/07/2014. Aceralquejigal. Arcillas-calizas. Leg.: J. García-Sánchez \& F. Soriguer. MGC 79657; Antequera. Sierra de las Cabras. Puerto Lucena. 30SUF7092, 850 m s.n.m. 13/04/2016. Espinares caducifolios con gayumba. Suelos arcillosos. Calizas. Leg.: J. García-Sánchez \& F. Soriguer. MGC 82223; ibídem. Umbría de Tajo Prieto (límite Sur de la gran dolina). 30SUF6992, 1070 m s.n.m. 09/07/2012. Bosquetes caducifolios, olmedas y acerales. Calizas/arcillas. 
Leg.: J. García-Sánchez \& F. Soriguer. MGC 76213; Villanueva del Rosario. El Hondonero. $1000 \mathrm{~m}$ s.n.m. 21/09/2003. Seto con Rubus ulmifolius. Calizas. Leg.: A. V. Pérez Latorre. MGC 55149

Especie Silvestre en Régimen de Protección Especial. Especie distribuida por casi toda la Península Ibérica, frecuente en el subsector Torcalense de la ZEC formando parte de espinares y setos.

\section{Prunus mahaleb L.}

MÁLAGA. Antequera. Sierra de las Cabras. Zona superior de la sierra, al Oeste del collado de los lastonares. 30SUF6893, 1150 m s.n.m. 24/06/2016. Piornales. Cresterío rocoso. Dolomías. Leg.: J. García-Sánchez \& F. Soriguer. MGC 83734; Antequera. Sierra del Co. Cara norte. 30SUF7590, 1180 m s.n.m. 28/04/1994. Leg.: B. Cabezudo, A. V. Pérez \& P. Navas. MGC 38199; Casarabonela. Sierra Prieta. Vertiente Norte. Desde la Umbría del Puerto de la Maera hasta el Mojón de los Tres Términos. 30SUF3218071710, $1225 \mathrm{~m}$ s.n.m. 17/06/2010. Dolomías. Leg.: B. Cabezudo, A. V. Pérez Latorre \& F. Soriguer. MGC 71956; Villanueva del Rosario. Sierra de Camarolos. Desde el Tajo de la Maera al puertecillo. Por encima del nacimiento del río Guadalmedina. 30SUF8092, 1225 m s.n.m. 13/06/2014. Lastonares. Lapiaces con suelo intersticial. Calizas. Leg.: A. V. Pérez Latorre, J. García-Sánchez \& F. Soriguer. MGC 79300; ibídem. Sierra del Jobo. Cercanías al Puerto de los Perdigones. Zona superior. 30SUF8293, 1480 m s.n.m. 15/06/2016. Peñón dolomítico. Orientación Norte. Leg.: B. Cabezudo \& F. Soriguer. MGC 83527; ibídem. Vertiente Norte del Chamizo. Alrededores del Rodaero. 30SUF8394, $1290 \mathrm{~m}$ s.n.m. 20/06/2013. Mosaico de espinares, piornales y herbazales. Zona rocosa en mosaico con suelos arcillosos profundos. Calizas. Leg.: B. Cabezudo \& F. Soriguer. MGC 77826; ibídem. Zona superior. Cercanías del Puerto de los Perdigones. 30SUF8293, 1425 m s.n.m. 03/06/2016. Peñón dolomítico. Orientación Norte. Leg.: B. Cabezudo, A. V. Pérez Latorre \& F. Soriguer. MGC 83133.

Especie Silvestre en Régimen de Protección Especial. Especie que en Andalucía se distribuye a lo largo de las Serranias Béticas desde Cadiz hasta Jaén; en la ZEC es frecuente en el piso supramediterraneo del subsector Torcalense, con hábitos rupícolas.

\section{Sorbus aria (L.) Crantz}

MÁLAGA. Alfarnate. Sierra del Jobo. El Chamizo. Contrafuertes de la cara Sur. 30SUF8393, 1500 m s.n.m. 15/06/2016. Tajos verticales y repisas. Dolomías. Leg.: B. Cabezudo \& F. Soriguer. MGC 83488; Villanueva del Rosario. Sierra del Jobo. El Chamizo. Zona cacuminal. 30SUF8393, $1620 \mathrm{~m}$ s.n.m. 18/06/2015. Lapiaces muy desarrollados. Torcas y simas. Calizas. Leg.: A. V. Pérez Latorre \& F. Soriguer. MGC 81334; ibídem. Vertiente Norte del Chamizo. Alrededores del Rodaero. 30SUF8394, 1290 m s.n.m. 20/06/2013. Mosaico de espinares, piornales y herbazales. Zona rocosa en mosaico con suelos arcillosos profundos. Calizas. Leg.: B. Cabezudo \& F. Soriguer. MGC 77835.

Especie Silvestre en Régimen de Protección Especial. En Andalucía se distribuye a lo largo de las sierras béticas; en la ZEC aparece esporadicamente en el piso supramediterraneo del subsector Torcalense. Incluida en la Lista Roja de la Flora Vascular de Andalucía (Cabezudo \& Talavera, 2005) como Casi Amenazado (NT)

\section{Hieracium texedense Pau}

MÁLAGA. Antequera. Sierra de las Cabras. Barranco entre el Cortijo de la Alhajuela y la zona superior de la sierra. Collado de Los Lastonares. 960 m s.n.m. 24/06/2016. Orientación Noroeste. Grandes espolones rocosos. Dolomías. Leg.: J. García-Sánchez \& F. Soriguer. MGC 83778; ibídem. Zona superior de la Sierra. Al Oeste del collado de Los Lastonares. Cresterío al Sur de la Vaguada. 1175 m s.n.m. 24/06/2016. Agujas dolomíticas. Vegetación rupícola con orientación Norte. Leg.: J. García-Sánchez \& F. Soriguer. MGC 83770; Villanueva del Rosario. Sierra del Jobo. Zona superior. Cercanías del Puerto de los Perdigones. 1425 m s.n.m. 03/06/2016. Peñón dolomítico. Orientación Norte. Leg.: B. Cabezudo, A. V. Pérez Latorre \& F. Soriguer. MGC 83141; ibídem. Cara Norte del Chamizo. 1450 m s.n.m. 29/06/2010. Rupícola. Calizas. Leg.: F. Soriguer. MGC 72133.

Especie En Peligro de Extinción (EN). Descrita de Sierra Tejeda (Málaga-Granada) de donde se consideraba endémica. Crece en 
roquedos dolomíticos y umbríos de altura. Las plantas localizadas en el subsector Torcalense (Sierra de las Cabras y del Jobo) no se diferencian de las típicas de la localidad clásica (MGC 21457, 21458, 21459, 34857, 49311, 58975).

\section{Scrophularia viciosoi Ortega Olivencia \&} Devesa

MÁLAGA. Antequera. Sierra de las Cabras, cerca del cortijo Garraso. 30SUF6792, m s.n.m. 17/04/2002. Sustrato calizo. Herbazal junto a nacimiento de agua. Leg.: P. Navas, O. Gavira \& D. Navas. MGC 51617; Antequera. Vía pecuaria de Fuente de los Remedios. Entre la Boca del Asno y el Cortijo de los Migueles. 30SUF6792, 870 m s.n.m. 15/03/2016. Herbazales en los bordes de los cultivos. Arcillas. Leg.: B. Cabezudo, A. V. Pérez Latorre \& F. Soriguer. MGC 81902; Villanueva del Rosario. Carril a Villanueva del Rosario desde Pedrizas, afluente del río Parroso. 30SUF7392, 750 m s.n.m. 26/04/2002. Arcillas. Herbazales de río. Leg.: B. Cabezudo \& P. Navas. MGC 51878.

Especie Vulnerable (VU). Endemismo del subsector Torcalense (Cabezudo et al., 2003; Becerra et al., 2007). Se han localizado varias poblaciones a lo largo de la vertiente S-SO de la Sierra de las Cabras. Considerada En Peligro Crítico de Extinción (CR), tanto en la Lista Roja de la Flora Vascular de España (Moreno, 2010) como de Andalucía (Cabezudo \& Talavera, 2005)

\section{Quercus faginea subsp. alpestris (Boiss.) Maire}

MÁLAGA. Alfarnate. Sierra del Jobo. Entre el Cortijo del Jobo y El Chamizo. 30SUF8495, 1180 m s.n.m. 05/07/2016. Quejigares con arces bien conservados. Calizas-arcillas. Leg.: B. Cabezudo, A. V. Pérez Latorre \& F. Soriguer. MGC 83884; Antequera. Sierra de Camarolos. Cortijo la Fresneda. 30SUF7580690873, 1100 m s.n.m. 25/05/2012. Leg.: B. Díez Garretas, A. Asensi \& J. Pereña. MGC 75842; Antequera. Sierra del Co. Finca La Fresneda. Cara Norte del Morrón de Gragea. 30SUF7590, 1200 m s.n.m. 23/06/2016. Quejigal-aceral y espinares caducifolios. Suelos arcillosos. Leg.: A. V. Pérez Latorre \& F. Soriguer. MGC 83666.
Especie Vulnerable (VU). Incluida como $Q$. alpestris Boiss. en las Listas Rojas de Flora Vascular de España (Moreno, 2010) y de Andalucía (Cabezudo \& Talavera, 2005) y considerado endémico de la zona cacuminal de la Sierra de las Nieves (Málaga); Amaral Franco (1990) lo asimila a Q. faginea subsp. faginea Lam. y Galán de Mera et al. (2009), lo citan como Q. faginea subsp. alpestris, con una distribución muy localizada en varias sierras de Andalucía Oriental

Sarcocapnos baetica (Boiss. \& Reut.) Nyman MÁLAGA. Antequera. Finca La Fresneda. Sierra del Co. Tajos entre el Cortijo de la Fresneda y el Cortijo Dornillo. Cara Sur. 30SUF7490, 900 m s.n.m. 08/06/2016. Vegetación rupícola. Tajos verticales y extraplomados. Dolomías. Leg.: B. Cabezudo \& F. Soriguer. MGC 83372.

Especie Vulnerable (VU). Su presencia en Andalucía (FVAO y FIB) se restringe a la Serranía de Ronda (subsector Rondeño) en Málaga y Sierras de Segura y Guilimona (Granada y Jaén). No hemos encontrado referencias previas a su presencia en el subsector Torcalense. Incluida en Listas Rojas de Flora Vascular de España (Moreno, 2010) y de Andalucía (Cabezudo \& Talavera, 2005) como Casi Amenazado (NT)

\section{Saxifraga biternata Boiss.}

MÁLAGA. Antequera. Sierra de Camarolos. Cresterío entre el cerro Cruz y el Realengo. 30SUF7991, 1380 m s.n.m. 10/06/2015. Rupícola. Tajos verticales. Calizas. Leg.: B. Cabezudo, J. A. Devesa, G. Martínez \& F. Soriguer. MGC 81320; ibídem. Sierra de las Cabras, cerca del cortijo Garraso. 30SUF6792, m s.n.m. 17/04/2002. Paredón calizo. Leg.: P. Navas, O. Gavira \& D. Navas. MGC 51623; Colmenar/Antequera. Sierra de Camarolos. Nacimiento del río Guadalmedina. Entre el Cerro Cruz y los Tajos de Marchena. 30SUF7991, 1325 m s.n.m. 13/06/2014. Rupícolas. Calizas. Leg.: A. V. Pérez Latorre, J. García-Sánchez \& F. Soriguer. MGC 79399; Villanueva del Rosario. Paredones al sureste del pueblo. 30SUF7994, 950 m s.n.m. 28/04/1994. Paredones, calizas. Leg.: B. Cabezudo, A. V. Pérez 
Latorre \& P. Navas. MGC 44149; ibídem. Sierra de Camarolos. Llano del Hondonero. 30SUF8093, m s.n.m. 29/03/2001. Calizas. Paredón. Leg.: P. Navas \& D. Navas. MGC 49388; ibídem. 30SUF7993, 1170 m s.n.m. 11/06/1996. Calizas. Leg.: Y. Gil \& A. V. Pérez Latorre. MGC 44145; Villanueva del Rosario. Sierra de Camarolos. Tajo de la Maera. Zonas del Hondonero. 30SUF8093, m s.n.m. 30/03/2006. Rupícola en tajos calizos. Leg.: F. Casimiro-Soriguer Solanas. MGC 63892; ibídem. Parte baja de los Llanos del Hondonero. 30SUF8093, 850 m s.n.m. 11/06/1996. Calizas. Leg.: Y. Gil \& A. V. Pérez Latorre. MGC 44160; Villanueva del Rosario. Sierra del Enebro. Proximidades del nacimiento del río Cerezo. Paredones. 30SUF7894, $875 \mathrm{~m}$ s.n.m. 26/04/2002. Calizas. Paredones verticales. Comunidades rupícolas. Leg.: B. Cabezudo \& P. Navas. MGC 51962.

Especie Vulnerable (VU). Endemismo del subsector Torcalense, localizado en las Sierras de la Chimenea, Torcal de Antequera y Sierra de Camarolos (Cabezudo et al., 2000). Considerada En Peligro de Extinción (EN) en la Lista Roja de la Flora Vascular de España (Moreno, 2010) y de Andalucía (Cabezudo \& Talavera, 2005).

\section{B. Otras Especies de Interés}

\section{Arabis serpillifolia Vill.}

JAÉN; Sierra de Cazorla. Pico Cabañas. 1990 m s.n.m. 24/07/1971. Leg.: J. Fernández Casas. MA 331885. MÁLAGA; Villanueva del Rosario. Sierra del Jobo. Cercanías al Puerto de los Perdigones. Zona superior. 1480 m s.n.m. 15/06/2016. Peñón dolomítico. Orientación Norte. Leg.: B. Cabezudo \& F. Soriguer. MGC 83519; ibídem. 1425 m s.n.m. 03/06/2016. Peñón dolomítico. Orientación Norte. Leg.: B. Cabezudo, A. V. Pérez Latorre \& F. Soriguer. MGC 83150.

Especie europeo-alpina que se distribuye por el Sur de Francia, Suiza, Norte de Italia y Península Ibérica, creciendo fundamentalmente sobre sustratos carbonatados en situaciones expuestas y medios rocosos. En la Península Ibérica se localiza en los Pirineos, NE de España y Sistema Ibérico (Talavera 1993), desconociéndose hasta el momento su presencia en su mitad meridional. La población malagueña presenta un hábitat rupestre, en callejones muy umbríos con orientación norte y sustrato dolomítico. Es novedad para la flora de Andalucía.

Con el fin de una identificación correcta de la población andaluza, se ha estudiado material de esta especie procedente de localidades de su distribución clásica depositados en el Herbario MA (Jardín Botánico, Madrid) (MA 48518, MA 48519, MA 48521, MA 48522, MA 48523, MA 48575, MA 48578, MA 227333, MA 299972, MA 300229, MA 300249, MA 331841 , MA 331842, MA 331843, MA 331845, MA 331870, MA 331875, MA 331876, MA 331877 , MA 331878, MA 331885, MA 407442, MA 454431, MA 764465). Al revisar estos pliegos se encontró uno recolectado en la Sierra de Cazorla. Esta población seguramente ha pasado desapercibida confundida con $A$. alpina, especie frecuente en estas sierras (Sierra del Pozo: HUAL 7634 y 7636) (Gómez Mercado 2011).

La población malacitana de Arabis serpillifolia está muy localizada y consta de menos de 20 ejemplares en una sola población. La mayoría de individuos observados son plantas adultas con rizomas bien desarrollados que penetran en las pequeñas fisuras del roquedo y que florecen y fructifican con aparente normalidad. Consideramos que las dos poblaciones andaluzas se encuentran amenazadas con la categoría de En Peligro (EN), tanto por el número de individuos como por lo reducido de su área (criterios B y D).

\section{Eryngium $L$.}

El género Eryngium esta representado en la zona de estudio por E. campestre L., E. aquifolium Cav. y E. caespitiferum Font Quer \& Pau. E. campestre se distribuye ampliamente por la ZEC y no presenta problemas de identificación. E. aquifolium, considerada una especie ibero-marroquí por Nieto Feliner (2003) y solo ibérica por Jury (2002), también tiene una amplia distribución en la zona, pero las 
poblaciones localizadas en las zonas altas han presentado ciertos problemas de identificación.

Las formas típicas de E. aquifolium (Cavanilles, 1801; Silvestre ,1987; Nieto Feliner, 2000) aparecen tanto en el subsector Antequerano como en el Torcalense, desde los $650 \mathrm{~m}$ hasta los 1200 , generalmente formando parte de pastizales de zonas arcillosas con encharcamiento temporal y esporádicamente sobre suelos margosos secos. En las Sierras de Camarolos y del Jobo, por encima de los $1200 \mathrm{~m}$, se localizan unas poblaciones de Eryngium con las siguientes características diferenciales respecto a las poblaciones típicas de E. aquifolium: hábito cespitoso; tallos decumbentes hasta $6 \mathrm{~cm}$ de longitud y de menos de $2 \mathrm{~mm}$ de diámetro; hojas basales de hasta $2,5 \mathrm{~cm}$ de longitud y hojas caulinares de hasta $2 \mathrm{~cm}$, las caulinares débilmente amplexicaules (dejando ver parte del tallo); capítulos menores de $1 \mathrm{~cm}$, con hasta 5 brácteas que raramente llegan a los $15 \mathrm{~mm}$ de longitud y hasta 3-4 espínulas en cada lado, raramente 5 y sin brácteas espinescentes intercaladas; bractéolas hasta $5 \mathrm{~mm}$ de longitud, enteras, raramente alguna de las externas tricuspidada.

La combinación de estos caracteres desviantes respecto a $E$. aquifolium encajan con la descripción original de E. caespitiferum Font Quer \& Pau (Font Quer \& Pau ,1931) y con los tipos depositados en el Herbario MA (MA 84839, MA 84840 -isotypus-) y BC (BC 98522, BC 809318 -typus-). Aunque pudiera pensarse que estos Eryngium de bajo porte y menores dimensiones corresponden a formas enanas de E. aquifolium afectadas por el sobrepastoreo, el hecho de que en diversas localidades del mismo territorio (Sierra de las Cabras, Sierra del Co) sometidas a la misma presión ganadera, crezcan poblaciones de E. aquifolium típicas parece negar esta posibilidad. Por último, en la Sierra de Camarolos, los llanos de Marchena y zonas colindantes, entre los 1200 y 1350 m., se localizan unas poblaciones con caracteres intermedios entre E. aquifolium y E. caespitiferum. Son plantas erguidas, pero con las dimensiones de hojas, tallo, capítulos y brácteas en el límite inferior descrito para $E$. aquifolium (Nieto Feliner, 2003), presentando una mayor espinescencia en las brácteas, así como una mayor frecuencia de bractéolas más de una vez cuspidadas.

\section{Eryngium caespitiferum Font Quer \& Pau}

MÁLAGA. Colmenar. Sierra de Camarolos. Nacimiento del río Guadalmedina. Alrededores del puerto en el límite de términos. 30SUF8092, 1325 m s.n.m. 05/08/2014. Pastizales pastoreados sobre suelos con encharcamiento temporal. Arcillas. Leg.: B. Cabezudo \& F. Soriguer. MGC 79787; ibídem. Sierra del Jobo. Puerto de los Perdigones. Alrededores de la gran dolina. 30SUF8293, 1396 m s.n.m. 15/06/2016. Pastizales sobre suelos con encharcamiento temporal. Leg.: B. Cabezudo \& F. Soriguer. MGC 83502; ibídem. Sierra Prieta. Llanos de Marchena. Cabecera del arroyo de Casa Palma. 30SUF8091, 1210 m s.n.m. 22/09/2016. Pastizales sobre suelos arcillosos con encharcamiento temporal. Leg.: F. Soriguer \& J. García-Sánchez. MGC 84118; Villanueva del Rosario. Sierra del Jobo. Próximo a la cara Norte del Tajo de la Magdalena. 30SUF8292, 1350 m s.n.m. 06/07/2016. Pastizales sobre suelos con encharcamiento temporal. Arcillas. Leg.: F. Soriguer \& J. García-Sánchez. MGC 83942

E. caespitiferum es una planta descrita de la alta montaña rifeña marroquí y citada en la Península Ibérica de la Sierra de Cabra (Córdoba), en La Nava (Triano, 2010). Esta localidad egabrense pertenece a la Subbética cordobesa donde al parecer no llega $E$. aquifolium (Triano, 2010). No se han podido localizar los pliegos de la población cordobesa.

\section{Eryngium aquifolium Cav.}

MÁLAGA. Antequera. Sierra de las Cabras. Gran dolina en la cabecera del arroyo de la Yedra. 30SUF6992, 1050 m s.n.m. 09/07/2009. Pastizales sobre suelos con encharcamiento temporal. Muy pastoreados. Arcillas. Leg.: J. García-Sánchez \& F. Soriguer. MGC 75744; ibídem. Cerro de las Minas. 30SUF6596, 650 m s.n.m. 10/06/2016. Matorrales y pastizales. Margas y areniscas. Leg.: F. Soriguer. MGC 83449; ibídem. Finca La Fresneda. Sierra del Co. Cabecera del arroyo de las Pelas. El Plato. 30SUF7590, 1000 m s.n.m. 08/06/2016. Pastizales. Suelos arcillosos con encharcamiento 
temporal. Pastoreo vacuno. Leg.: B. Cabezudo \& F. Soriguer. MGC 83397; ibídem. Puerto de la Fresneda. 30SUF7391, 850 m s.n.m. 08/06/2016. Pastizales y matorrales pastoreados. Suelos con encharcamiento temporal. Margas-arcillas. Leg.: B. Cabezudo \& F. Soriguer. MGC 83366; ibídem. Sierra de las Cabras. Entre el Cortijo de la Alhajuela y el Cortijo de Piedra Solana. 30SUF6794, 780 m s.n.m. 24/06/2016. Suelos con encharcamiento temporal. Arcillas. Leg.: J. García-Sánchez \& F. Soriguer. MGC 83765; ibídem. Zona superior de la sierra, al Oeste del Collado de los Lastonares. 30SUF6893, 1150 m s.n.m. 24/06/2016. Pastizales perennes sobre suelos hidromorfos. Arcillas. Leg.: J. García-Sánchez \& F. Soriguer. MGC 83750; ibídem. Sierra del Co. Vertiente Norte de Peña Negra. Finca La Fresneda. Fuente de los 6 pilones. 30SUF7590, 1000 m s.n.m. 23/06/2016. Herbazales muy pastoreados. Espinares y pastizales. Suelos arcillosos con encharcamiento temporal. Leg.: A. V. Pérez Latorre \& F. Soriguer. MGC 83615; Colmenar. Entre Sierra Prieta y Sierra de Camarolos (El Pelado). Llanos por debajo de los Tajos del Rodadero. 30SUF8091, 1160 m s.n.m. 15/07/2016. Pastizales higrófilos. Suelos arcillosos con encharcamiento temporal. Leg.: B. Cabezudo \& F. Soriguer. MGC 84025

\section{Eryngium aquifolium $\mathrm{x}$ E. caespitiferum}

MÁLAGA. Colmenar. Llanos de Marchena. Entre la umbría de Sierra Prieta y la Sierra de Camarolos. 30SUF7991, 1200 m s.n.m. 15/07/2016. Pastizales. Suelos con encharcamiento temporal. Arcillas. Leg.: B. Cabezudo \& F. Soriguer. MGC 83979; ibídem. Sierra de Camarolos. Llanos de Marchena. 30SUF7991, 1200 m s.n.m. 02/07/2009. Zona hidrófila. Suelo hidromorfo vértico. Leg.: B. Cabezudo, A. V. Pérez Latorre \& F. Soriguer. MGC 70451; Colmenar/Antequera. Sierra de Camarolos. Nacimiento del río Guadalmedina. Entre el Cerro Cruz y los Tajos de Marchena. 30SUF7991, 1325 m s.n.m. 13/06/2014. Pastizales sobre suelos con encharcamiento temporal. Arcillas. Leg.: A. V. Pérez Latorre, J. García-Sánchez \& F. Soriguer. MGC 79354

\section{Hieracium L.}

En el territorio estudiado hemos localizado tres especies del género Hieracium, identificadas utilizando la revisión que del género aparece en la Flora Vascular de Andalucía Oriental
(Blanca \& Cueto, 2009). La especie de identificación menos compleja corresponde a Hieracium amplexicaule L., en la que incluimos plantas robustas, de hojas caulinares grandes y amplexicaules y densamente glandularpubescentes en tallos y hojas. Hieracium baeticum Arv.-Touv. \& E.Rev. presenta plantas con indumento de pelos largos denticulados abundantes en la parte inferior del tallo y el capítulo y hojas más o menos pelosas. Hieracium texedense Pau presenta plantas glabras en la base de los tallos con ninguno o escasos pelos largos denticulados en el involucro y hojas glabras o con pelos denticulados solo en el nervio medio y los márgenes (en la parte proximal).

En la aproximación al conocimiento del genero Hieracium en la Península Ibérica llevada a cabo por Mateo Sanz (2007) para Flora Iberica, $H$. texedense Pau, quedaría englobado dentro de $H$. aragonense Scheele como una forma intermedia distribuida por el centro y este peninsular y $H$. baeticum Arv.-Touv. \& E. Rev., lo sinonimiza a $H$. bourgaei Boiss. Distribuido por el sur, este y centro de la Península, alcanzando las estribaciones cantábricas.

\section{Hieracium amplexicaule $\mathrm{L}$.}

MÁLAGA. Villanueva del Rosario. Sierra del Jobo. Entre el Puerto de los Perdigones y el Tajo de la Magdalena. 1480 m s.n.m. 06/07/2016. Peñón dolomítico. Orientación Norte. Leg.: F. Soriguer \& J. García-Sánchez. MGC 83969.

Especie rupícola y orófila que se distribuye por el Mediterráneo occidental. En Andalucía se localiza en algunas sierras de las provincias más orientales, no estando citada con anterioridad ni en la provincia de Málaga ni en la comarca de Ronda (Blanca \& Cueto, 2009), estando citadas las poblaciones más cercanas en la Sierra Nevada calizo-dolomítica (Losa Quintana \& Pérez Raya, 1986). La población malagueña seria por tanto la más suroccidental de la especie en la Península Ibérica. 
Hieracium baeticum Arv.-Touv. \& E. Rev

MÁLAGA. Antequera. Sierra del Co. Finca La Fresneda. Morrón de Gragea. 1200 m s.n.m. 23/06/2016. Agujas dolomíticas. Leg.: A. V. Pérez Latorre \& F. Soriguer. MGC 83659; Villanueva del Rosario. Sierra del Jobo. Cercanías al Puerto de los Perdigones. Zona superior. 1480 m s.n.m. 15/06/2016. Peñón dolomítico. Orientación Norte. Leg.: B. Cabezudo \& F. Soriguer. MGC 83523; ibídem. 1425 m s.n.m. 03/06/2016. Peñón dolomítico. Orientación Norte. Leg.: B. Cabezudo, A. V. Pérez Latorre \& F. Soriguer. MGC 83147.

Endemismo bético propio de pedregales y roquedos calizos y dolomíticos de alta montaña y del que no teníamos referencias en la cordillera antequerana (subsector Torcalense).

\section{Bromus erectus Huds.}

MÁLAGA. Alfarnate. Sierra del Jobo. Cara Sur del Chamizo. Desde el final de la pista del Cortijo del Chamizo al Puerto de los Perdigones. 30SUF8393, 1375 m s.n.m. 03/06/2016. Mosaico de lastonares en los lapiaces y pastizales y espinares en las vaguadas. Calizas y arcillas. Leg.: B. Cabezudo, A. V. Pérez Latorre \& F. Soriguer. MGC 83037; Colmenar. Sierra del Jobo. Puerto de los Perdigones. Alrededores de la gran dolina. 30SUF8293, 1410 m s.n.m. 15/06/2016. Piornales espinosos. Leg.: B. Cabezudo \& F. Soriguer. MGC 83507; Villanueva del Rosario. Sierra del Jobo. Próximo a la cara Norte del Tajo de la Magdalena. 30SUF8292, 1350 m s.n.m. 06/07/2016. Piornales espinosos. Suelos arcillosos. Leg.: F. Soriguer \& J. García-Sánchez. MGC 83943; ibídem. Sierra del Jobo. Zona superior. Cercanías del Puerto de los Perdigones. 30SUF8293, $1425 \mathrm{~m}$ s.n.m. 03/06/2016. Lastonares y piornales espinosos. Calizas. Leg.: B. Cabezudo, A. V. Pérez Latorre \& F. Soriguer. MGC 83108.

Especie distribuida por las provincias más orientales de Andalucía (FVAO). No estaba citada en el área natural de Ronda (FVAO) ni en la provincia de Málaga (Cabezudo et al., 1990).

\section{Bupleurum baldense Turra}

MÁLAGA. Villanueva del Rosario. Sierra del Jobo. Vertiente Oeste del Tajo de la Víbora. 30SUF8394, 1475 m s.n.m. 18/06/2015. Pastizales. Suelos arcillosos. Leg.: A. V. Pérez Latorre \& F.
Soriguer. MGC 81425.

Novedad para la provincia de Málaga, área natural de Ronda (FIB, FVAO). Las poblaciones más cercanas se localizan en la subbética cordobesa (Triano, 2008) y en la parte granadina de Sierra Almijara (Cabezudo et al., 2005).

Conopodium arvense (Coss.) Calest.

MÁLAGA. Villanueva del Rosario. Zona superior. Cercanías del Puerto de los Perdigones. 30SUF8293, 1425 m s.n.m. 03/06/2016. Lastonares y piornales espinosos. Calizas. Leg.: B. Cabezudo, A. V. Pérez Latorre \& F. Soriguer. MGC 83102.

Endemismo ibérico que en Andalucía se localizaba solo en las provincias de Jaén y Huelva (FIB). En FVAO solo aparece reseñado para el área natural de Cazorla.

\section{Epilobium brachycarpum C. Presl}

MÁLAGA. Alfarnate. Llanos de Alfarnate. Carretera A-4152. 30SUF8696, m s.n.m. 22/09/2016. Borde de la carretera. Pastizales ruderales. Leg.: F. Soriguer \& J. García-Sánchez. MGC 84117.

Neófito de origen americano citado en Andalucía solo en el área natural de Sierra Morena (FVAO). Esta especie se comporta en la provincia de Málaga como diáfito.

Epipactis microphylla (Ehrh.) Sw.

MÁLAGA. Alfarnate. Sierra de San Jorge. Desde el Navazo al Cortijo Alto. 30SUF8897, 1100 m s.n.m. 05/07/2016. Matorrales y quejigales con alcornoques. Dolomías con introgresiones de vulcanitas. Zona pastoreada. Leg.: B. Cabezudo, A. V. Pérez Latorre \& F. Soriguer. MGC 83927.

Especie citada en Andalucía en las provincias de Córdoba, Granada y Jaén (FIB). Recogida solo para las áreas naturales de Cazorla y Nevado-Filabres (FVAO). Esta sería la única población conocida hasta el momento para Ronda (FVAO) y Málaga.

Ferulago granatensis Boiss.

MÁLAGA. Antequera. Sierra de Camarolos. Cumbre del Cerro Cruz y alrededores. 30SUF7892, 1397 m s.n.m. 02/07/2014. Zona muy pastoreada. 
Lapiaces. Calizas. Leg.: J. García-Sánchez \& F. Soriguer. MGC 79678; ibídem. Nacimiento del río Guadalmedina (zona superior). Entre el Cerro Cruz y los Tajos de Marchena. 30SUF7992, 1330 m s.n.m. 05/08/2014. Piornal sobre suelos con encharcamiento temporal. Margas/calizas. Leg.: B. Cabezudo \& F. Soriguer. MGC 79800; ibídem. Sierra del Co. Finca La Fresneda. Puerto entre el Morrón de Gragea y Peña Negra. 30SUF7590, 1180 m s.n.m. 23/06/2016. Matorrales en zonas muy expuestas. Dolomías. Leg.: A. V. Pérez Latorre \& F. Soriguer. MGC 83680; Colmenar/Antequera. Sierra de Camarolos. Nacimiento del río Guadalmedina. Entre el Cerro Cruz y los Tajos de Marchena. 30SUF7991, 1325 m s.n.m. 13/06/2014. Matorrales sobre suelos con encharcamiento temporal. Arcillas-Calizas. Leg.: A. V. Pérez Latorre, J. García-Sánchez \& F. Soriguer. MGC 79404; Villanueva del Rosario. Sierra de Camarolos. Desde el Tajo de la Maera al puertecillo. Por encima del nacimiento del río Guadalmedina. 30SUF8092, 1225 m s.n.m. 13/06/2014. Lastonares. Lapiaces con suelo intersticial. Calizas. Leg.: A. V. Pérez Latorre, J. García-Sánchez \& F. Soriguer. MGC 79292.

Endemismo de las sierras béticas orientales desde Albacete hasta Sierra Nevada. Novedad para la provincia de Málaga (FIB) y el área natural de Ronda (FVAO).

\section{Festuca iberica (Hack.) K. Richt.}

MÁLAGA. Villanueva del Rosario. Sierra de Camarolos. Vereda de subida al puerto de los 3 términos. Por encima del nacimiento del río Guadalmedina. 30SUF8092, 1320 m s.n.m. 10/06/2015. Suelos arcillosos. Leg.: B. Cabezudo, J. A. Devesa, G. Martínez \& F. Soriguer. MGC 81286

Especie que en Andalucía se localiza en las sierras béticas más orientales, (FVAO, Devesa et al., 2013). Novedad para la provincia de Málaga (Cabezudo et al., 1990) y el área natural de Ronda (FVAO).

Festuca segimonensis Fuente, Joch. Müll. \& Ortúñez

MÁLAGA. Colmenar. Sierra del Jobo. Puerto de los Perdigones. Alrededores de la gran dolina. 30SUF8293, 1396 m s.n.m. 15/06/2016. Pastizales sobre suelos con encharcamiento temporal. Leg.: B. Cabezudo \& F. Soriguer. MGC 83496; Villanueva del Rosario. Sierra del Jobo. Cara Norte del Pico Chamizo. 30SUF8394, 1290 m s.n.m. 20/06/2013. Rupícola. Calizas. Leg.: B. Cabezudo \& F. Soriguer. MGC 76195; ibídem. Puerto entre el Chamizo y La Torca. 30SUF8393, 1596 m s.n.m. 18/06/2015. Piornales. Calizas. Leg.: A. V. Pérez Latorre \& F. Soriguer. MGC 81359; ibídem. Vertiente Norte del Chamizo. Alrededores del Rodaero. 30SUF8394, 1290 m s.n.m. 20/06/2013. Mosaico de espinares, piornales y herbazales. Zona rocosa en mosaico con suelos arcillosos profundos. Calizas. Leg.: B. Cabezudo \& F. Soriguer. MGC 77836; ibídem. Zona superior. Cercanías del Puerto de los Perdigones. 30SUF8293, 1425 m s.n.m. 03/06/2016. Lastonares y piornales espinosos. Calizas. Leg.: B. Cabezudo, A. V. Pérez Latorre \& F. Soriguer. MGC 83112

Especie endémica de las sierras Béticas orientales del sur de la Península Ibérica y una población disyunta en la Sierra de las Nieves (Devesa et al., 2013). No existían referencias previas a su presencia en la cordillera antequerana (subsector Torcalense).

\section{Helianthemun sanguineum (Lag.) Lag.}

MÁLAGA. Antequera. Las Viñas. Cordel del Puente de los Remedios. 30SUF6396, $630 \mathrm{~m}$ s.n.m. 22/04/2016. Jaral sobre areniscas. Leg.: B. Cabezudo, J. Garcia-Sanchéz \& F.Soriguer. MGC 82394.

Especie muy localizada en Andalucía oriental (FVAO). Ha sido recientemente citada para la provincia de Málaga (Casimiro-Soriguer Solanas et a.l, 2013). Se amplía su área de la especie en Andalucía Oriental al área natural de Guadalquivir (FVAO).

Helictotrichon sarracenorum (Gand.) Holub

MÁLAGA. Antequera. Finca La Fresneda. Sierra del Co. Vertiente Norte de Peña Negra. Carril al Cortijo del Enebral. 30SUF7689, 1130 m s.n.m. 08/06/2016. Quejigal y matorral. Dolomías. Leg.: B. Cabezudo \& F. Soriguer. MGC 83319; ibídem. Sierra del Co. Finca La Fresneda. Puerto entre el Morrón de Gragea y Peña Negra. 30SUF7590, 1180 m s.n.m. 23/06/2016. Matorrales en zonas muy expuestas. Dolomías. Leg.: A. V. Pérez Latorre \& F. Soriguer. MGC 83684; Villanueva del Rosario. Sierra del Jobo. Zona superior. Cercanías del Puerto de los 
Perdigones. 30SUF8293, 1425 m s.n.m. 03/06/2016. Lastonares y piornales espinosos. Calizas. Leg.: B. Cabezudo, A. V. Pérez Latorre \& F. Soriguer. MGC 83113; Villanueva del Trabuco. Sierra de San Jorge. Entre el puerto y la laguna. 30SUF8697, 1275 m s.n.m. 27/05/2016. Lastonares. Lapiaces muy desarrollados. Calizas. Leg.: F. Soriguer. MGC 82879

Especie endémica de las serranías béticas, desde la subbética cordobesa hasta Albacete. En Málaga solo estaba indicada su presencia en la vertiente oeste de Sierra Tejeda (Romero Zarco, 1984; Cabezudo et al., 1990), no estando citada para el área natural de Ronda (FVAO). Incluida en la Lista Roja de la Flora Vascular de Andalucía (Cabezudo \& Talavera, 2005) como Vulnerable (VU) bajo el epíteto H. filifolium subsp. velutinum (Boiss.) Romero Zarco.

\section{Lactuca virosa L. subsp. virosa}

MÁLAGA. Antequera. Sierra de Camarolos. Cara Norte del Cerro de la Cruz. Finca La Fresneda. 30SUF7992, 1200 m s.n.m. 30/06/2016. Quejigalaceral denso con pastoreo vacuno. Suelos arcillosos. Leg.: J. García-Sánchez \& F. Soriguer. MGC 83799; Colmenar. Llanos de Marchena. Entre la umbría de Sierra Prieta y la Sierra de Camarolos. 30SUF7991, 1200 m s.n.m. 15/07/2016. Espinares caducifolios densos y pastizales esciófilos. Suelos arcillosos con encharcamiento temporal. Leg.: B. Cabezudo \& F. Soriguer. MGC 84012.

Novedad para el área natural de Ronda (FVAO).

Lepidium calycotrichum Kunze subsp. anticarium Valdés Bermejo \& G. López MÁlAGA. Antequera. Sierra del Co. 28/04/1994. Leg.: B. Cabezudo, A. V. Pérez Latorre \& P. Navas. MGC 38225; ibídem. Sierra Llana. Zona superior y tajo de Ballesteros. 30SUF4490, 975 m s.n.m. 17/05/2013. Tajos verticales y torcal. Calizas. Leg.: B. Cabezudo \& F. Soriguer. MGC 77387; Villanueva del Rosario. Cara Norte del Chamizo. 1300 m s.n.m. 18/06/2008. Roquedo. Calizas. Leg.: M. Becerra \& J. Pereña. MGC 68535; ibídem. Sierra del Jobo. Cercanías al Puerto de los Perdigones. Zona superior. 30SUF8293, $1480 \mathrm{~m}$ s.n.m. 15/06/2016. Peñón dolomítico. Orientación
Norte. Leg.: B. Cabezudo \& F. Soriguer. MGC 83533; ibídem. Subida al Chamizo. 30SUF8394, 1500 m s.n.m. 28/04/1994. Margocalizas. Leg.: B. Cabezudo, A. Pérez \& P. Navas. MGC 38326; ibídem. Vertiente Norte. Vaguada entre el Chamizo y La Torca. 30SUF8394, 1550 m s.n.m. 18/06/2015. Espinares caducifolios. Arcillas. Leg.: A. V. Pérez Latorre \& F. Soriguer. MGC 81363; ibídem. Zona superior. Cercanías del Puerto de los Perdigones. 30SUF8293, 1425 m s.n.m. 03/06/2016. Peñón dolomítico. Orientación Norte. Leg.: B. Cabezudo, A. V. Pérez Latorre \& F. Soriguer. MGC 83126

Taxón endémico del subsector Torcalense, distribuido desde la Sierra de la Chimenea hasta la Sierra de Camarolos (FIB, FVAO) alcanzando la Sierra del Valle de Abdalajís (Pérez Latorre et al., 2014). Especie Vulnerable (VU), en la Lista Roja de la Flora Vascular de España (Moreno, 2010) y de Andalucía (Cabezudo \& Talavera, 2005), en ambas bajo el epíteto Lepidium villarsii subsp. anticarium (Valdés Berm. \& G. López) Hern.-Berm.

Linum austriacum subsp. collinum (Boiss.) Nyman

MÁLAGA. Villanueva del Rosario. Sierra del Jobo. Cercanías al Puerto de los Perdigones. Zona superior. 30SUF8293, 1420 m s.n.m. 15/06/2016. Piornales espinosos. Leg.: B. Cabezudo \& F. Soriguer. MGC 83517.

Especie citada para Almería, Granada y Málaga (FIB). En FVAO se citaba solo para el área natural de Nevada-Filabres (Sierra de los Filabres, Almería). La cita malagueña de FIB se basa en un pliego de Sierra de las Nieves (MGC 46122) en el sector Rondeño, siendo por tanto novedad para la cordillera antequerana (sector Antequerano, subsector Torcalense).

Milium vernale $\mathrm{M}$. Bieb. subsp. montianum (Parl.) K. Richt

MÁLAGA. Villanueva del Rosario. Sierra del Jobo. Zona superior. Cercanías del Puerto de los Perdigones. 30SUF8293, 1425 m s.n.m. 03/06/2016. Peñón dolomítico. Orientación Norte. Leg.: B. Cabezudo, A. V. Pérez Latorre \& F. Soriguer. MGC 83124. 
Novedad para la provincia de Málaga (Cabezudo et al., 1990) y el área natural de Ronda (FVAO). Las poblaciones más cercanas se encuentran en la Sierra Tejeda granadina (Cabezudo et al., 2005)

\section{Narcissus elegans (Haw.) Spach}

MÁLAGA. Antequera. Sierra del Co. 950 m s.n.m. 16/10/2007. Leg.: B. Cabezudo, A. V. Pérez Latorre \& O. Gavira. MGC 66809; ibídem. Villanueva del Cauche. Pared roja de la cara Sureste de Peña Negra. 30SUF7991, 1200 m s.n.m. 02/11/2016. Pastizales. Arcillas. Leg.: B. Cabezudo \& F. Soriguer. MGC 84149; Sierra de Camarolos. m s.n.m. 26/10/2005. Leg.: J. Ramírez López. MGC 64458.

Endemismo del Mediterráneo occidental muy localizada en la provincia de Málaga. Las poblaciones malagueñas han sido propuestas por Fernández Casas (2010) como una especie independiente bajo el nombre de $N$. malacitanus Fernández Casas.

Ornithogalum pyrenaicum L. subsp. pyrenaicum

MÁLAGA. Villanueva del Rosario. Sierra del Jobo. Cercanías al Puerto de los Perdigones. Zona superior. 30SUF8293, 1420 m s.n.m. 15/06/2016. Piornales espinosos. Leg.: B. Cabezudo \& F. Soriguer. MGC 83518; ibídem. Vertiente Norte del Chamizo. Alrededores del "Rodaero". 30SUF8394, 1290 m s.n.m. 20/06/2013. Mosaico de espinares, piornales y herbazales. Zona rocosa en mosaico con suelos arcillosos profundos. Calizas. Leg.: B. Cabezudo \& F. Soriguer. MGC 77788; ibídem. Vertiente Norte. Vaguada entre el Chamizo y La Torca. 30SUF8394, 1550 m s.n.m. 18/06/2015. Espinares caducifolios. Arcillas. Leg.: A. V. Pérez Latorre \& F. Soriguer. MGC 81360; ibídem. Vertiente Oeste del Tajo de la Víbora. 30SUF8394, 1475 m s.n.m. 18/06/2015. Lapiaces. Calizas. Leg.: A. V. Pérez Latorre \& F. Soriguer. MGC 81429.

Especie que en Andalucía se localiza en las provincias de Huelva, Cordoba, Jaén y Málaga (FIB). Las poblaciones malagueñas se encuentran exclusivamente en esta ZEC (Casimiro-Soriguer et al., 2013).

\section{Silene cretica L.}

MÁLAGA. Alfarnate. Sierra del Jobo. Entre el Cortijo del Jobo y El Chamizo. 30SUF8495, $1180 \mathrm{~m}$ s.n.m. 05/07/2016. Pastizales en pequeñas dolinas. Arcillas. Leg.: B. Cabezudo, A. V. Pérez Latorre \& F. Soriguer. MGC 83894; Colmenar. Sierra del Jobo. Puerto de los Perdigones. 30SUF8293, 1382 m s.n.m. 03/06/2016. Gran dolina. Majadales. Suelos arcillosos. Leg.: B. Cabezudo, A. V. Pérez Latorre \& F. Soriguer. MGC 83077; ibídem. Alrededores de la gran dolina. 30SUF8293, 1396 m s.n.m. 15/06/2016. Pastizales sobre suelos con encharcamiento temporal. Leg.: B. Cabezudo \& F. Soriguer. MGC 83505; Villanueva del Rosario. Llanos del HondoneroCamarolos. 30SUF8186893478, 1125 m s.n.m. 22/05/2011. Calizas y arcillas. Leg.: A. V. Pérez Latorre \& M. Pavón Núñez. MGC 72986.

Especie muy rara en Andalucía (FIB) y citada solo para el área natural TrevenqueAlmijara (FVAO). Aparicio \& Silvestre (1987) la habían citado con anterioridad para la serranía de Ronda. Muy localizada en la zona formando poblaciones con una alta densidad de individuos $\mathrm{y}$ en depresiones temporalmente inundadas. Novedad para el sector Antequerano, subsector Torcalense (Pérez Latorre et al., 2009).

\section{Thymelaea pubescens subsp. elliptica (Boiss.) \\ Kit Tan}

MÁLAGA. Antequera. Sierra de Camarolos. Nacimiento del río Guadalmedina. Llanos superiores. 30SUF7992, 1325 m s.n.m. 10/06/2015. Pastizales. Suelos arcillosos con encharcamiento temporal. Leg.: B. Cabezudo, J. A. Devesa, G. Martínez \& F. Soriguer. MGC 81299; Colmenar/Antequera. Sierra de Camarolos. Nacimiento del río Guadalmedina. Entre el Cerro Cruz y los Tajos de Marchena. 30SUF7991, 1325 m s.n.m. 13/06/2014. Matorrales sobre suelos con encharcamiento temporal. ArcillasCalizas. Leg.: A. V. Pérez Latorre, J. García-Sánchez \& F. Soriguer. MGC 79416.

Endemismo ibérico no citado para el área natural de Ronda (FVAO) y por tanto novedad para el subsector Torcalense. Citado para la vertiente malagueña de Sierra Almijara (FIB).

Trifolium leucanthum M. Bieb. MÁLAGA. Colmenar. Sierra del Jobo. 
Puerto de los Perdigones. 30SUF8293, $1382 \mathrm{~m}$ s.n.m. 03/06/2016. Gran dolina. Majadales. Suelos arcillosos. Leg.: B. Cabezudo, A. V. Pérez Latorre \& F. Soriguer. MGC 83078

Especie muy rara en Andalucía. Citada en la Serranía de Ronda (FIB) y en el área natural de Cazorla (FVAO). No hemos encontrado citas anteriores para el subsector Torcalense.

\section{Trifolium suffocatum L.}

MÁLAGA. Villanueva del Trabuco. Sierra de San Jorge. La Laguna. 30SUF8697, 1160 m s.n.m. $27 / 05 / 2016$. Majadales en el fondo de la dolina. Suelos con encharcamiento temporal. Leg.: F. Soriguer. MGC 82862.

Novedad para la flora de la provincia de Málaga (FIB) y el área natural de Ronda (FVAO).

Xeranthemun cylindraceum Sibth. \& Sm.

MÁLAGA. Villanueva del Rosario. Sierra de Camarolos. Zona superior de los Llanos del Hondonero. 30SUF7992, 1200 m s.n.m. 30/06/2016. Pastizales. Suelos arcillosos. Leg.: J. García-Sánchez \& F. Soriguer. MGC 83834; ibídem. Sierra del Jobo. Subida al Chamizo desde el Alto del Hondonero. 30SUF8394, 1400 m s.n.m. 18/06/2015. Ladera de fuerte pendiente. Piornales. Margas/calizas. Leg.: A. V. Pérez Latorre \& F. Soriguer. MGC 81355.

Citada para las provincias de Córdoba, Granada, Jaén y Málaga (FIB). La cita para la provincia de Málaga se basa en un pliego de la Serranía de Ronda (SEV 59849). No citada en el área natural de Ronda ni en el subsector Torcalense (FVAO).

\section{Xiphion serotinum (Willk.) Soják}

MÁLAGA. Villanueva del Rosario. Sierra de Camarolos. Entre el Tajo de la Maera y el Puerto en el límite de términos. 30SUF8092, 1200 m s.n.m. 05/08/2014. Matorrales pastoreados. Calizas. Leg.: B. Cabezudo \& F. Soriguer. MGC 79803.

Endemismo del cuadrante SE de la Península Ibérica, concentrado en las Sierras Subbéticas andaluzas, no estando citado con anterioridad ni en la provincia de Málaga (FIB) ni en el area natural de Ronda (FVAO, sub. Iris serotina Willk.). Especie incluida como DD (Datos Insuficientes) en la Lista Roja de la Flora Vascular de Andalucía (Cabezudo \& Talavera, 2005)

\section{Vegetación: novedades y comentarios sintaxonómicos}

\section{Charetum vulgaris Corillion 1957}

Vegetación algal carofítica, pionera y sumergida, que se desarrolla en el fondo de las charcas y balsas ganaderas, con aguas dulces, mesotróficas ricas en bases en el subsector Torcalense. Se trata de hábitats muy escasos e incluidos en la Directiva 92/43UE. Esta asociación se encuentra extendida por la provincia de Málaga según Asensi \& Nieto (1975: 108-109), aunque sus inventarios con C. vulgaris subsp. crassicaulis proceden solo de Sierra Tejeda, macizo montañoso limítrofe con la ZEC de Camarolos.

Localidad: Granada. Loja. Sierra de San Jorge. Puerto de Los Alazores. El Navazo. 30SUF8898. Orientación: -. Inclinación: $0^{\circ}$. Área: $25 \mathrm{~m}^{2}$. Litología: arcillas. Altitud: 1050 m. Altura vegetación: $-10 \mathrm{~cm}$. Cobertura vegetación: $100 \%$. Característica y diferencial de asociación: Chara vulgaris subsp. crassicaulis 5. Compañera: Ranunculus peltatus subsp. saniculifolius + .

\section{Comunidad de Zannichellia palustris BC [Tabla 2]}

Vegetación hidrofítica de macrófitos sumergidos y enraizados en aguas dulces en pequeñas charcas y balsas agrícolas o ganaderas, de muy poca profundidad. Existe otra comunidad presidida por Z. palustris pero en los arrozales de Valencia (Stubbing et al., 1993). Se trata de vegetación ligada a hábitats muy escasos en todo el sector biogeográfico y de importancia comunitaria (Directiva 92/43UE). 
Tabla 2

2. Comunidad de Zannichellia palustris BC (Potametea, Potametalia, Potamion)

\begin{tabular}{|c|c|c|}
\hline INVENTARIO N ${ }^{\circ}$ & 1 & 2 \\
\hline Orientación & - & - \\
\hline Inclinación $\left({ }^{\circ}\right)$ & - & - \\
\hline Área $\left(\mathrm{m}^{2}\right)$ & 4 & 50 \\
\hline Litología & Arc & Arc \\
\hline Altitud (m) & 1180 & 1085 \\
\hline Altura vegetación (cm.) & -5 & -10 \\
\hline Cobertura vegetación $(\%)$ & 90 & 100 \\
\hline \multicolumn{3}{|c|}{ Características de comunidad } \\
\hline Zannichellia palustris & 5 & 3 \\
\hline \multicolumn{3}{|l|}{ Compañeras } \\
\hline Mentha pulegium & + & 2 \\
\hline Chara vulgaris & & \\
\hline subsp. crassicaulis & . & 4 \\
\hline Eleocharis palustris & & \\
\hline subsp. palustris & + & \\
\hline Juncus articulatus & . & 1 \\
\hline
\end{tabular}

Localidades. 1. Málaga. Colmenar. Sierra Prieta. 30S 380026/4091399. 2. Granada. Loja. Sierra de S. Jorge. Cortijo de la Manga. 30S 388103/4099296. Arc: arcillas y margas.

Ranunculion aquatilis Passarge 1964 [Tabla 3] 3. Comunidad de Ranunculus peltatus subsp. saniculifolius sensu Pérez Raya (1987)

4. Comunidad de Ranunculus peltatus subsp. peltatus

Vegetación hidrofítica localizada en el subsector Torcalense en la ZEC, constituida por batráquidos flotantes enraizados en el fondo de pequeñas lagunas tenporales y balsas ganaderas con aguas dulces básicas. La comunidad de Ranunculus peltatus subsp. saniculifolius también está presente en Sierra Nevada calizo-dolomítica (Pérez Raya, 1987: 107). La cita de Callitricho stagnalis-Ranunculetum saniculifolii Galán in A. V. Pérez, Galán, P. Navas, D. Navas, Y. Gil \& Cabezudo 1999 para las lagunas de Zafarraya (subsector Torcalense,
Pérez Latorre et al., 2009) deben referirse a ésta comunidad, ya que dicha asociación está descrita para aguas ligeramente ácidas en el sector Aljíbico y presenta varias especies del género Callitriche, ausentes en la ZEC (Pérez Latorre et al., 1999). Respecto a la comunidad de Ranunculus peltatus subsp. peltatus, la asociación Ranunculetum peltati Segal 1967 es europea y norteafricana, de aguas oligótrofas, ácidas (Pérez Latorre et al., op. cit.). Otra asociación con $R$. peltatus subsp. peltatus es Callitricho brutiae-Ranunculetum peltati Pérez Latorre \& Cabezudo 2002 in Pérez Latorre, P. Navas, D. Navas, Y. Gil \& Cabezudo 2002, pero es una asociación del centro y suroccidente ibérico (Pérez Latorre et al., 2005) de aguas ácidas oligótrofas.

\section{Comunidad de Juncus bufonius y Centaurium pulchellum sensu Pérez Raya (1987)}

Nanojuncales terofíticos que se desarrollan sobre arcillas temporalmente encharcadas por aguas dulces a finales de primavera en el subsector Torcalense de la ZEC. Consideramos que esta comunidad detectada se corresponde con la inventariada por Pérez Raya (1987) en los sustratos básicos de Sierra Nevada, con la inventariada en Sierra de Huma (también subsector Torcalense) por Pérez Latorre et al. (2014) y por Hidalgo \& Pérez Latorre en el Valle del Guadalhorce (2013). Están caracterizados por Juncus bufonius, Centaurium pulchellum, Centaurium tenuiflorum y Juncus acutiflorus y presentes desde el termotipo termomediterráneo al oromediterráneo de la provincia Bética.

Localidad: Granada. Loja. Puerto de los Alazores. 30S388524/4098676. Orientación -. Inclinación: $0^{\circ}$. Área: $2 \mathrm{~m}^{2}$. Litología: arcillas. Altitud: $1050 \mathrm{~m}$. Altura vegetación: $5 \mathrm{~cm}$. Cobertura vegetación: 40\%. Características y diferenciales de comunidad: Juncus bufonius 3, Centaurium tenuiflorum 1, Juncus acutiflorus +. Característica de unidades superiores: 
Tabla 3

Ranunculion aquatilis Passarge 1964

3. Comunidad de Ranunculus peltatus subsp. saniculifolius sensu Pérez Raya (1987), 4. Comunidad de Ranunculus peltatus subsp. peltatus

(Potametea, Potametalia, Ranunculion aquatilis)

\begin{tabular}{lcccc}
\hline INVENTARIO N & & & 3 & 4 \\
Orientación & 1 & - & - & - \\
Inclinación $\left({ }^{\circ}\right)$ & - & - & - & - \\
Área $\left(\mathrm{m}^{2}\right)$ & - & - & 20 & 50 \\
Litología & 2 & $\operatorname{Arc}$ & $\mathrm{Arc}$ & $\mathrm{Mac}$ \\
Altitud $(\mathrm{m})$ & $\mathrm{Arc}$ & 1050 & 1160 & 1130 \\
Altura vegetación $(\mathrm{cm})$. & 1360 & -5 & -5 & -5 \\
Cobertura vegetación $(\%)$ & -10 & 100 & 80 & 70
\end{tabular}

Características y diferenciales de asociaciones y comunidad

Ranunculus peltatus subsp. saniculifolius 2

Ranunculus peltatus subsp. peltatus

25

54

.

Compañeras

Chara vulgaris subsp. crassicaulis

Eleocharis palustris subsp. palustris

Juncus inflexus

Juncus sphaerocarpus

Mentha pulegium

\begin{tabular}{cccc}
$\cdot$ & 4 &. & 1 \\
$\cdot$ & $\cdot$ & 1 & 1 \\
+ & $\cdot$ & 3 &. \\
+ & $\cdot$ &. &. \\
\hline
\end{tabular}

Localidades. 1. Málaga. Antequera. Morrón de la Cruz. 30S 379151/4092087. 2. Granada. Loja. Sierra de San Jorge. Puerto de los Alazores. El Navazo. 30SUF8898. 3. Málaga. Villanueva del Trabuco. Sierra de San Jorge. La Laguna. 30SUF8697. 4. Málaga. Alfarnate. Sierra Gorda. Camino a cortijo del Jobo. 30S 385908/4096448. Arc: arcillas. Mac: margocalizas.

Mentha pulegium 2. Compañeras: Polypogon maritimus subsp. maritimus 1 , Linum tenue + , Lotus corniculatus subsp. delortii + , Trifolium fragiferum + , Kickxia lanigera + .

\section{Glycerio declinatae-Apietum nodiflori J. A. Molina 1996}

Herbazales helofíticos téneros, de arroyos con fuerte estiaje y ligeramente nitrificados. Se trata de su primera cita para el subsector Torcalense (Pérez Latorre et al., 2009). La asociación más extendida en las béticas occidentales es Helosciadetum nodiflori Maire 1924 (Pérez Latorre et al., 1998, 2012).

Localidad: Málaga. Antequera. Sierra de Camarolos. Arroyo Pilones. 30S377063/ 4091859. Orientación: -. Inclinación: $0^{\circ}$. Área: 20m². Litología: arcillas. Altitud: $1010 \mathrm{~m}$. Altura vegetación: $45 \mathrm{~cm}$. Cobertura vegetación: 100\%. Características y diferenciales de asociación: Glyceria declinata 4, Nasturtium officinale 4, Apium nodiflorum +. Características de unidades superiores: Veronica anagallis-aquatica +, Oenanthe globulosa +. Compañeras: Elymus repens + , Festuca mediterranea + , Hordeum bulbosum + , Juncus articulatus + , Juncus inflexus + , Lythrum junceum 1, Polypogon monspelliensis 3.

9. Saxifragetum camposii Cuatrecasas ex Martínez Parras \& Peinado Lorca 1990 [Tabla 4]

Asociación rupícola casmofítica, supramediterránea, que se desarrolla sobre 
Tabla 4

9. Saxifragetum camposii Cuatrecasas ex Martínez Parras \& Peinado Lorca 1990

(Asplenietea trichomanis, Potentilletalia caulescentis, Saxifragion camposii)

\begin{tabular}{lcc}
\hline INVENTARIO N & 1 & 2 \\
Orientación & $\mathrm{N}$ & $\mathrm{N}$ \\
Inclinación $\left(^{\circ}\right)$ & 90 & 90 \\
Área $\left(\mathrm{m}^{2}\right)$ & 8 & 15 \\
Litología & $\mathrm{Cal}$ & $\mathrm{Cal}$ \\
Altitud $(\mathrm{m})$ & 1400 & 1430 \\
Altura vegetación $(\mathrm{m})$. & 20 & 25 \\
Cobertura vegetación $(\%)$ & 60 & 40
\end{tabular}

Características y diferenciales de asociación

Saxifraga camposii

subsp. camposii

$2 \quad 2$

Características de unidades superiores

Coincya monensis subsp. cheiranthos

Crepis albida

Linaria verticillata subsp. anticaria

Silene andryalifolia

Biscutella frutescens

$\begin{array}{ll}1 & 1 \\ + & 1 \\ & \\ + & + \\ 3 & 2 \\ - & 1\end{array}$

Compañeras

Chaenorhinum villosum $\quad+\quad 1$

Stachys circinata

$1+$

Otras compañeras. En 1: Briófitos 3, Sedum album +. En 2: Musgo pleurocárpico 3, Prunus mahaleb + , Ranunculus spicatus subsp. blepharicarpos +, Sisymbrium officinale + .

Localidades. 1. Villanueva del Rosario. El Hondonero. Sierra del Jobo NE. Realengo de la Vereda de Alfarnate. 30S 383494/4094724. 2. Ídem. 30S 383509/4094725. Cal: calizas.

roquedos calizos muy expuestos, de morfología convexa, en grietas verticales. La asociación es propia de sierras del sector Subbético tales como Sierra Mágina o La Pandera y ya había sido citada en el subsector Torcalense (Pérez Latorre et al., 2009). Las nuevas localizaciones en la ZEC se consideran las más extremas hacia el suroeste de las Béticas y además se encuentran a alturas bastante inferiores que las de su descripción original (Martínez Parras \& Peinado, 1990).
10. Hieracietum baetici-texedensis Pérez Latorre, Casimiro-Soriguer \& Cabezudo ass. nova [Tabla 5, holotypus hoc loco inv. $\mathrm{n}^{\mathrm{o}} 3$ ]

Vegetación rupícola casmofítica y dolomitícola, que se desarrolla en los termotipos supra y mesomediterráneo bajo ombrotipos subhúmedo y húmedo, exclusiva hasta el momento del subsector Torcalense, distrito de Las Pedrizas. Asociación caracterizada por la combinación de Hieracium texedense e $H$. baeticum, que se acompañan de modo más puntual por Festuca plicata, Pimpinella tragium subsp. litophilla, Linaria verticillata subsp. anticaria, Armeria villosa subsp. longiaristata, Dianthus anticarius, Hieracium amplexicaule y Arabis serpyllifolia, los cuales la diferencian de las dos comunidades fitosociológicamente más cercanas: Rhamno pumili-Saxifragetum granatensis Pérez Latorre \& Cabezudo in Pérez Latorre, P. Navas, D. Navas, Y. Gil \& Cabezudo 1998 (sector Rondeño) e Hieracio texedensis-Jasionetum minutae Pérez Latorre \& Cabezudo in Pérez Latorre, D. Navas, Gavira, Caballero \& Cabezudo 2004 (sector Almijaro-Granatense). Se incluye en el orden Potentilletalia caulescentis por su posición bioclimática $\mathrm{y}$ por sus bioindicadores: Rhamnus pumila, Erinus alpinus, Hieracium baeticum, Draba hispanica, Sedum dasyphyllum, Asplenium ruta-muraria y Campanula rotundifolia subsp. hispanica. La presencia de Hieracium texedense nos permite incluirla en Saxifragion camposii y relacionarla fitogeográficamente con Hieracio texedensis-Jasionetum minutae, bética oriental (endémica del sector AlmijaroGranatense) y también dolomitícola. Especies propias de Rhamno pumili-Saxifragetum granatensis (rondeña) que no están en la nueva asociación: Saxifraga globulifera, Erodium cheilanthifolium, Armeria villosa subsp. villosa, Centranthus nevadensis $\mathrm{y}$ Jasione foliosa subsp. minuta. Especies 
Tabla 5

10. Hieracietum baetici-texedensis Pérez Latorre, Casimiro-Soriguer \& Cabezudo ass. nova (Asplenietea trichomanis, Potentilletalia caulescentis, Saxifragion camposii)

\begin{tabular}{|c|c|c|c|c|c|c|c|c|c|}
\hline INVENTARIO Nº & 1 & 2 & 3 & 4 & 5 & 6 & 7 & 8 & 9 \\
\hline Orientación & $\mathrm{N}$ & $\mathrm{N}$ & $\mathrm{N}$ & NW & NW & $\mathrm{N}$ & $\mathrm{N}$ & $\mathrm{N}$ & $\mathrm{N}$ \\
\hline Inclinación $\left({ }^{\circ}\right)$ & 60 & 90 & 85 & 75 & 90 & 90 & 70 & 90 & 90 \\
\hline Área $\left(\mathrm{m}^{2}\right)$ & 2 & 5 & 4 & 6 & 4 & 4 & 25 & 10 & 4 \\
\hline Litología & Dol & Dol & Dol & Dol & Dol & Dol & Dol & Dol & Dol \\
\hline Altitud (m) & 1450 & 1440 & 1445 & 1190 & 1200 & 1205 & 1000 & 1200 & 1150 \\
\hline Altura vegetación $(\mathrm{cm})$. & 5 & 5 & 5 & 10 & 10 & 10 & 20 & 15 & 4 \\
\hline Cobertura vegetación $(\%)$ & 15 & 10 & 15 & 40 & 15 & 15 & 30 & 40 & 30 \\
\hline \multicolumn{10}{|c|}{ Características y diferenciales de asociación } \\
\hline Hieracium texedense & + & 1 & 1 & & & & + & 2 & 1 \\
\hline Hieracium baeticum & 1 & 1 & + & + & + & 1 & . & . & . \\
\hline Festuca plicata & 1 & 1 & + & + & 1 & 1 & . & . & \\
\hline Pimpinella tragium subsp. litop & . & . & . & 1 & . & 1 & . & . & . \\
\hline Linaria verticillata subsp. anticaria & . & . & . & + & . & . & + & . & . \\
\hline
\end{tabular}

Otras diferenciales. En 3: Arabis serpyllifolia +, Hieracium amplexicaule +. En 6: Armeria villosa subsp. longiaristata + . En 7: Dianthus anticarius + .

Características de unidades superiores (Potentilletalia caulescentis)

$\begin{array}{llllllllll}\text { Campanula rotundifolia subsp. hispanica } & 1 & + & 1 & 1 & 1 & + & 1 & 2 & \text {. } \\ \text { Rhamnus pumila } & . & + & + & 1 & + & . & . & . & 1 \\ \text { Erinus alpinus } & . & . & + & + & . & . & . & 1 & 1 \\ \text { Draba hispanica } & . & + & + & . & . & . & . & . & . \\ \text { Sedum dasyphyllum } & . & . & + & . & + & . & . & . & . \\ \text { Asplenium ruta-muraria } & . & + & . & . & . & . & . & . & .\end{array}$

Otras características de unidades superiores

Campanula mollis

Crepis albida

Silene andryalifolia

Compañeras

Chaenorhinum villosum

Arenaria armerina

Asplenium trichomanes subsp. quadrivalens

Galium lucidum subsp. lucidum

Asplenium ceterach

Chaenorhinum villosum subsp. granatensis

Dianthus brachyanthus

Geranium rotundifolium

Sedum mucizonia

Stachys circinata

Viola demetria

\begin{tabular}{|c|c|c|c|c|c|c|c|c|}
\hline - & + & - & + & 1 & . & + & . & . \\
\hline • & $\cdot$ & $\cdot$ & + & + & + & 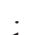 & 1 & + \\
\hline - & $\cdot$ & - & + & $\cdot$ & + & 1 & . & - \\
\hline
\end{tabular}

Otras compañeras. En 1: Amelanchier ovalis + . En 3: Briófitos 2. En 4: Erinacea anthyllis + . En 5: Prunus mahaleb +. En 6: Bunium macuca + , Scabiosa turolensis subsp. grosii 1. En 7: Crambe filiformis + , Dactylis glomerata subsp. hispanica + , Festuca triflora + , Silene vulgaris + .

Localidades. 1. Málaga. Villanueva del Rosario. Puerto de los Perdigones. 30S 382642/4093178. 2. Málaga. Villanueva del Rosario. Puerto de los Perdigones. 30S 382617/4093170. 3. Málaga. Villanueva del Rosario. Puerto de los Perdigones. 30S 382612/4093166. 4. Málaga. Antequera. Morrón de Gragea. 30S376017/4090503. 5. Ídem. 30S 376020/4090578. 6. Ídem. 376030/4090586. 7. Málaga. Antequera. Sierra de las Cabras. 30SUF6793. 8 y 9. Ídem. 30SUF6893. Dol: dolomías. 
propias de Hieracio texedensis-Jasionetum minutae (almijaro-granatense) que no están en la nueva asociación: Jasione foliosa subsp. minuta, Saxifraga erioblasta, Galium erytrorrhizon, Teucrium fragile, Centranthus nevadensis y Globularia spinosa. Las demás asociaciones rupícolas casmofíticas del subsector Torcalense se desarrollan sobre calizas, y de éstas, la única incluida en Potentilletalia caulescentis (Saxifragetum camposii) presenta como taxon directriz a Saxifraga camposii, completamente ausente de esta nueva asociación.

\section{Comunidad de Cystopteris dickieana BC}

Vegetación pteridofítica ténera, glerícola y esciófila que aparece puntualmente en el termotipo supramediterráneo húmedo del subsector Torcalense de la ZEC. Está presidida por Cystopteris dickieana, taxon característico de Androsacetalia vandellii, cuya alianza fitogeográficamente más cercana es Saxifragion nevadensis del sector Nevadense. Una comunidad similar se presenta en la Sierra de las Nieves (sector Rondeño), en el tránsito entre los termotipos supra y oromediterráneo, por encima de los $1700 \mathrm{~m}$. (comunidad de Cystopteris fragilis, Pérez Latorre et al, 1998) que también lleva Cystopteris dickieana (MGC44980-1).

Localidad: Málaga. Villanueva del Rosario. Puerto de los Perdigones. 30S382604/4093167. Orientación: -. Inclinación: $0^{\circ}$. Área: $1 \mathrm{~m}^{2}$. Litología: dolomías. Altitud: $1440 \mathrm{~m}$. Altura vegetación: $20 \mathrm{~cm}$. Cobertura vegetación: $80 \%$. Características y diferenciales de comunidad: Cystopteris dickieana 3. Características de unidades superiores: Asplenium trichomanes 3. Compañeras: Briófitos 3. Galium aparine subsp. aparine +. Geranium lucidum +.

\section{Biscutello frutescentis-Saxifragetum} reuterianae Socorro \& Marín Calderón 1983 [Tabla 6]

\section{saxifragetosum reuterianae}

var. con Erodium cheilanthifolium

Vegetación rupícola casmofítica, generalmente instalada en grietas verticales en orientación norte, sobre calizas, en los pisos meso y supramediterráneo del subsector Torcalense en la ZEC, siendo la más abundante de su alianza. En zonas medias y altas se presenta como la variante orófila con Erodium cheilanthifolium y Campanula rotundifolia subsp. hispanica. Es sustituida por el Hieracietum baetici-texedensis sobre roca dolomítica y por el Saxifragetum camposii en roquedos convexos expuestos. En un trabajo anterior sobre el subsector Torcalense, los inventarios de esta misma asociación (Pérez Latorre et al., 2009: 160, tabla 8) no presentan Saxifraga reuteriana; se trata de zonas periféricas al núcleo de la Sierra de Camarolos.

16. Sarcocapnetum baeticae Pérez Latorre \& Cabezudo in Pérez Latorre, P. Navas, D. Navas, Gil \& Cabezudo 1998

Asociación espeluncícola, hasta ahora de sincorología Rondeña (subsector Rondense) en las Sierras de las Nieves, Prieta, Blanquilla y Alcaparaín (Pérez Latorre et al., 1998, 2012, 2015) que ha sido inventariada en la ZEC en el subsector Torcalense, aumentando por tanto su área de distribución hacia la provincia Bética en su zona oriental. Se ha localizado de manera muy puntual (una sola localidad) y sobre dolomías, como en el resto de su areal.

Localidad: Málaga. Antequera. La Fresneda. Cortijo Dornillo. 30SUF7490. Orientación: S. Inclinación: $180^{\circ}$. Área: $5 \mathrm{~m}^{2}$. Litología: calizo-dolomía. Altitud: $900 \mathrm{~m}$. Altura vegetación: $3 \mathrm{~cm}$. Cobertura vegetación: $10 \%$. Característica y diferencial de asociación: Sarcocapnos baetica subsp. baetica 1. Compañeras: Polygala rupestris + , Chaenorrhinum villosum + , Campanula mollis + , Parietaria judaica + . 
Tabla 6

12. Biscutello frutescentis-Saxifragetum reuterianae Socorro \& Marín Calderón 1983 saxifragetosum reuterianae, var. con Erodium cheilanthifolium (Asplenietea trichomanis, Asplenietalia petrarchae, Campanulion velutinae)

\begin{tabular}{lccccc}
\hline INVENTARIO N & & & & 4 & 5 \\
Orientación & 1 & 2 & 3 & $\mathrm{~N}$ & $\mathrm{~N}$ \\
Inclinación $\left({ }^{\circ}\right)$ & $\mathrm{N}$ & $\mathrm{N}$ & $\mathrm{N}$ & 80 & 80 \\
Área $^{\left(\mathrm{m}^{2}\right)}$ & 90 & 75 & 90 & 2 & 40 \\
Litología & 15 & 50 & 10 & $\mathrm{Cal}$ & $\mathrm{Cal}$ \\
Altitud $(\mathrm{m})$ & $\mathrm{Cal}$ & $\mathrm{Cal}$ & $\mathrm{Cal}$ & $\mathrm{Cal}$ & 115 \\
Altura vegetación $(\mathrm{cm})$. & 1540 & 1445 & 1435 & 1200 & 5 \\
Cobertura vegetación $(\%)$ & 15 & 10 & 25 & 5 & 45 \\
& 35 & 15 & 20 & 10 & 20
\end{tabular}

Características y diferenciales de asociación

Saxifraga reuteriana

Biscutella frutescens

$\begin{array}{lllll}1 & 2 & 1 & 1 & 1 \\ 2 & \cdot & \cdot & \cdot & .\end{array}$

Diferenciales de variante

Campanula rotundifolia subsp. hispanica

Erodium cheilanthifolium

Características de unidades superiores

Crepis albida

Asplenium trichomanes

Linaria verticillata subsp. anticaria

Silene andryalifolia

Coincya monensis subsp. cheiranthos

Cystopteris fragilis subsp. fragilis

Cystopteris dickieana

\section{Compañeras}

Asplenium ceterach

Stachys circinata

Chaenorrhinum villosum

Galium lucidum subsp. lucidum

Ranunculus blepharicarpos

Briófitos

Festuca plicata

Fumaria macrosepala

Poa flaccidula

Prunus mahaleb

Sedum dasyphyllum

Sedum mucizonia

Umbilicus gaditanus

$\begin{array}{lllll}2 & \cdot & . & 1 & 1 \\ . & . & . & . & 1\end{array}$

Otras compañeras. En 1: Hormatophylla spinosa 1. En 2: Antirrhinum graniticum 1. En 3: Anthyllis vulneraria +, Hedera helix subsp. helix +, Muscari atlanticum 1. En 5: Anthemis pedunculata 1, Armeria villosa subsp. longiaristata + , Campanula cabezudo + , Sisymbrium crassifolium + .

Localidades. 1. Málaga. Alfarnate. Sierra del Jobo. Umbría entre El Jobo y La Torca. 30S 383781/4094130. 2. Málaga. Alfarnate. Cara sur del Chamizo. 30S 383403/4093235. 3. Málaga. Colmenar. Puerto de los Perdigones. 30S 383325/4093468. 4 y 5. Málaga. Antequera. La Fresneda. Sierra del Enebral. 30SUF7690. Cal: calizas. 
20. Eryngio aquifolii-Cynaretum baeticae Pérez Latorre, Casimiro-Soriguer \& Cabezudo ass. nova [Tabla 7, holotypus hoc loco inv. $\left.\mathrm{n}^{\circ} 1\right]$

Asociación constituida por cardales macroterofíticos, de elevada talla, que se desarrollan sobre suelos vérticos arcillosos, con grado de humedad temporal hasta finales de primavera y principios de verano, que es cuando alcanza su máximo desarrollo. Se localiza en el piso mesomediterráneo subhúmedohúmedo del subsector Torcalense en la ZEC. Está caracterizada por la combinación de Cynara baetica (endemismo bético) y Eryngium aquifolium, especie que representa la vegetación propia del tipo de suelos descritos anteriormente. La asociación constituye etapa sinfenosucesional de la geopermaserie verticícola temporihigrófila. Existe otra asociación descrita para la provincia Bética para las zonas de sustrato básico en Sierra Nevada, denominada Scolymo hispanici-Cynaretum albae (Pérez Raya, 1987), de la que la nueva asociación se diferencia en que la de $\mathrm{S}$. Nevada es de distribución Almijaro-Granatense, bajo ombrotipo seco-subhúmedo, no ocupa suelos vérticos y constituye etapa dinámica de la serie climatófila del encinar supramediterráneo de Berberido-Querceto rotundifoliae S. Además, la nueva asociación presenta como diferenciales más frecuentes frente a Scolymo hispaniciCynaretum albae: Carlina corymbosa, Cynara humilis y Notobasis syriaca, entre otras.

\section{Elymo hispanici-Brachypodietum sylvatici \\ Gómez-Mercado \& F. Valle 1991}

Herbazales graminoides esciohumícolas, supra-mesomediterráneos, basófilos, que prosperan en el ambiente nemoral de bosques caducifolios de la provincia Bética. En la ZEC se han hallado en el sotobosque de quejigales y acerales de Vinco difformis-Quercetum fagineae típico y aceretosum monspessulani. Fueron citados muy recientemente para el subsector Torcalense y por primera vez por Pavón et al. (2015) sin aportar inventario, lo que hacemos a continuación.

Localidad: Granada. Loja. Sierra de San Jorge. Cortijo de la Manga. 30S387772/4099533. Orientación: NE. Inclinación: $5^{\circ}$. Área: $25 \mathrm{~m}^{2}$. Litología: arcillas. Altitud: $1030 \mathrm{~m}$. Altura vegetación: $100 \mathrm{~cm}$. Cobertura vegetación: $100 \%$. Características y diferenciales de asociación: Elymus hispanicus 2, Brachypodium sylvaticum 4. Características de unidades superiores: Piptatherum paradoxum +. Compañeras: Brachypodium phoenicoides 1, Cichorium intybus + , Galium verum + , Linum tenue + , Phleum bertolonii + , Poa trivialis 1 , Potentilla reptans + , Ptilostemon hispanicus + .

\section{Chaenorrhino reyesii-Campanuletum} fastigiatae Rivas-Martínez \& Izco in Izco 1974 corr. Alcaraz, Ríos, De la Torre, Delgado \& Inocencio 1998

avellinietosum festucoidis Cabezudo, Pérez Latorre \& Casimiro-Soriguer 2013

Pastizales nanoterofíticos efímeros, primaverales, sobre yesos masivos que en la ZEC se desarrollan exclusivamente en el subsector Antequerano, de donde son endémicos (Cabezudo et al., 2013). Se presentan con muy escasas localizaciones, aunque manteniendo sus tres especies características (Chaenorrhinum reyesii, Campanula fastigiata y Avellinia festucoides), siempre en rellanos en los claros del matorral gipsófito (albaidal) de Hippocrepido bourgaei-Anthyllidetum cytisoidis ass. nova. Son más abundantes otras agrupaciones de pastizal anual, caracterizados básicamente por Astragalus hamosus y Hedysarum spinosissimum en los claros de dicho albaidal, o formaciones terofíticas de Moricandia moricandioides subsp. giennensis, sobre todo en taludes y bordes de carril.

Localidad: 1. Málaga. Antequera. Lagunillas Altas. Sobre cantera. 30S363981/4098093. 
Tabla 7

21. Eryngio aquifolii-Cynaretum baeticae Pérez Latorre, Casimiro-Soriguer \& Cabezudo ass. nova (Artemisietea vulgaris, Carthametalia lanati, Onopordion castellani)

\begin{tabular}{|c|c|c|c|c|c|}
\hline INVENTARIO No & 1 & 2 & 3 & 4 & 5 \\
\hline Orientación & - & - & - & - & W \\
\hline Inclinación $\left(^{\circ}\right)$ & - & - & - & - & 20 \\
\hline Área $\left(m^{2}\right)$ & 100 & 25 & 100 & 50 & 50 \\
\hline Litología & Arc & Arc & Arc & Arc & Arc \\
\hline Altitud (m) & 1200 & 1100 & 1170 & 770 & 1280 \\
\hline Altura vegetación (m.) & 120 & 120 & 170 & 150 & 120 \\
\hline Cobertura vegetación (\%) & 60 & 60 & 90 & 70 & 60 \\
\hline \multicolumn{6}{|c|}{ Características y diferenciales de asociación } \\
\hline Cynara baetica subsp. baetica & 4 & 2 & 3 & 2 & 2 \\
\hline Eryngium aquifolium & 2 & 3 & + & 3 & . \\
\hline Carlina corymbosa & + & 1 & 2 & . & . \\
\hline Cynara humilis & 2 & . & 1 & 2 & . \\
\hline Notobasis syriaca & . & . & 3 & . & 2 \\
\hline \multicolumn{6}{|c|}{ Características de unidades superiores } \\
\hline Scolymus hispanicus & 2 & 2 & 2 & 2 & 2 \\
\hline Cirsium echinatum & + & + & + & . & \\
\hline Eryngium campestre & + & . & 1 & . & 2 \\
\hline Carduus pycnocephalus & . & 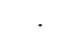 & 4 & . & 2 \\
\hline
\end{tabular}

Otras características. En 3: Onopordum illyricum subsp. illyricum 2, Silybum marianum 2. En 4: Echinops strigosus 2. En 5: Centaurea calcitrapa 2, Carthamus lanatus 1.

\section{Compañeras}

Carlina racemosa

Hordeum bulbosum

$\begin{array}{ccccc}+ & \cdot & + & & \\ \cdot & \cdot & \cdot & 2 & +\end{array}$

Otras compañeras. En 1: Linum tenue + , Pallenis spinosa + , Thymus mastichina + , Ulex parviflorus 1, Phlomis herba-venti +. En 2: Thapsia villosa 1, Thymus baeticus +. En 4: Festuca ampla 1. En 5: Elymus repens + .

Localidades. 1. Málaga. Colmenar. Sierra Prieta. 30S 379879/4091424. 2. Málaga. Antequera. Sierra de las Cabras.30SUF6893. 3. Málaga. Antequera. Sierra de las Cabras. Collado de Los Lastonares. 30SUF6893. 4. Málaga. Antequera. Sierra de las Cabras. Frente al cortijo de las Alhajuelas. 30SUF6694. 5. Málaga. Antequera. Sierra de Camorolos. Cara noroeste del Cerro Cruz. 30SUF7892. Arc: arcillas.

Orientación: W. Inclinación: 5. Área: 0,25 $\mathrm{m}^{2}$. Litología: yesos. Altitud: $515 \mathrm{~m}$. Altura vegetación: $10 \mathrm{~cm}$. Cobertura vegetación: $10 \%$. Características y diferenciales de asociación y subasociación: Chaenorrhinum reyesii + , Campanula fastigiata 1, Avellinia festucoides +. Característica de unidades superiores: Narduroides salzmanii + . Compañera: Bromus rubens + .

\section{Scillo autumnalis-Ranunculetum bullati}

Pérez Latorre \& Cabezudo in Pérez Latorre, Caballero, Casimiro-Soriguer, Gavira \& Cabezudo 2008

Pastizal caracterizado por geófitos otoñales, que incluyen en la ZEC a Narcissus elegans, y que se desarrolla en el único enclave termófilo del subsector Torcalense, donde constituye 
Tabla 8

\begin{tabular}{|c|c|c|}
\hline \multicolumn{3}{|c|}{$\begin{array}{l}\text { 38. Comunidad de Festuca segimonensis y } \\
\text { Koeleria filifolia } \\
\text { (Festuco hystricis-Ononidetea striatae, Festuco } \\
\text { hystricis-Poetalia ligulatae, Sideritido } \\
\text { fontquerianae-Arenarion aggregatae) }\end{array}$} \\
\hline INVENTARIO N ${ }^{\circ}$ & 1 & 2 \\
\hline Orientación & NW & - \\
\hline Inclinación $\left({ }^{\circ}\right)$ & 5 & - \\
\hline Área $\left(\mathrm{m}^{2}\right)$ & 5 & 5 \\
\hline Litología & Cal & Cal \\
\hline Altitud (m) & 1460 & 1485 \\
\hline Altura vegetación (cm.) & 25 & 25 \\
\hline Cobertura vegetación (\%) & 60 & 40 \\
\hline \multicolumn{3}{|l|}{ Características de comunidad } \\
\hline Festuca segimonensis & 3 & 1 \\
\hline Koeleria filifolia & 2 & 1 \\
\hline Avenula bromoides subsp. pauneroi & + & 3 \\
\hline Asperula aristata subsp. scabra & 1 & + \\
\hline \multicolumn{3}{|l|}{ Compañeras } \\
\hline Dianthus hispanicus & 1 & + \\
\hline \multicolumn{3}{|l|}{ Helianthemum appeninum } \\
\hline subsp. stoechadifolium & 2 & 2 \\
\hline
\end{tabular}

Otras compañeras. En 1: Arenaria armerina subsp. armerina +, Musgo acrocárpico 2, Plantago lagopus + , Poa bulbosa 2, Polygala monspeliaca + . En 2: Anthyllis vulneraria subsp. arundana + , Bupleurum spinosum + , Erinacea anthyllis + , Sanguisorba verrucosa 1, Sedum mucizonia + , Thymus baeticus + .

Localidades. 1. Málaga. Villanueva del Rosario. El Hondonero. Sobre la Vereda de Alfarnate. 30S 383560/4094666. 2. Idem. 30S 383665/4094643. Cal: calizas.

primera cita.

Localidad: Antequera. Sierra del Co. Finca la Fresneda. Entre cortijo La Fresneda y ctjo. Dornillo. 30SUF7390. Orientación: N. Inclinación: $20^{\circ}$. Área: $25 \mathrm{~m}^{2}$. Litología: calizas. Altitud: $850 \mathrm{~m}$. Altura vegetación: 20 $\mathrm{cm}$. Cobertura vegetación: 70\%. Características y diferenciales de asociación: Ranunculus bullatus 3, Scilla autumnalis + . Características de unidades superiores: Arisarum simorrhinum 1, Lobularia maritima +. Compañeras: Crocus serotinus subsp. salzmannii 2, Urginea martima + .
38. Comunidad de Festuca segimonensis y Koeleria filifolia [Tabla 8]

Pastizales vivaces graminoides y de caméfitos postrados, xerofíticos, que se desarrollan en litosuelos y rankers pedregosos, con signos de crioturbación y pastoreo, en topografías de rellanos en crestas venteadas. Se han localizado en el termotipo supramediterráneo húmedo y sobre calizas. Están caracterizados por Koeleria filifolia y Festuca segimonensis, siendo frecuentes Asperula aristata subsp. scabra y Avenula bromoides subsp. pauneroi. Es destacable la ausencia de Poa ligulata, y Festuca hystrix, frecuentes en este mismo tipo de comunidades tanto en la Serranía de Ronda (Koelerio dasyphyllae-Arenarietum erinacei Pérez Latorre \& Cabezudo (1998) 2002) como en Sierras Tejeda y Almijara (Erodio daucoidis-Saxifragetum erioblastae erodietosum cheilanthifolii Pérez Latorre \& Cabezudo in Pérez Latorre, D. Navas, Gavira, Caballero \& Cabezudo 2004).

39. Thrincio hispidae-Poetum bulbosae Pérez Latorre, Casimiro-Soriguer \& Cabezudo ass. nova [Tabla 9, holotypus hoc loco inv. $\left.n^{\circ} 2\right]$

(Comunidad de Poa bulbosa sensu Pérez Latorre et al. (1998) p.p.: excluida variante orófila)

(Poo bulbosae-Astragaletum sesamei Rivas Goday \& Ladero 1970 southern race with Erodium recoderi and Ranunculus blepharicarpos sensu Galán de Mera et al. (2000: 261-262)

(Poo bulbosae-Astragaletum sesamei in Gómez Mercado et al. 2000: 218, Tabla 3.13

(Comunidad de Poa bulbosa sensu Asensi et al. 2005: 54)

(Comunidad de Erodium primulaceum BC sensu Pérez Latorre, Caballero, CasimiroSoriguer, Gavira y Cabezudo 2009; Pérez Latore et al., 2014) 
Tabla 9

39. Thrincio hispidae-Poetum bulbosae Pérez Latorre, Casimiro-Soriguer \& Cabezudo ass. nova (Poetea bulbosae, Poetalia bulbosae, Plantaginion serrariae)

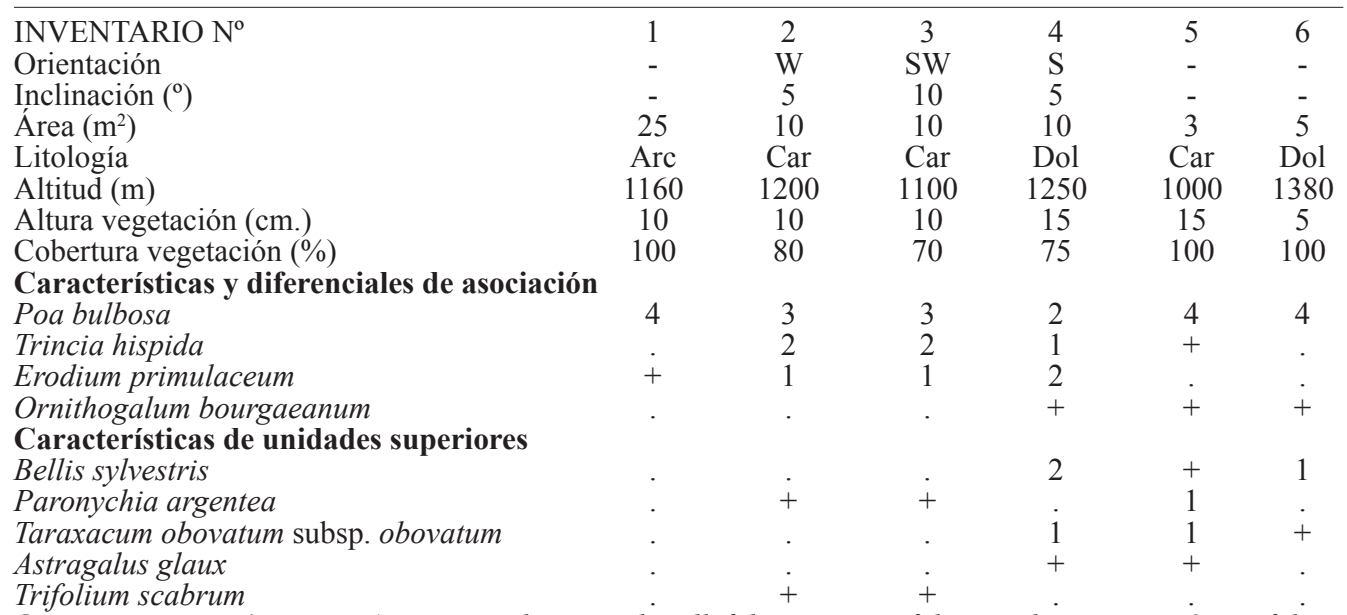

Otras características. En 1: Ranunculus pseudomillefoliatus + , Trifolium subterraneum 3, Trifolium suffocatum 3. En 2: Trifolium tomentosum 1. En 4: Astragalus macrorhizus + .

\section{Características de Tuberarietea guttatae}

Medicago minima

Minuartia hybrida

Rumex bucephalophorus

Trifolium stellatum

$\begin{array}{ccccc}+ & . & + & . & + \\ 2 & + & \cdot & \cdot & 1 \\ 1 & i & . & \cdot & .\end{array}$

Otras características. En 1: Aphanes cornucopiodes +, Vulpia bromoides 3. En 2: Linaria oblongifolia + , Petrorrhagia nanteuillii + , Trifolium campestre + . En 3: Helianthemum salicifolium + , Velezia rigida + . En 4: Logfia gallica +. En 5: Euphorbia exigua subsp. exigua + , Evax pygmaea +, Hippocrepis biflora + , Neatostema apulum +. En 6: Cerastium pumilum + , Crucianella angustifolia + , Erophila verna + , Scandix australis + , Trifolium arvense + .

Compañeras

Plantago lagopus

Anthemis arvensis

Bromus rubens

Catapodium rigidum

Carlina corymbosa

Sherardia arvensis

Otras compañeras. En 1: Filago pyramidata +, Herniaria glabra 1, Polycarpon tetraphyllum 1. En 2: Carduus tenuiflorus 1, Crambe filiformis + , Dactylis glomerata subsp. hispanica + , Lagurus ovatus + , Papaver rhoeas + , Polygala rupestris + . En 3: Capsella bursa-pastoris + , Hedypnois rhagadioloides 2, Klasea pinnatifida 1, Medicago orbicularis + . En 4: Anthyllis vulneraria subsp. maura + , Astragalus hamosus + , Centaurea pullata subsp. baetica + , Medicago lupulina + , Muscari comosum,+ Ophrys apifera,+ Plantago lanceolata + , Thapsia transtagana + , Raponthicum coniferum + . En 5: Bellardia trixago +, Bromus madritensis + , Erodium cicutarium 2, Galium verrucosum + , Helianthemum asperum + , Poa flaccidula + , Reichardia intermedia +, Sanguisorba minor subsp. balearica +, Scorpiurus muricatus +, S. sulcatus +. En 6: Agrostis stolonifera 1, Conopodium thalictrifolium + , Ranunculus spicatus subsp. blepharicarpos 1 , Rumex acetosella subsp. angiocarpus + , Sanguisorba hybrida +, Scandix pecten-veneris + , Veronica cymbalaria + .

Localidades. 1. Málaga. Villanueva del Trabuco. Sierra de San Jorge. Dolina de La Laguna. 30SUF8697. 2. Málaga. Alfarnate. Sierra de Vilo. 30SUF8993. (tomado de Pérez Latorre et al., 2009). 3. Málaga. Antequera. Sierra del Valle de Abdalajís. La Capilla, cara oeste. 30SUF4789 (tomado de Pérez Latorre et al., 2014). 4. Málaga. Ronda. Camino del Ctjo. Quejigales a la cañada del Cuerno. 30SUF 1762. 5. Málaga. Parauta. Llano de las Conejeras. 30SUF1359. 6. Málaga. Ronda. Base de la cañada de las Ánimas. 30S UF1964.Arc: arcillas, Car: calizas y arcillas, Dol: dolomías. Inventarios 4, 5 y 6 tomados de Cabezudo et al., 1998: 269, Tabla 44. 
Pastizales dominados por hemicriptófitos, geófitos y terófitos postrados, originados y modelados por el pastoreo más o menos constante de ganado ovino. Están dominados y caracterizados por Poa bulbosa y como especies diferenciales se acompaña de Thrincia hispida, Erodium primulaceum y Ornithogalum bourgaeanum. Se desarrollan sobre suelos arcillosos compactados, derivados fundamentalmente de materiales calizos, a veces por procesos kársticos, aunque también pueden ser dolomíticos. Se localizan bioclimáticamente en los termotipos meso y supramediterráneo inferior, entre 1000 y 1400 metros, bajo ombrotipos subhúmedo y húmedo. Dinámicamente aparecen en la zonopotencialidad de encinares de Paeonio coriaceae-Quercetum rotundifoliae y quejigales de Vinco difformis-Quercetum fagineae. Fitogeográficamente se distribuyen por los sectores Rondeño, Antequerano (subsector Torcalense) y Subbético (zona occidental). Constituyen una transformación dinámica de pastizales oligotróficos de Tuberarietea por el constante pastoreo y pisoteo de ganado ovino, por lo que son frecuentes especies de esa clase como Medicago minima, Minuartia hybrida, Rumex bucephalophorus o Trifolium stellatum. Sintaxonómicamente es una asociación a caballo entre Plantaginion serrariae, por la presencia frecuente de Erodium primulaceum, y Astragalo-Poion bulbosae por Astragalus glaux, A. macrorhizus y Trifolium scabrum. Nos inclinamos por incluir esta nueva asociación en Astragalo-Poion bulbosae, por la altitud a que se desarrolla (meso-supramediterránea, 1000-1400 m.) en comparación con Trifolio subterraneiPlantaginetum serrariae (Plantaginion serrariae) que también presenta frecuencia alta de Erodium primulaceum pero solo llega hasta $900 \mathrm{~m}$. (termotipos termomediterráneo y mesomediterráneo inferior) (Galán de Mera et al., 2000). Florísticamente la nueva asociación se diferencia de las fitogeográficamente más próximas: a/ por la ausencia de las características de Trifolio subterraneiPlantaginetum serrariae (Sierra de Grazalema y Los Alcornocales: Plantago serraria, Biscutella baetica, Leontodon tuberosus, Otospermum glabrum y Vicia lutea subsp. cavanillesii) además de que ésta asociación está ligada dinámicamente a series de acebuchales de Olea europaea var. sylvestris y alcornocales de Quercus suber (Galán de Mera et al., 2000); b/ se diferencia de los majadales descritos en Sierra Tejeda (Comunidad de Hieracium pseudopilosella y Poa bulbosa) en que éstos son silicícolas y llevan Hieracium pseudopilosella y Parentucellia viscosa (Pérez Latorre et al., 2004). Esta nueva asociación engloba a otras comunidades y tablas o partes de tablas descritas en trabajos anteriores de Sierra de las Nieves (Pérez Latorre et al. 1998; Galán de Mera et al., 2000), Subbéticas cordobesas (Gómez Mercado et al., 2000), Torcal de Antequera (Asensi et al., 2005) y Cordillera Torcalense y Sierras de Huma-El Chorro (Pérez Latorre et al., 2009, 2014).

\section{Thymo gracilis-Stipetum tenacissimae} Pérez Raya \& Molero 1988

thymetosum capitati Pérez Latorre, Casimiro-Soriguer \& Cabezudo subass. nova [Tabla 10, holotypus hoc loco inv. $\left.n^{\circ} 1\right]$

En la ZEC, la vegetación graminoide perenne y xerófila con Stipa tenacissima solo se desarrolla en el subsector Antequerano, sobre carniolas, margas y yesos. La elevada termicidad en este subsector (termotipo mesomediterráneo inferior) favorece la presencia de elementos termófilos, lo que lleva a proponer una subasociación, thymetosum capitati subass. nova, para estos espartales termófilos antequeranos en ombrotipo seco, sobre materiales triásicos. La subasociación típica es mesomediterránea, entre 700 y 1100 metros y con distribución bético-oriental (AlmijaroGranatense, Subbético y Antequerano) (Pérez 
Tabla 10

\begin{tabular}{|c|c|c|}
\hline \multicolumn{3}{|c|}{$\begin{array}{l}\text { 41. Thymo gracilis-Stipetum tenacissimae Pérez } \\
\text { Raya \& Molero } 1988 \\
\text { thymetosum capitati Pérez Latorre, Casimiro- } \\
\text { Soriguer \& Cabezudo subass. nova } \\
\text { (Lygeo sparti-Stipetea tenacissimae, Lygeo sparti- } \\
\text { Stipetalia tenacissimae, Stipion tenacissimae) }\end{array}$} \\
\hline INVENTARIO N ${ }^{\circ}$ & 1 & 2 \\
\hline Orientación & $\mathrm{S}$ & $\mathrm{S}$ \\
\hline Inclinación $\left({ }^{\circ}\right)$ & 20 & 50 \\
\hline Área $\left(\mathrm{m}^{2}\right)$ & 100 & 100 \\
\hline Litología & Car & Myc \\
\hline Altitud (m) & 682 & 650 \\
\hline Altura vegetación (cm.) & 120 & 80 \\
\hline Cobertura vegetación (\%) & 50 & 40 \\
\hline \multicolumn{3}{|c|}{ Características y diferenciales de asociación } \\
\hline Stipa tenacissima & 3 & 2 \\
\hline Dactylis glomerata subsp. hispanica & . & + \\
\hline Thymus zygis subsp. gracilis & + & . \\
\hline \multicolumn{3}{|l|}{ Diferenciales de subasociación } \\
\hline Thymus capitatus & 1 & 2 \\
\hline Urginea maritima & + & . \\
\hline \multicolumn{3}{|l|}{ Características de unidades superiores } \\
\hline Brachypodium retusum & 1 & 1 \\
\hline Phlomis lychnitis & 1 & + \\
\hline \multicolumn{3}{|l|}{ Compañeras } \\
\hline Cistus albidus & 1 & + \\
\hline Fumana thymifolia & 1 & 1 \\
\hline Ophrys speculum & + & + \\
\hline Phagnalon rupestre & + & + \\
\hline
\end{tabular}

Otras compañeras. En 1: Andryala ragusina var. ragusina + , Carex halleriana + , Convolvulus lanuginosus 1, Helianthemum origanifolium 1, Hippocrepis rupestris +, Pistacia lentiscus +, Polygala rupestris + , Quercus coccifera + , Staehelina dubia + , Teucrium capitatum 1, Teucrium lusitanicum 1. En 2: Asparagus horridus +, Asperula hirsuta + , Astragalus hamosus + , Cistus monspeliensis + , Hedysarum spinosissimum 1, Helianthemum syriacum 1, Moricandia moricandioides subsp. giennensis + , Phlomis purpurea + , Rosmarinus officinalis + , Thapsia villosa + .

Localidades. 1. Málaga. Antequera. La Trinidad. 30S 365300/4095295. 2. Málaga. Antequera. Las Suertes. 30S 365200/4097410. Car: carniolas. Myc: margas, yesos y carniolas.
Raya \& Molero, 1988) y la subass. nova podría alcanzar la Subbética cordobesa por presentarse sobre sustrato margoso y con algunas especies termoxerófilas (Gómez Mercado et al. 2000: 218-219). No se han hallado espartales en el resto del subsector Torcalense (Pérez Latorre et al., 2009, 2014). En las zonas yesíferas antequeranas estudiadas por Cabezudo et al. (2013), el espartal correspondería a la nueva subasociación termófila, en base a la presencia de los bioindicadores de la misma.

\section{Stachydo officinalis-Eryngietum caespitiferi Pérez Latorre, Casimiro- Soriguer \& Cabezudo 2014 corr. hoc loco [Tabla 11] \\ [Stachydo officinalis-Eryngietum aquifolii Pérez Latorre, Casimiro-Soriguer \& Cabezudo 2014 (art. 43)] eryngietosum caespitiferi var. con Eryngium aquifolium}

Prados edafohigrófilos hemicriptofíticogeofíticos de pequeña talla, verticícolas, torcalenses, que ocupan extensiones considerables sobre afloramientos margosos y arcillosos con encharcamiento temporal, humedad edáfica hasta entrado el verano y pastoreados-pisoteados (Pérez Latorre et al., 2014). En la descripción original de la asociación (Pérez Latorre et al., op. cit.) la tabla muestra solo a Eryngium aquifolium. Los nuevos inventarios, las nuevas recolecciones realizadas durante este trabajo en todo el areal de la ZEC, y la revisión de los pliegos del trabajo de Pérez Latorre et al. (op. cit.) demuestran que el material previamente identificado como E. aquifolium pertenece mayoritariamente a E. caespitiferum (ver apartado de flora) y que éste es el dominante en las zonas más elevadas, supramediterráneas (Sierra de Camarolos y Cerro de la Cruz), de donde procede el tipo de la asociación y los inventarios de la tabla original. Por ello procede la corrección del nombre de la asociación (art. 
Tabla 11

46. Stachydo officinalis-Eryngietum caespitiferi Pérez Latorre, Casimiro-Soriguer \& Cabezudo 2014 corr. hoc loco

eryngietosum caespitiferi var. con Eryngium aquifolium

(Molinio-Arrhenatheretea, Holoschoenetalia, Deschampsion mediae)

\begin{tabular}{|c|c|c|c|c|c|}
\hline INVENTARIO No & 1 & 2 & 3 & 4 & 5 \\
\hline Orientación & . & $\overline{\mathrm{W}}$ & NW & NW & - \\
\hline Inclinación $\left({ }^{\circ}\right)$ & & 5 & 5 & 5 & - \\
\hline Área $\left(\mathrm{m}^{2}\right)$ & 50 & 250 & 250 & 150 & 25 \\
\hline Litología & Arc & Arc & Arc & Arc & Arc \\
\hline Altitud (m) & 780 & 1030 & 1010 & 1180 & 1350 \\
\hline Altura vegetación (cm.) & 100 & 5 & 50 & 45 & 30 \\
\hline Cobertura vegetación (\%) & 100 & 90 & 100 & 100 & 100 \\
\hline \multicolumn{6}{|c|}{ Características y diferenciales de asociación y Deschampsion mediae } \\
\hline Carex flacca & 1 & 1 & + & . & 1 \\
\hline Achillea ageratum & & . & 1 & + & . \\
\hline Festuca ampla & 2 & . & . & 1 & \\
\hline Lotus corniculatus subsp. carpetanus & 1 & & 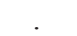 & . & 1 \\
\hline Neoschischkinia reuteri & . & & + & . & 2 \\
\hline Prunella laciniata (transgr.) & & & . & + & 2 \\
\hline
\end{tabular}

Otras características. En 2: Trifolium lappaceum 1. En 3: Prunella hyssopyfolia +. En 5: Eryngium caespitiferum 2, Stachys officinalis 2.

Diferencial de variante

Eryngium aquifolium

Características de unidades superiores

Gaudinia fragilis

Hordeum bulbosum

Leontodon tingitanus

Phleum bertolonii

Trifolium fragiferum

Linum tenue

Festuca mediterranea

Galium verum

Prunella vulgaris

Phalaris caerulescens

Otras características. En 1: Linum bienne 3. En 4: Trifolium repens 1. En 5: Orchis coriophora +, Agrostis castellana var. olivetorum + , Holcus lanatus + .

Compañeras

Convolvulus arvensis

Ammoides pusilla

Anthemis arvensis

Cuscuta planiflora

Dactylis glomerata subsp. hispanica

Onobrychis matritensis

Scorpiurus muricatus

Trifolium arvense

$\begin{array}{lllll}3 & 4 & 4 & 4 & . \\ 2 & . & 1 & 1 & 2 \\ 4 & 1 & 2 & 3 & . \\ 1 & 1 & 1 & . & 2 \\ + & . & 1 & 1 & 3 \\ . & + & + & 1 & . \\ . & 2 & 2 & 2 & . \\ 2 & . & 3 & + & + \\ . & . & + & + & + \\ . & . & + & + & +\end{array}$

Otras compañeras. En 1: Dactylis hispanica + , Oenanthe globulosa + . En 2: Aegilops geniculata + , Bromus hordeaceus + , Medicago orbiculare + , Sherardia arvensis + , Trifolium stellatum + . En 3: Cichorium intybus 1, Centaurium tenuiflorum +, Daucus carota + , Lotus corniculatus subsp. delortii 1, Mentha pulegium +, Phoeniculum vulgare + , Plantago lagopus + , Plantago serraria + , Scabiosa atropurpurea + , Trifolium campestre +, En 4: Bellis microcephala +, Crepis pulchra 1, Cynara baetica +, Ononis mitissima 1. En 5: Asperula aristata +, Brachypodium phoenicoides, Bromus erectus + .

Localidades. 1. Málaga. Antequera. Sierra de las Cabras. Entre el cortijo de las Alhajuelas y el cortijo de Piedra Solana. 30SUF6694. 2. Málaga. Antequera. Sierra del Co. Fuente. 30S 375239/4090514. 3. Málaga. Antequera. Sierra del Co. Cabecera arroyo Peñas. 30S 375311/4090881. 4. Málaga. Antequera. Sierra del Co. Morrón de Gragea. 30S 375694/4090955. 5. Málaga. Villanueva del Rosario. Sierra del Jobo. Entre Tajo de la Magdalena y Hondonero. 30SUF8292. Arc: arcillas. 
Tabla 12

51. Elymo repentis-Phalaridetum coerulescentis Pérez Latorre, Galán \& Cabezudo in Pérez Latorre, P. Navas, D. Navas, Y. Gil \& Cabezudo 1998

phalaridetosum coerulescentis, var. con Eryngium caespitiferum, var. con Oenanthe globulosa (Molinio-Arrhenatheretea, Phalaridetalia coerulescentis, Gaudinio fragilis-Hordeion bulbosi)

\begin{tabular}{lcccc}
\hline INVENTARIO N $^{\circ}$ & 1 & 2 & 3 & 4 \\
Orientación & $\mathrm{S}$ & $\mathrm{SW}$ & $\mathrm{NW}$ & $\mathrm{NW}$ \\
Inclinación $\left({ }^{\circ}\right)$ & 5 & 5 & 5 & 5 \\
Área $\left(\mathrm{m}^{2}\right)$ & 200 & 100 & 250 & 75 \\
Litología & Arm & Arc & Arc & Mar \\
Altitud (m) & 1200 & 1190 & 1340 & 1250 \\
Altura vegetación (cm.) & 80 & 130 & 90 & 60 \\
Cobertura vegetación $(\%)$ & 100 & 100 & 100 & 100
\end{tabular}

Características y diferenciales de asociación y Gaudinio fragilis-Hordeion bulbosi

Hordeum bulbosum

Phalaris caerulescens

Phleum bertolonii

Elymus repens subsp. repens

Gaudinia fragilis

Achillea ageratum

Narcissus pseudonarcissus

subsp. nevadensis

Poa trivialis

Scilla peruviana

Diferenciales de variantes

Oenanthe globulosa

Eryngium caespitiferum

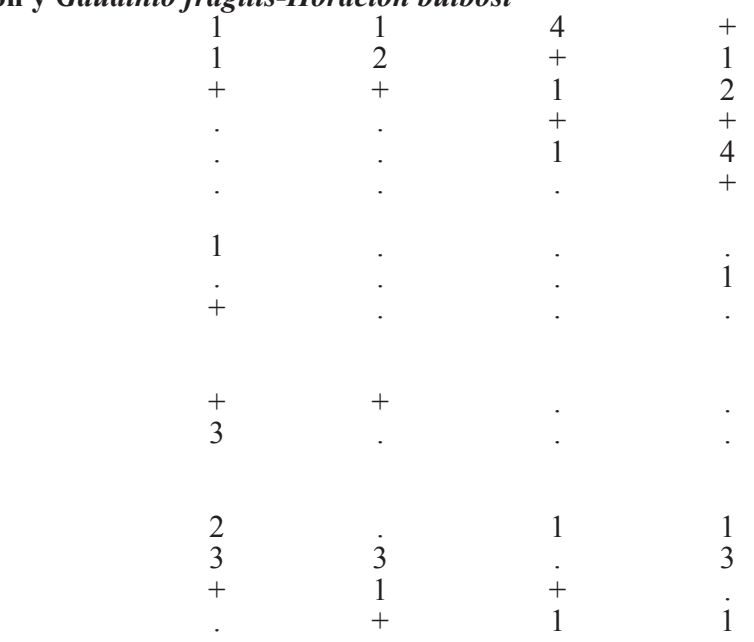

Carcaterísticas de unidades superiores

Carex flacca

Festuca mediterranea

Galium verum

Linum tenue

Otras características. En 1: Juncus striatus + , Ranunculus paludosus + , Orchis laxiflora 1. En 3: Holcus lanatus 1, Lolium perenne +, Lotus corniculatus subsp. carpetanus 1, Potentilla reptans + . En 4: Juncus inflexus + , Mentha pulegium +, Ranunculus macrophyllus 1, Trifolium fragiferum 1.

\section{Compañeras}

Convolvulus arvensis

Allium roseum

Cynara baetica

$\begin{array}{lll}+ & 1 & 1 \\ + & + & \\ + & + & \end{array}$

Otras compañeras. En 1: Carduncellus caeruleus + , Centaurea pullata + , Convolvulus meonanthus + , Xiphion vulgare 1, Lotus edulis 1, Ophrys fusca +, Ornithogalum narbonense 1, Phlomis herba-venti +, Stachys germanica + . En 2: Cichorium inty bus + , Carlina racemosa + , Lotus corniculatus subsp. delortii 1, Ononis mitissima +. En 3: Anthemis cotula 1, Bromus hordeaceus 1, Bromus rubens +, Carduus tenuiflorus 1, Cynosurus echinatus 1, Dactylis glomerata subsp. hispanica 2, Eryngium campestre +, Galactites tomentosa + , Scolymus hispanicus 1 , Silene vulgaris + , Torilis leptophylla + , Trifolium campestre 1, Trifolium stellatum + , Vulpia muralis 1. En 4: Aegilops triuncialis + , Anacamptis pyramidalis + , Daucus carota subsp. carota +, Geropogon hybridus +, Thrincia hispida 1, Medicago polymorpha +, Sherardia arvensis + , Sisymbrella aspera + , Trifolium angustifolium + , Vicia pubescens + .

Localidades. 1. Riogordo. Sierra Prieta. 30S 379438/4091319. 2. Antequera. Sierra Prieta. El Realengo. 30S 379420/4091370. 3. Málaga. Villanueva del Rosario. Las Camarolas. 30S 380161/4092136. 4. Málaga. Villanueva del Rosario. El Hondonero. Realenga Camino de Alfarnate. 30S 382790/4094307. Arm: arcillas y margas. Arc: arcillas. Mar: margas. 
43). También existe el híbrido entre ambos Eryngium en las zonas de altitud intermedia de las sierras de Camarolos y de la Cruz. En las zonas mesomediterráneas, sin embargo la especie dominante es E. aquifolium, lo cual ocurre en Sierra de las Cabras, en La Fresneda y Sierra del Co y zonas bajas del nacimiento del río Guadalmedina, siempre por debajo de $1200 \mathrm{~m}$., de donde proceden mayoritariamente los inventarios que ahora proveemos. En su composición aparecen especies boindicadoras de interés por su rareza como Prunella laciniata, que además enlaza estos pastizales con los de Festuco-Brometea de óptimo eurosiberiano templado-submediterráneo (Rivas Martínez, 2011) o Festuca iberica más propia de prados orófilos en esta zona de las Béticas (Pérez Latorre et al., 2015). La presencia importante de especies de Gaudinio-Hordeion bulbosi, como Hordeum bulbosum o Festuca mediterranea, indica la estrecha dinámica sucesional e incluso sinfenosucesional de esta asociación con los prados altos de Elymo repentis-Phalaridetum coerulescentis y con la comunidad de Festuca mediterranea $\mathrm{BC}$, en el momento en que el pastoreo y/o la humedad edáfica disminuyen o se acerca la epoca veraniega.

\section{Elymo repentis-Phalaridetum} coerulescentis Pérez Latorre, Galán \& Cabezudo in Pérez Latorre, P. Navas, D. Navas, Y. Gil \& Cabezudo 1998 [Tabla 12] phalaridetosum coerulescentis var. con Eryngium caespitiferum var. con Oenanthe globulosa

Praderas graminoides, higrófilas y verticícolas, supra-mesomediterráneas, descritas para el sector Rondeño, que alcanzan el subsector Torcalense y posiblemente las Subbéticas cordobesas. En la ZEC, ocupan zonas en los afloramientos arcillosos y margosos que mantienen humedad hasta final de primavera, mayoritariamente en la Sierra de Camarolos. Presentan una variante con Eryngium caespitiferum que indica cierto pastoreo, pisoteo y la duración mayor de la humedad, en una transición hacia los prados de Stachydo officinalis-Eryngietum caespitiferi. Otra variante, con Oenanthe globulosa, indica la mayor duración del encharcamiento, debido a pequeñas topografías cóncavas. Se incluyen en esta asociación los herbazales de biotopos similares en el Torcal de Antequera (Asensi et al., 2005: 33). En la base de la Sierra de las Cabras (occidente Torcalense) estas praderas se difuminan y empobrecen en características, debido a la menor altitud y el ombrotipo subhúmedo inferior, transformándose en la comunidad de Festuca mediterranea BC (Pérez Latorre et al., 2014). La cita de ElymoPhalaridetum coerulescentis en el subsector Torcalense pero en cotas bajas (760 m.), mesomediterráneas (Pérez Latorre et al., 2009: 162), se muestra empobrecida en características más orófilas, por lo que debe ser asignada a la comunidad de $F$. mediterranea. La asociación propuesta por Pérez Raya (1987) como Junco inflexi-Phalaridetum coerulescentis podría ser incluida en Elymo-Phalaridetum coerulescentis como una facies muy empobrecida, finícola, que alcanza Sierra Nevada en su área AlmijaroGranatense. A este respecto, formaciones con Juncus inflexus alcanzan la ZEC como comunidad de Juncus inflexus, que es a su vez una facies empobrecida del Ranunculo macrophylli-Jucetum inflexi Pérez Latorre, Galán \& Cabezudo in Pérez Latorre, P. Navas, D. Navas, Y. Gil \& Cabezudo 1998, propia del sector Rondeño, que alcanza también de modo finícola la Sierra de Huma (Torcalense occidental).

\section{Gaudinio fragilis-Agrostietum castellanae} Rivas Martínez \& Belmonte 1985

festucetosum amplae Pérez Latorre, Casimiro-Soriguer \& Cabezudo subass. nova [Tabla 13, holotypus hoc loco inv. $\left.\mathrm{n}^{\mathrm{o}} 2\right]$

Vallicares temporihigrófilos dominados por gramíneas perennes que se desarrollan sobre 
Tabla 13

53. Gaudinio fragilis-Agrostietum castellanae Rivas Martínez \& Belmonte 1985

festucetosum amplae Pérez Latorre, CasimiroSoriguer \& Cabezudo subass. nova

(Molinio-Arrhenatheretea, Agrostidetalia casteIlanae, Agrostion castellanae)

$\begin{array}{lccc}\text { INVENTARIO N } & & & \\ \text { Orientación } & 1 & 2 & 3 \\ \text { Inclinación }\left(^{\circ}\right) & - & \text { NW } & \text { NW } \\ \text { Área }\left(\mathrm{m}^{2}\right) & 20 & 5 & 5 \\ \text { Litología } & 100 & 150 & 20 \\ \text { Altitud (m) } & \text { Arc } & \text { Mar } & \text { Mar } \\ \text { Altura vegetación (cm.) } & 1100 & 1130 & 1080 \\ \text { Cobertura vegetación (\%) } & 100 & 50 & 90 \\ & & 100 & 90\end{array}$

Características y diferenciales de asociación

Gaudinia fragilis

Agrostis castellana

var. olivetorum

Holcus lanatus

Diferenciales de subasociación

Festuca ampla

Carex flacca

Festuca mediterranea

Neoschischkinia reuteri

Phleum bertolonii

Características de unidades superiores

Galium verum

Linum tenue

Potentilla reptans

$\begin{array}{lll}5 & 2 & 1 \\ \cdot & 2 & 2 \\ \cdot & 2 & 3 \\ . & + & 3 \\ + & . & +\end{array}$

Otras características. En 1: Eryngium aquifolium 2, Hordeum bulbosum 2, Leontodon tingitanus 2, Linum bienne +, Plantago lanceolata 1. En 2: Jasonia tuberosa 1. En 3: Juncus articulatus 2, Mentha pulegium 1, Prunella hyssopyfolia + , Ranunculus macrophyllus,+ Scilla peruviana +

\section{Compañeras}

Centaurium tenuiflorum

Convolvulus arvensis

Dactylis glomerata subsp. hispanica

Lotus corniculatus subsp. delortii

Plantago lagopus

Stachys germanica

$\begin{array}{ccc}\cdot & + & + \\ + & \cdot & 1 \\ 1 & + & \cdot \\ & & \\ \cdot & 1 & 1 \\ \cdot & + & + \\ \cdot & + & +\end{array}$

Otras compañeras. En 1: Convolvulus tricolor + . En 2: Brachypodium phoenicoides 3, Cichorium intybus + , Elymus hispanicus + , Scabiosa atropurpurea + , Trifolium angustifolium + . En 3: Allium roseum +, Anacamptys piramidalis + . sustratos arcillosos, húmedos hasta principios de verano, en el piso mesomediterráneo con ombrotipo húmedo en el subsector Torcalense. La asociación fue descrita con ámbito de distribución Luso-Extremadurense (Rivas Martínez \& Belmonte, 1985), sin embargo alcanzan las cordilleras Béticas en el subsector Torcalense, diferenciados por la subasociación festucetosum amplae subass. nova con Festuca ampla, Phleum bertolonii y Festuca mediterranea. También alcanza las zonas calizo-dolomíticas de Sierra Nevada donde fue citado como Festuco amplaeAgrostietum castellanae (Carpetano-IbéricoLeonés, silicícola; Rivas Martínez \& Belmonte op. cit.) por Pérez-Raya (1987: 198, tabla 33) cuyos inventarios encajan en la nueva subasociación. La duración de la humedad edáfica hacia entrado el verano permite la presencia de especies de Deschampsion mediae, como Jasonia tuberosa, indicadoras de un contacto con Stachydo officinalis-Eryngietum caespitiferi en zonas pastoreadas y pisoteadas. Del mismo modo las especies de Phalaridetalia, como Hordeum bulbosum, indican el contacto con praderas higrófilas verticícolas de ElymoPhalaridetum coerulescentis.

\section{Lavandulo stoechadis-Genistetum} equisetiformis Rivas Goday \& Rivas-Martínez 1969

thymetosum capitati Martínez Parras, Peinado \& Alcaraz 1986 [Tabla 14]

55. Comunidad de Cistus ladanifer y Ulex parviflorus sensu Pérez Latorre, Caballero, Casimiro-Soriguer, Gavira \& Cabezudo (2008) [Tabla 14]

Localidades. 1. Málaga. Antequera. Sierra de las Cabras. 30SUF6893. 2. Granada Loja. Sierra de San Jorge. Cortijo de la Manga. 30S 388320/4099047. 3. Granada. Loja. Sierra de S. Jorge. Cortijo de la Manga. 30S 388076/4099300. Arc: arcillas, Mar: margas. 
Tabla 14

54. Lavandulo stoechadis-Genistetum equisetiformis Rivas Goday \& Rivas-Martínez 1969, thymetosum capitati Martínez Parras, Peinado \& Alcaraz 1986

55. Comunidad de Cistus ladanifer y Ulex parviflorus sensu Pérez Latorre, Caballero, CasimiroSoriguer, Gavira \& Cabezudo (2008)

(Cisto-Lavanduletea, Lavanduletalia stoechadis, Calicotomo-Cistion ladaniferi)

$\begin{array}{lcc}\text { INVENTARIO N } & & \\ \text { Orientación } & 1 & 2 \\ \text { Inclinación }\left(^{\circ}\right) & - & \text { W } \\ \text { Área }\left(\mathrm{m}^{2}\right) & - & 30 \\ \text { Litología } & 100 & 200 \\ \text { Altitud }(\mathrm{m}) & \text { Are } & \text { Are } \\ \text { Altura vegetación }(\mathrm{cm} .) & 620 & 600 \\ \text { Cobertura vegetación }(\%) & 80 & 150 \\ & 90 & 90\end{array}$

Características y diferenciales de asociación y subasociación

Lavandula stoechas

2

Genista umbellata

subsp. equisetiformis

Thymus capitatus

Características y diferenciales de comunidad

Cistus ladanifer subsp. africanus

3 4

Ulex parviflorus

1

Características de unidades superiores

Cistus monspeliensis

Cistus salvifolius

Lavandula stoechas

$\begin{array}{ll}3 & 2 \\ 2 & 1 \\ . & 2\end{array}$

\section{Compañeras}

Phlomis lychnitis

Phlomis purpurea

Quercus rotundifolia

$\begin{array}{ll}+ & + \\ 2 & + \\ + & +\end{array}$

Otras compañeras. En 1: Brachypodium retusum 2, Daphne gnidium + , Dorycnium pentaphyllum +, Genista cinerea +, Helmintotheca echioides 1, Hippocrepis rupestris + , Margotia gummifera 1, Thapsia villosa + , Thymelaea argentata,+ Tuberaria guttata +. En 2: Cistus albidus +, Pinus halepensis (ref.) + , Rosmarinus officinalis + , Teucrium fruticans + .

Localidades. 1. Málaga. Antequera. Las Viñas. 30S 363409/4095366. 2. Ídem. 30SUF6396. Are: areniscas rojas. ref: reforestado.
La única representación de vegetación silicícola en la ZEC corresponde a los jaguarzales y jarales que se desarrolla sobre isleos edáficos de areniscas rojas silíceas en el subsector Antequerano, lo que constituye una extensión de su areal. Los jaguarzales de Lavandulo stoechadis-Genistetum equisetiformis thymetosum capitati ocupan los suelos menos erosionados y los jarales pirófitos de la comunidad de Cistus ladanifer (representado por la subsp. africanus) y Ulex parviflorus aparecen en litosuelos con signos de antiguos incendios. Evolucionan dinámicamente a coscojares y encinares de la serie del Paeonio coriaceae-Querceto rotundifoliae $S$, aunque no descartamos la presencia pretérita, hoy criptoclimácica, de Quercus suber (var. de Quercus suber del encinar). Esta representación de jarales de Cistus ladanifer subsp. africanus fuera del sector Aljíbico (Cistetum africanomonspeliensis Pérez Latorre, Galán \& Cabezudo in Pérez Latorre, Galán, P. Navas, D. Navas, Y. Gil \& Cabezudo 1999) se añade a los ya detectados en los Montes de Málaga también sobre areniscas triásicas (Pérez Latorre et al., 2008), en la Sierra de Cártama (Hidalgo \& Pérez Latorre, 2013) sobre gneis y en la base de la Sierra de Alcaparaín sobre micaesquistos y gneises y peridotitas (Pérez Latorre et al., 2015).

56. Genisto speciosae-Ulicetum parviflorii Rivas Goday \& Rivas-Martínez ex Pérez Latorre y Cabezudo 2009 nom. inv. propos. [Tabla 15]

ulicetosum parviflorii

lavanduletosum lanatae Rivas Goday \& Rivas Martínez ex Pérez Latorre, Casimiro-Soriguer \& Cabezudo 2014 var. con Teucrium webbianum sensu Pérez Latorre, Casimiro-Soriguer. García-Sánchez \& Cabezudo (2014)

Los matorrales constituyen uno de los tipos de vegetación más abundantes en la 
Tabla 15

56. Genisto speciosae-Ulicetum parviflorii Rivas Goday \& Rivas-Martínez ex Pérez Latorre y Cabezudo 2009 nom. inv. propos.

lavanduletosum lanatae Rivas Goday \& Rivas Martínez ex Pérez Latorre,

Casimiro-Soriguer \& Cabezudo 2014, var. con Teucrium webbianum

(Cisto-Micromerietea julianae, Rosmarinetalia officinalis, Saturejo micranthae-Thymbrion capitati)

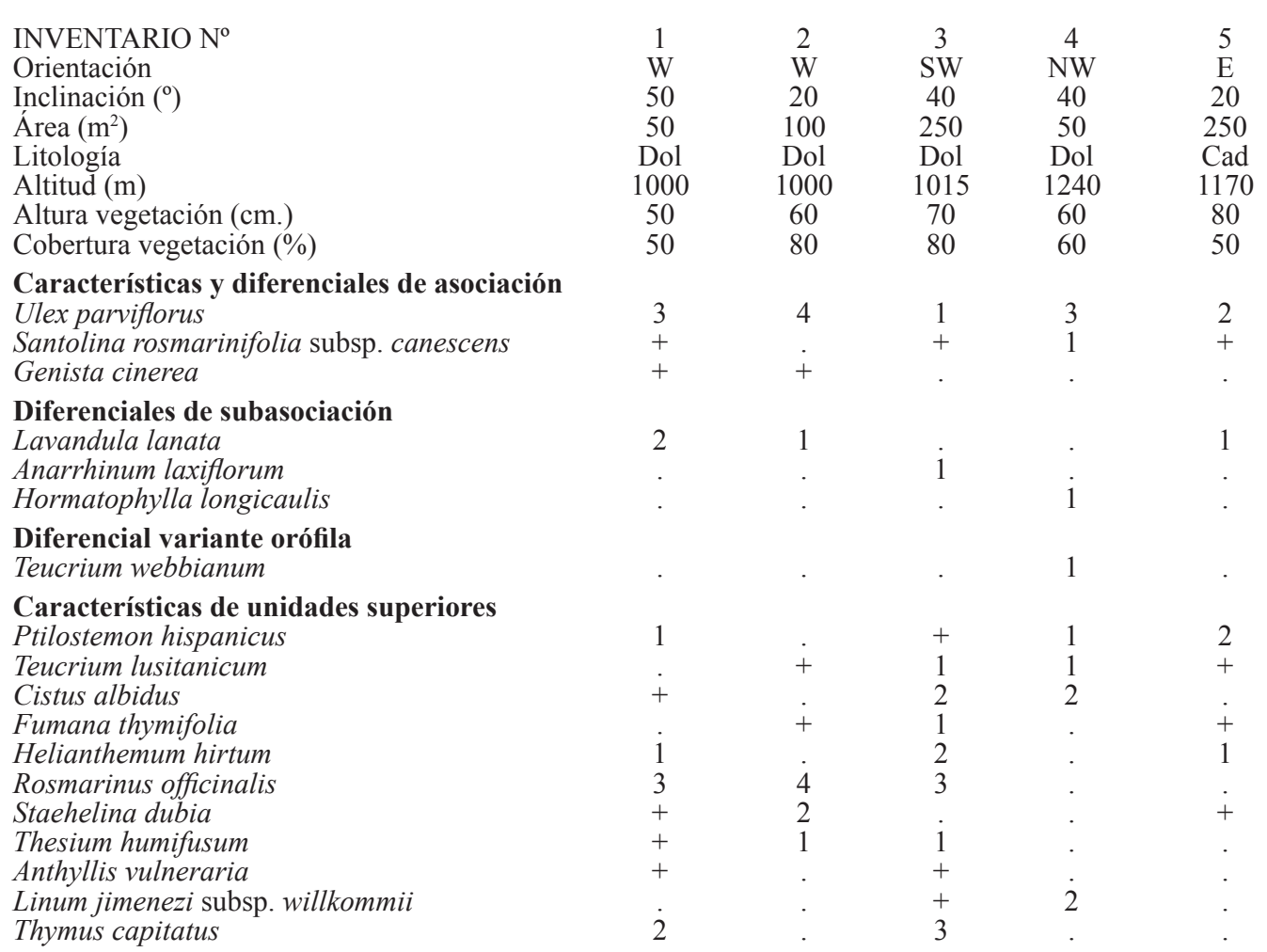

Otras características. En 1: Argyrolobium zanonni +, Fumana ericifolia 1, Helianthemum syriacum + . En 3: Convolvulus lanuginosus + , Euphorbia nicaeensis susbp. nicaeensis + . En 4: Helianthemum appeninum subsp. suffruticosum 1, Helianthemum cinereum subsp. rotundifolium + . En 5: Cephalaria leucantha + , Ononis pusilla subsp. pusilla + .

\section{Compañeras}

Asperula aristata subsp. scabra

Brachypodium retusum

Quercus rotundifolia

Dactylis glomerata

Festuca scariosa

Helichrysum serotinum

Micromeria graeca

Phlomis lychnitis

Polygala rupestris

Quercus coccifera

Quercus faginea

Rhaponticum coniferum

Stipa tenacissima

Thymus mastichina

\begin{tabular}{|c|c|c|c|}
\hline+ & & + & 1 \\
\hline 1 & 2 & 1 & . \\
\hline+ & 1 & 1 & + \\
\hline+ & . & + & . \\
\hline • & . & 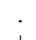 & + \\
\hline+ & $\cdot$ & ${ }_{1}^{+}$ & $\cdot$ \\
\hline & . & $\begin{array}{l}1 \\
+\end{array}$ & . \\
\hline+ & 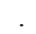 & + & . \\
\hline • & 1 & + & . \\
\hline . & 1 & . & + \\
\hline • & + & . & + \\
\hline & + & + & \\
\hline & . & & 1 \\
\hline
\end{tabular}


ZEC. En el subsector Torcalense, corresponden siempre a la asociación Genisto speciosaeUlicetum parviflorii, que se desarrollan generalmente sobre margas y calizas en el piso mesomediterráneo (subass. típica ulicetosum parviflorii). Sin embargo, la existencia de afloramientos dolomíticos (con más potencia en el extremo oriental de la ZEC) permiten la existencia de la subasociación lavanduletosum lanatae, que constituye, junto con la vegetación rupícola de Hieracietum baetici-texedensis ass. nova, la principal representación de la vegetación dolomitícola en la ZEC y por tanto el hábitat para algunos dolomitófitos o magnesiófitos, como la propia Lavandula lanata, Hormatophylla longicaulis o Chaenorrhinum macropodum subsp. degenii. Hemos localizado también la variante orófila de este matorral, con Teucrium webbianum a más de $1200 \mathrm{~m}$. de altitud.

\section{Fumano hispidulae-Hippocrepidenion bourgaei Pérez Latorre, Casimiro- Soriguer \& Cabezudo suball. nova hoc loco \\ [Holotypus hoc loco: Hippocrepido bourgaei-Anthyllidetum cytisoidis Pérez Latorre, Casimiro-Soriguer \& Cabezudo ass. nova en este trabajo]}

\section{Hippocrepido bourgaei-Anthyllidetum cytisoidis Pérez Latorre, Casimiro- Soriguer \& Cabezudo ass. nova [Tabla 16 , holotypus hoc loco inv. $\left.\mathrm{n}^{\mathrm{o}} 4\right]$ anthyllidetosum cytisoidis}

\section{var. con Thymus capitatus}

Los matorrales (albaidales) gipsícolas edafoxerófilos con distribución en el sector Antequerano de la provincia Bética fueron propuestos como comunidad de Hippocrepis bourgaei y Anthyllis cytisoides por Cabezudo et al. (2013) e incluidos en la alianza Saturejo micranthae-Thymbrion capitati (Rosmarinetalia officinalis) por la ausencia de gipsófitos (Mota et al., 2011). Durante el inventario de la ZEC, hemos ampliado la distribución de este tipo de vegetación, y además hemos constatado su constancia en la composición florística y estructura y su independencia de los otros matorrales del subsector, sobre margocalizas a veces abigarradas con yesos, de Genisto equisetiformis-Cytisetum fontanesii, de dinámica climatófila, por lo que estimamos necesario elevar la comunidad a asociación: Hippocrepido bourgaei-Anthyllidetum cytisoidis ass. nova. Presenta como especies caracerísticas y/o diferenciales: Fumana hispidula, Hippocrepis bourgaei, Hedysarum boveanum subsp. europaeum y Anthyllis cytisoides. Se desarrolla en los pisos termo y mesomediterráneo bajo ombrotipos seco y subhúmedo sobre los yesos triásicos del subsector Antequerano (provincia Bética). En las yeseras con termotipo termomediterráneo y mesomediterráneo inferior se desarrolla una variante termófila caracterizada por Thymus capitatus. En la ZEC este matorral (albaidal) ocupa exclusivamente los territorios incluidos en el subsector Antequerano, en laderas orientadas

\footnotetext{
Otras compañeras. En 1: Avenula gervaisii subsp. gervaisii + , Orobanche gracilis subsp. deludens, +. En 2: Carex hallerana 1. En 3: Celtica gigantea + , Centaurea aspera subsp. aspera,+ Daphne gnidium,+ Genista umbellata + , Hippocrepis rupestris + , Melica minuta + , Piptatherum coerulescens + , Ruta montana + . En 4 : Bupleurum fruticosum 1, Carduus granatensis + , Piptatherum paradoxum 1, Chaenorrhinum macropodum subsp. degenii +. En 5: Achnatherum bromoides +, Asperula hirsuta +, Carlina corymbosa +, Catananche caerulea +, Centaurea castellanoides + , Dianthus brachyanthus + , Dianthus broteroi + , Linum tenue +, Mantisalca salmantica +, Phlomis purpurea 3.
}

Localidades. 1 y 2. Málaga. Alfarnate. Cabecera Arroyo Morales. El Barranco. 30SUF8898. 3. Málaga. Antequera. Sierra del Co. Cabecera arroyo Peñas. 30S 375331/4090936. 4. Málaga. Antequera. Sierra de Camorolos. Cara norte del Cerro Cruz. 30SUF7892. 5. Málaga. Alfarnate. Sierra de San Jorge. Cortijo Alto. 30S 387819/4097126. Dol: dolomías. Cad: calizas y dolomías. 
Tabla 16

58. Hippocrepido bourgaei-Anthyllidetum cytisoidis Pérez Latorre, Casimiro-Soriguer \& Cabezudo ass. nova anthyllidetosum cytisoidis, var. con Thymus capitatus

(Cisto-Micromerietea julianae, Rosmarinetalia officinalis, Saturejo micranthae-Thymbrion capitati)

\begin{tabular}{lccccccc}
\hline INVENTARIO No & 1 & 2 & 3 & 4 & 5 & 6 & 7 \\
Orientación & $\mathrm{S}$ & $\mathrm{S}$ & $\mathrm{S}$ & $\mathrm{NW}$ & $\mathrm{S}$ & $\mathrm{W}$ &. \\
Inclinación $\left({ }^{\circ}\right)$ & 45 & 45 & 60 & 50 & 45 & 30 &. \\
Área $\left(\mathrm{m}^{2}\right)$ & 200 & 50 & 150 & 250 & 300 & 100 & . \\
Litología & Yem & Yem & Yem & Yem & Yem & Yem & Yes \\
Altitud (m) & 592 & 655 & 525 & 520 & 570 & 700 & $250-820$ \\
Altura vegetación (cm.) & 40 & 20 & 40 & 110 & 25 & 150 &. \\
Cobertura vegetación $(\%)$ & 40 & 40 & 40 & 40 & 30 &. &.
\end{tabular}

Total inventarios

Características y diferenciales de asociación Anthyllis cytisoides

Hippocrepis bourgaei

Fumana hispidula

Hedysarum spinosissimum

$\begin{array}{ccccccc}3 & . & 3 & 3 & 1 & 3 & \text { IV } \\ + & 1 & \cdot & 1 & + & 1 & \text { II } \\ + & + & \cdot & \cdot & \cdot & . & \text { II } \\ 1 & \cdot & \cdot & . & + & . & \text { II }\end{array}$

Diferencial de variante

Thymus capitatus

Características de unidades superiores

Fumana thymifolia

Helianthemum syriacum

Cistus albidus

Hedysarum boveanum subsp. europaeum

Rosmarinus officinalis

Convolvulus lanuginosus

Helianthemum appeninum

Helianthemum cinereum

Helianthemum hirtum

Helianthemum marifolium subsp. marifolium

Teucrium lusitanicum

Cistus clusii

Globularia alypum

Onobrychis matritensis

\section{Compañeras}

Stipa tenacissima

Moricandia moricandioides subsp. giennensis

Phagnalon rupestre

Asperula hirsuta

Astragalus hamosus

Brachypodium retusum

Pinus halepensis (rep)

Sedum sediforme

Dactylis hispanica

Filago ramossisima

Hedysarum spinosissimum

Phlomis lychnitis

Phlomis purpurea

Putoria calabrica

Thapsia villosa

Thymus mastichina 
al sur, con elevadas pendientes (entre $45 \mathrm{y}$ $60^{\circ}$ ), sobre litosuelos de composición yesífera y frecuentes acarcavamientos. Se considera etapa serial de los pinares edafoxerófilos de la comunidad de Anthyllis cytisoides y Pinus halepensis descrita por Cabezudo et al. (2013). En el resto del territorio y sobre margocalizas y carniolas el matorral corresponde a Genisto equisetiformis-Cytisetum fontanesii, etapa dinámica en las series de encinares y quejigares. Cabezudo et al. (2013) reflejan las semejanzas de esta nueva asociación con otra descrita para el sector Subbético (Guadiana Menor), Thymo orospedani-Anthyllidetum cytisoidis Cano, Torres, Cano-Ortíz \& Montilla 2005 (Cano et al., 2005) sobre el mismo tipo de sustratos a base de margas y yesos triásicos. Esta asociación fue incluida en Lavandulo-Echinospartion boissieri por sus autores, pero la altitud a la que se desarrolla (mayoritariamente entre 500 y $700 \mathrm{~m}$.) y la ausencia de indicadores de esa alianza fundamentalmente supramediterránea, nos lleva a incluir dicha asociación en la alianza termófila Saturejo-Thymbrion capitati. Por otro lado, la existencia de estas dos asociaciones, emparentadas entre sí por la dominancia de Anthyllis cytisoides y la presencia de especies gipsovagas, con distribución Antequerana y Subbética y sobre sustratos triásicos margo-yesíferos, nos lleva a proponer una subalianza que las englobe: Fumano hispidulaeHippocrepidenion bourgaei suball. nova, con especies características como: Fumana hispidula, Hedysarum boveanum subsp. europaeum, Hippocrepis bourgaei y Launea fragilis ( $L$. resedifolia). Constituirían la transición ecológica y fitosociológica desde Rosmarinetalia hacia el orden Gypsophyletalia.

\section{Festuco segimonensis-Erinaceetum anthyllidis Pérez Latorre, Casimiro- Soriguer \& Cabezudo ass. nova [Tabla 17 , holotypus hoc loco inv. $\mathrm{n}^{\circ} 2$ ] \\ (Comunidad de Ptilotrichum spinosum BC sensu Pérez Latorre et al., 2009) \\ (Comunidad de Erinacea anthyllis BC sensu Pérez Latorre et al., 2014)}

Piornales xeroacánticos caracterizados por el piorno azul (Erinacea anthyllis) y otros caméfitos espinosos almohadillados (Bupleurum spinosum, Ptilotrichum spinosum) que se desarrollan sobre roquedos y suelos erosionados en los pisos supramediterráneo y mesomediterráneo superior del subsector Torcalense. Constituye una etapa dinámica de los acerales de Vinco difformis-Quercetum fagineae aceretosum monspessulani sobre suelos arcillosos y sobre formas kársticas tipo lapiaz, se trataría de vegetación permanente. Esta nueva asociación presenta una característica que la diferencia del resto de las de Erinacetalia consideradas supramediterráneas superiores y oromediterráneas (Rivas Martínez et al., 2002: 528) y es su presencia en el piso mesomediterráneo, donde deberían de dominar

Otras compañeras. En 1: Cetaurea ornata + , Margotia gummifera + , Sanguisorba verrucosa + . En 2: Polygala rupestris + . Ulex parviflorus + . En 3: Asparagus horridus + , Medicago minima + . En 4: Brachypodium distachyon 1. Bromus rubens 1 . Euphorbia exigua + . Ophrys lutea + . Plantago afra + . En 5: Cuscuta epithymum +, Plantago albicans 1, Scilla maritima +, Thymus zygis subsp. gracilis 1. En 6: Cistus monspeliensis II, Genista umbellata +, Juniperus turbinata I, Pistacia lentiscus +, Quercus coccifera I, Reseda lutea + , Teucrium pseudochamaepitys + .

Localidades. 1. Málaga. Antequera. La Trinidad. Sobre arroyo Las Adelfas. 30S 365230/4094692. 2. Málaga. Antequera. Cerro de las Minas. 30S 365537/4096202. 3. Málaga. Antequera. Arroyo de la Plata. Cerca cantera. 30S 364373/4097643. 4. Málaga. Antequera. Lagunillas Altas. Sobre cantera. 30S 363990/4098100. 5. Málaga. Antequera. Sobre Fábrica de Harinas. 30S361966/4096211. 6. Inventario procedente de Cabezudo et al. (2013: 196, inv. 10, tabla 2): Málaga. Archidona. Angosturas del río Guadalhorce. 30SUG7200. 7. Inventario sintético de Cabezudo et al. (2013:196, Tabla 2). Yem: yesos cristalinos con margas. Yes: yesos. 
Tabla 17

59. Festuco segimonensis-Erinaceetum anthyllidis Pérez Latorre, Casimiro-Soriguer \& Cabezudo ass. nova

(Cisto-Micromerietea julianae, Erinacetalia anthyllidis, Xeroacantho-Erinaceion anthyllidis) erinaceetosum anthyllidis, var. con Celtica gigantea

\begin{tabular}{|c|c|c|c|c|c|c|}
\hline INVENTARIO N ${ }^{\circ}$ & 1 & 2 & 3 & 4 & 5 & 6 \\
\hline Orientación & $\mathrm{N}$ & $\mathrm{N}$ & NW & $\mathrm{NE}$ & $\mathrm{NE}$ & $\mathrm{N}$ \\
\hline Inclinación $\left({ }^{\circ}\right)$ & 10 & 20 & 5 & 35 & 30 & 20 \\
\hline Área $\left(\mathrm{m}^{2}\right)$ & 100 & 200 & 150 & 250 & 200 & 100 \\
\hline Litología & $\mathrm{Car}$ & Mac & Cam & $\mathrm{Car}$ & Dol & Dol \\
\hline Altitud (m) & 1340 & 1350 & 1480 & 1415 & 1200 & 1170 \\
\hline Altura vegetación (m.) & 35 & 30 & 40 & 35 & 30 & 40 \\
\hline Cobertura vegetación (\%) & 60 & 100 & 80 & 100 & 50 & 100 \\
\hline
\end{tabular}

Características y diferenciales de asociación

Erinacea anthyllis

Teucrium webbianum

Bupleurum spinosum

Festuca segimonensis

Ferulago granatensis

Ptilotrichum spinosum

Diferenciales de variante

Celtica gigantea

Helictotrichon sarracenorum

Pimpinella tragium subsp. litophilla

Iberis saxatilis subsp. cinerea

Características de unidades superiores

Ptilostemon hispanicus

Thymus baeticus

Dianthus hispanicus

Euphorbia nicaeensis

Helianthemum appeninum subsp. stoechadifolium

Helianthemum cinereum subsp. cinereum

Klasea pinnatifida

Teucrium similatum

Thymelaea pubescens subsp. elliptica

Thymus zygis subsp. gracilis

\section{Compañeras}

Cerastium boissieri

Rhamnus infectoria

Cirsium echinatum

Crataegus granatensis

Dactylis glomerata subsp. hispanica

Eryngium campestre

Heleborus foetidus

Scabiosa turolensis subsp. grosii

Acinos alpinus

Asperula aristata

Avenula bromoides subsp. pauneroi

Berberis hispanica

Carduus platypus subsp. granatensis

Carlina corymbosa

Crataegus monogyna

Festuca scariosa

Marrubium supinum

Santolina canescens 


\section{Festuco segimonensis- Erinaceetum anthy- \\ Convolvulo lanuginosi- Lavanduletum lanatae llidis ass. nova \\ Astragalo nevadensis- Bupleuretum spinosi \\ Genisto viciosoi-Velletum spinosi}

- $1170-1480 \mathrm{~m}$.

- Cordillera

Torcalense

- Calizas, dolomías

- Supramediterráneo y mesomediterráneo
- 1500-1900 m.

- Sierra Nevada

- Dolomías, calizas

- Supramediterráneo
- 1440-1750 m.

- Sierra de las Nieves - Calizas

- Oromediterráneo y supramediterráneo
- 1500-2050 m.

- Tejeda-Almijara y Sierra de las Nieves

- Dolomías

- Oromediterráneo y supramediterráneo
Festuca segimonensis, Teucrium webbianum, Ferulago granatensis, Celtica gigantea
Salvia lavandulifolia,

Lavandula lanata,

Linum suffruticosum,

Helianthemum rubellum,

Teucrium montanum,

Ulex parviflorus, Thymus granatensis,

Echinospartum boissieri.
Astragalus sempervirens subsp. nevadensis, Phlomis crinita, Ononis reuteri, Erysimum rondae, Veronica fontqueri, Koeleria dasyphylla
Vella spinosa, Genista longipes subsp. viciosoi, Anthyllis tejedensis, Thymus longiflorus, Astragalus granatensis, Echinospartum boissieri, Arenaria erinacea, Salvia lavandulifolia, Teucrium similatum, Lavandula lanata, Teucrium lerrouxi, Ulex baeticus subsp. borgaeanus.

Tabla 18. Comparación de Festuco segimonensis-Erinaceetum anthyllidis ass. nova, con las asociaciones fitosociológicamente más cercanas. Comparison among Festuco segimonensis-Erinaceetum anthyllidis ass. nova with other similar associations.

Otras compañeras. En 1: Acer monspessulanum +. En 2: Centaurea castellanoides subsp arundana 1, Paeonia broteroi 1, Silene andryalifolia +, Silene mellifera + . En 3: Arenaria armerina subsp. armerina + , Festuca iberica + , Inula montana + , Linum narbonense,+ Poa flaccidula,+ Sanguisorba verrucosa + . En 4: Arrhenatherum elatius subsp. baeticum 1, Avenula gervaisii 1, Centaurea triumfetti + Koeleria vallesiana + , Ornithogalum bourgaeanum +, Prunus prostrata + , Quercus rotundifolia + , Valeriana tuberosa + . En $\mathbf{5}$ : Anacamptys piramidalis + , Armeria villosa subsp. longiaristata + Crambe filiformis,+ Melica bocquetii 1 Dianthus brachyanthus + , Erodium cheilanthifolium 1, Sedum amplexicaule subsp. amplexicaule 1. En 6: Asperula hirsuta + , Crataegus monogyna 1, Festuca ampla + , Iris foetidissima,+ Piptatherum paradoxum 1, Thapsia villosa + .

Localidades. 1. Málaga. Villanueva del Rosario. Sierra del Jobo NE. 30S 384007/4095055. 2. Málaga. Antequera. Morrón de la Cruz. 30S 379214/4092042. 3. Málaga. Villanueva del Rosario. El Hondonero. Sobre la Vereda de Alfarnate. 30S 383625/4094586. 4. Málaga. Colmenar. Puerto de los Perdigones. 30S382742/4093298. 5. Málaga. Antequera. Morrón de Gragea. 30S 375894/4090532. 6. Málaga. Antequera. Sierra de las Cabras. 30SUF6893. Car: calizas y arcillas. Mac: margocalizas. Cam: calizas y margas. Dol: dolomías. 
los matorrales de Rosmarinetalia. Festuca segimonensis, Teucrium webbianum y Ferulago granatensis, diferencian esta comunidad de las más cercanas fitogeográficamente: a/ Convolvulo lanuginosi-Lavanduletum lanatae Rivas Goday \& Rivas-Martínez 1969 en Sierra Nevada calizo-dolomúitica (Pérez Raya, 1987, Pérez Raya et al., 1990), b/ Bupleuro spinosiAstragaletum nevadensis Pérez Latorre, Galán \& Cabezudo in Pérez Latorre, P. Navas, D. Navas, Y. Gil \& Cabezudo 1998 en Sierra de las Nieves caliza (Pérez Latorre et al., 1998) y c/ Genisto viciosoi-Velletum spinosi Pérez Latorre \& Cabezudo in Pérez Latorre, P. Navas, D. Navas, Gil \& Cabezudo 1998 en Sierra de las Nieves y Sierras de Tejeda-Almijara dolomíticas (Pérez Latorre et al., 1998, 2004). En la tabla 18 se encuentran especies diferenciales de estas tres asociaciones frente a la nueva asociación. En los extremos de la Cordillera Torcalense y fuera de la ZEC se han descrito tanto la comunidad de Erinacea anthyllis BC (piornal xeroacántico mesomediterráneo culminícola de la Sierra de Huma) como la comunidad de Ptilotrichum spinosum BC (piornal xeroacántico dolomitícola de la Sierra de Zafarraya), que estimamos que son las representaciones finícolas de esta nueva asociación y por tanto quedan incluidas en ella, tanto en sentido ecológico como sincorológico (altitud de 1100 a $1200 \mathrm{~m} \mathrm{y}$ representación más occidental en Huma -var. de Centaurea boissieri- y representaciones más orientales en Zafarraya). En ambos casos se trata de vegetación permanente culminícola, por efecto del viento y la escasa potencia del suelo (litosuelos, canchales y lapiaces). Igualmente se puede clasificar el "matorral abierto almohadillado" de Erinacea anthyllis en el Torcal de Antequera (Asensi et al., 2005: 31). En las Sierras Subbéticas del sur de Córdoba, en el piso supramediterráneo, existe el piornal de Erinaceo anthyllidis-Genistetum longipedis O. Bolòs \& Rigual in O. Bolòs 1967 (Gómez Mercado et al., 2000), que presenta Echinospartum boissieri, Genista longipes, Thymus granatensis y Glandora nitida, entre otras, que están ausentes del Festuco segimonensis-Erinaceetum anthyllidis ass. nova. La asociación Astragalo boissieriFestucetum hystricis Quézel 1953 es otro piornal de Sierra Nevada, pero en este caso es oromediterráneo con inventarios a más de 2000 m. de altitud (Pérez Raya, 1987).

\section{Spartio juncei-Rubetum ulmifolii Pérez} Latorre \& Cabezudo in Pérez Latorre, Caballero, Casimiro-Soriguer, Gavira \& Cabezudo 2008 [Tabla 19] rubetosum ulmifolii

var. con Rosa sempervirens sensu Pérez Latorre, Caballero, Casimiro-Soriguer, Gavira \& Cabezudo (2008)

var. con Prunus insititia

Forma con Crataegus monogyna

Zarzales con gayumbas y majuelos, de gran talla (entre 2 y 4 metros) que se desarrollan fundamentalmente sobre sustratos arcillosos que pueden tener duración larga de humedad edáfica (temporihigrófilos). Habían sido detectados en los sectores MalacitanoAxarquiense y Antequerano (aquí solo en el subsector Torcalense) (Pérez Latorre et al. 2008, 2009). Con los inventarios aportados para la ZEC, se amplía su distribución al subsector Antequerano, donde aparece la variante termófila con Rosa sempervirens y Nerium oleander de estos zarzales ligados a la serie de las fresnedas de Ficario ranunculoidisFraxinetum angustifoliae. En el subsector Torcalense, en zonas elevadas, la asociación lleva en su composición Prunus insititia. En zonas más elevadas (horizonte superior mesomediterráneo), pastoreadas con majadales, este zarzal se puede mostrar como una etapa abierta de espinares arbustivos, donde predomina Crataegus monogyna.

\section{Lonicero arboreae-Crataegetum}


Tabla 19

62. Spartio juncei-Rubetum ulmifolii Pérez Latorre \& Cabezudo in Pérez Latorre, Caballero, CasimiroSoriguer, Gavira \& Cabezudo 2008

rubetosum ulmifolii, var. con Rosa sempervirens sensu Pérez Latorre, Caballero, Casimiro-Soriguer,

Gavira \& Cabezudo (2008), var. con Prunus insititia, f. con Crataegus monogyna

(Rhamno-Prunetea, Prunetalia spinosae, Pruno-Rubion ulmifolii)

\begin{tabular}{|c|c|c|c|c|c|}
\hline INVENTARIO No & 1 & 2 & 3 & 4 & 5 \\
\hline Orientación & - & - & SW & W & $\mathrm{W}$ \\
\hline Inclinación $\left(^{\circ}\right)$ & - & - & 5 & 5 & 30 \\
\hline Área $\left(\mathrm{m}^{2}\right)$ & 100 & 100 & 100 & 300 & 200 \\
\hline Litología & Mar & Arc & Arc & Aca & Aca \\
\hline Altitud (m) & 550 & 650 & 945 & 1040 & 1000 \\
\hline Altura vegetación (m.) & 3,5 & 3 & 2,3 & 3,5 & 2,5 \\
\hline Cobertura vegetación (\%) & 100 & 100 & 100 & 80 & 100 \\
\hline
\end{tabular}

\section{Características y diferenciales de asociación}

Rubus ulmifolius

Spartium junceum

Crataegus monogyna

Rosa canina

$\begin{array}{ccccc}4 & 3 & 4 & 2 & 1 \\ 3 & 2 & 3 & + & . \\ + & . & 1 & 4 & 5 \\ . & . & 2 & . & 3\end{array}$

\section{Diferenciales de variantes}

Rosa sempervirens

Nerium oleander

Prunus insititia

\section{Características de unidades superiores}

Rosa pouzinii

Lonicera periclymenum subsp. hispanica

2
+
+

\section{Compañeras}

Hordeum bulbosusm

Rhamnus alaternus

Smilax aspera

Euphorbia characias

Fraxinus angustifolia

Hedera helix subsp. helix

Linum tenue

Phlomis purpurea

Salix pedicellata

Ulmus minor

Vinca difformis

Vitis sylvestris

\section{5}

.

$\cdot$

$\begin{array}{ccc}\cdot & 2 & \cdot \\ \cdot & \cdot & \cdot\end{array}$

Otras compañeras. En 1: Allium roseum +, Asparagus acutifolius 1, Carex hispida + , Dorycnium rectum + , Geranium purpureum +, Osyris alba 1, Phragmites australis subsp. australis 1, Quercus faginea +, Ulex parviflorus + , Xiphion vulgare +. En 2: Bupleurum fruticosum +. En 3: Ballota hirsuta +, Quercus rotundifolia + . En 4: Cynara humilis + , Xiphion planifolium + , Ranunculus macrophyllus + , Thymus mastichina + . En 5: Scirpoides holoschoenus + .

Localidades. 1. Málaga. Antequera. Arroyo de las Adelfas. La Pasarela. 30S 364743/4094841. 2. Málaga. Antequera. Arroyo de las Adelfas. 30SUF6495. 3. Málaga. Antequera. Sierra del Co. Cortijo del Dornillo. 30S 374699/4090407. 4. Málaga. Antequera. Sierra del Co. Fuente. 30S 375301/4090553. 5. Málaga. Antequera. Sierra de las Cabras. 30SUF6793. Mar: margas. Arc: arcillas. Aca: arcillas y calizas. 
Tabla 20

63. Lonicero arboreae-Crataegetum granatensis O. Bolòs 1954 nom invers. propos.

(Rhamno-Prunetea, Prunetalia spinosae, Lonicero arboreae-Berberidion hispanicae)

\begin{tabular}{|c|c|c|c|c|c|c|c|}
\hline INVENTARIO N ${ }^{\circ}$ & 1 & 2 & 3 & 4 & 5 & 6 & 7 \\
\hline Orientación & NW & NW & $\mathrm{N}$ & $\mathrm{NE}$ & NE & $\mathrm{N}$ & $\mathrm{NE}$ \\
\hline Inclinación $\left({ }^{\circ}\right)$ & 15 & 30 & - & 40 & 30 & 15 & 10 \\
\hline Área $\left(m^{2}\right)$ & 50 & 125 & 100 & 200 & 200 & 150 & 200 \\
\hline Litología & $\mathrm{Cal}$ & Cal & Cal & Car & Cal & Cal & $\mathrm{Cal}$ \\
\hline Altitud (m) & 1300 & 1400 & 1300 & 1300 & 1550 & 1570 & 1540 \\
\hline Altura vegetación (m.) & 3 & 4 & 3 & 4 & 5 & 5 & 4.5 \\
\hline Cobertura vegetación $(\%)$ & 100 & 100 & 90 & 70 & 90 & 80 & 70 \\
\hline \multicolumn{8}{|c|}{ Características y diferenciales de asociación } \\
\hline Crataegus granatensis & 2 & 1 & 2 & 3 & 4 & 3 & 4 \\
\hline Lonicera arborea & + & + & . & . & . & . & . \\
\hline \multicolumn{8}{|l|}{ Características de unidades superiores } \\
\hline Berberis hispanica & & + & . & & + & 1 & + \\
\hline Rubus ulmifolius & 2 & + & & + & . & + & . \\
\hline Crataegus monogyna & 2 & 2 & 1 & ${ }^{\circ}$ & . & . & . \\
\hline Rhamnus infectoria & & & & + & . & + & + \\
\hline Rosa canina & 1 & 2 & + & & & 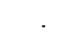 & . \\
\hline Rosa pouzinii & . & . & . & 1 & 1 & + & . \\
\hline Prunus insititia & + & + & 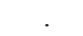 & . & . & . & . \\
\hline Lonicera etrusca & + & + & + & . & . & . & . \\
\hline Prunus spinosa & . & . & 1 & . & . & . & . \\
\hline Rosa micrantha & . & + & . & . & . & . & . \\
\hline \multicolumn{8}{|l|}{ Compañeras } \\
\hline Acer monspessulanum & 1 & 1 & + & . & + & + & + \\
\hline Daphne laureola & + & 1 & 1 & . & + & 2 & + \\
\hline Arum italicum & . & + & + & . & + & & + \\
\hline Cerastium boissieri & & & & 1 & + & 2 & 2 \\
\hline Hedera helix subsp. helix & 1 & + & 1 & . & + & & \\
\hline Paeonia coriacea & & 1 & + & . & . & 2 & 3 \\
\hline Brachypodium sylvaticum & 2 & 1 & 1 & . & . & . & . \\
\hline Elymus hispanicus & . & 2 & 2 & . & . & & + \\
\hline Geranium lucidum & . & . & 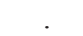 & . & 3 & 1 & + \\
\hline Helleborus foetidus & + & . & + & . & & 1 & . \\
\hline Carduus tenuiflorus & . & . & . & . & 1 & 1 & . \\
\hline Crocus serotinus & + & + & . & . & . & . & 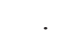 \\
\hline Dactylis glomerata subsp. hispanica & . & 1 & . & . & 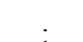 & . & + \\
\hline Euphorbia nicaeensis & . & . & . & . & 1 & 2 & \\
\hline Geranium purpureum & . & . & . & . & . & + & 1 \\
\hline Marrubium supinum & . & . & . & + & + & . & . \\
\hline Ranunculus ficaria & . & . & + & . & 1 & . & \\
\hline Rubia peregrina & . & 1 & + & & & & \\
\hline
\end{tabular}

Otras compañeras. En 1: Chamaeiris foetidissima + , Genista speciosa,+ Mentha rotundifolia,+ Paeonia broteroi 1, Quercus faginea + , Ruscus aculeatus + , Sorbus aria + , Thymus mastichina + . En 2: Oryzopsis paradoxa +. En 3: Geum sylvaticum +, Hyacinthoides hispanica +, Opopanax chironium +, Smyrnium olusatrum 3, Tamus communis + . En 4: Bupleurum spinosum + , Campanula cabezudoi + , Dianthus hispanicus ,+ Festuca scariosa 1, Ptilostemon hispanicus +. En 5: Musgo acrocárpico 3. En 6: Jasminum fruticans +, Myrrhoides nodosa +, Polygonatum odoratum 1. En 7: Alliaria petiolata,+ Cynosorus echinatus 2 Luzula forsteri 1, Ornithogalum pyrenaicum + , Prunus prostrata + .

Localidades. 1. Málaga. Villanueva del Rosario. Llanos del Hondonero. 30S 383054/4094165. 2. Idem. 30S 383343/4094145. 3. Idem. 30S 383096/4094138. 4. Málaga. Villanueva del Rosario. Sierra del Jobo NE. 30S 383968/4095095. 5. Málaga. Alfarnate. Puerto entre El Jobo y La Torca. 30S 383760/4094142. 6. Málaga. Villanueva del Rosario. El Chamizo. 30S 383519/4093946. 7. Málaga. Villanueva del Rosario. El Chamizo. 30S 383563/4094035. Cal: calizas. Car: calizas y arcillas. (invs. 1, 2 y 3 de A. V. Pérez Latorre y M. Pavón). 
granatensis O. Bolòs 1954 nom. invers. propos. [Tabla 20]

[Crataego granatensis-Loniceretum arboreae O. Bolòs 1954 corr. RivasMartínez, T.E. Díaz, Fernández-González, Izco, Loidi, Lousã \& Penas 2002, art. 42]

Vegetación arbustiva de gran talla (3 a 5 $\mathrm{m}$.), espinescente y caducifolia, que puede constituir la zonopotencialidad climácica en el piso supramediterráneo del subsector Torcalense, aunque con una relación dinámica con los acerales de Vinco difformis-Quercetum fagineae aceretosum monspessulani. En la tabla original de Bolós (1954) Crataegus granatensis constituye la mayor biomasa de la asociacion y tiene los índices muchos más elevados que Lonicera arborea, por lo que proponemos la inversión del nombre (art. 42).

\section{Pruno mahalebo-Berberidetum hispanicae}

Asensi \& Rivas-Martínez 1979

prunetosum postratae Pérez Latorre \& Cabezudo in Pérez Latorre, P. Navas, D. Navas, Y. Gil \& Cabezudo 1998 [Tabla 21]

Espinares caducifolios espinescentes de baja talla (1 a $2 \mathrm{~m}$.), que se desarrollan en el piso supramediterráneo por encima de 1500 metros, en la Sierra del Jobo (subsector Torcalense). Estas formaciones ya habían sido inventariadas por Ceballos y Vicioso (1933: 180) haciéndose eco además de las formas erectas mostradas por Prunus postrata al emerger desde el fondo de las profundas fisuras de los lapiaces de la cumbre del Chamizo (1640 m). La subasociación había sido descrita para Sierra de las Nieves (sector Rondeño) en el tránsito del termotipo supramediterráneo al oromediterráneo (1700-1750 m) (Pérez Latorre et al., 1998), por lo que se amplía su areal hasta el subsector Torcalense, aunque a un altitud ligeramente inferior y con cierto empobrecimiento en especies.
Tabla 21

64. Pruno mahalebo-Berberidetum hispanicae Asensi \& Rivas-Martínez 1979

prunetosum postratae Pérez Latorre \& Cabezudo in Pérez Latorre, P. Navas, D. Navas, Y. Gil \& Cabezudo 1998 (Rhamno-Prunetea, Prunetalia spinosae, Lonicero arboreae-Berberidion hispanicae)

$\begin{array}{lcc}\text { INVENTARIO } \mathrm{N}^{\mathrm{o}} & 1 & 2 \\ \text { Orientación } & \mathrm{N} & \mathrm{E} \\ \text { Inclinación }\left(^{\circ}\right) & 30 & 20 \\ \text { Área }\left(\mathrm{m}^{2}\right) & 15 & 20 \\ \text { Litología } & \mathrm{Cal} & \mathrm{Cal} \\ \text { Altitud }(\mathrm{m}) & 1530 & 1550 \\ \text { Altura vegetación }(\mathrm{cm} .) & 60 & 200 \\ \text { Cobertura vegetación }(\%) & 60 & 100\end{array}$

Características y diferenciales de asociación Berberis hispanica

Prunus mahaleb

35

Diferencial de subasociación

Prunus prostrata

Características de unidades superiores

Crataegus granatensis

Ononis aragonensis

Rhamnus infectoria

Compañeras

Euphorbia nicaeensis

Cerastium boissieri

Geranium lucidum

$\begin{array}{ll}. & 1 \\ + & +\end{array}$

Otras compañeras. En 1: Paeonia coriacea +, Crambe filiformis 1, Hormatophylla spinosa + , Marrubium supinum 1, Briófitos 3, Geranium purpureum + . En 2: Rumex induratus + , Hedera helix subsp. helix + , Jasminum fruticans + .

Localidades. 1. Málaga. Villanueva del Rosario. Sierra del Jobo. 30S 383715/4094254. 2. Málaga. Alfarnate. Puerto entre El Jobo y La Torca. 30S 383760/4094142. Cal: calizas.

\section{Comunidad de Cytisus reverchonii y Rhamnus infectoria [Tabla 22]}

Espinares caducifolios postrados (50-80 $\mathrm{cm}$.) que se desarrollan en lapiaces calizos en el piso supramediterráneo Torcalense, en 
Tabla 22

65. Comunidad de Cytisus reverchonii y Rhamnus infectoria

(Rhamno-Prunetea, Prunetalia spinosae, Lonicero arboreae-Berberidion hispanicae)

\begin{tabular}{lcc}
\hline INVENTARIO N & & \\
Orientación & $3 / 14$ & $41 / 16$ \\
Inclinación $\left({ }^{\circ}\right)$ & $\mathrm{W}$ & $\mathrm{NW}$ \\
Área $^{\left(\mathrm{m}^{2}\right)}$ & 5 & 20 \\
Litología & 100 & 10 \\
Altitud $(\mathrm{m})$ & $\mathrm{Cal}$ & $\mathrm{Cal}$ \\
Altura vegetación $(\mathrm{cm})$. & 1300 & 1385 \\
Cobertura vegetación $(\%)$ & 80 & 50 \\
& 65 & 90
\end{tabular}

Características de comunidad

Rhamnus infectoria

$3 \quad 3$

Cytisus reverchonii

67. Ficario ranunculoidis-Fraxinetum angustifoliae Rivas-Martínez \& Costa in Rivas-Martínez, Costa, Castroviejo y Valdés 1980 [Tabla 23]

salicetosum pedicellatae Díez-Garretas, Cuenca \& Asensi 1986, raza bética con Spartium junceum

var. con Nerium oleander sensu Pérez Latorre Casimiro-Soriguer, Gavira \& Cabezudo 2012

var. con Ficus carica

Las fresnedas que se desarrollan en la ZEC pertenecen a la subasociación suribérica salicetosum pedicellatae y a la raza bética con Spartium junceum. En zonas bajas, subsector Antequerano, se ha inventariado la variante

Características de unidades superiores

Crataegus monogyna

Prunus mahaleb

Rosa canina

Rosa pouzinii

$\begin{array}{ll}1 & 2 \\ \cdot & + \\ i & + \\ 1 & +\end{array}$

\section{Compañeras}

Acer monspessulanum

Cerastium boissieri

$+\quad+$

$+2$

Otras compañeras. En 1: Anacamptys pyramidalis + , Aristolochia longa + , Asparagus acutifolius +, Daphne laureola +, Delphinium emarginatum subsp. nevadense + , Dianthus anticarius,+ Festuca scariosa 1, Galium mollugo subsp. erectum + , Holcus lanatus +, Jasminum fruticans 1, Paeonia coriacea +, Piptatherum paradoxum 1, Polygonatum odoratum +, Ptilostemon hispanicus +, Quercus rotundifolia 1, Silene vulgaris +, Tamus communis + , Thapsia villosa 1. En 2: Bupleurum spinosum 1, Dactylis hispanica 1, Euphorbia nicaeensis +, Geranium lucidum +, Marrubium supinum 1.

Localidades. 1. Málaga. Villanueva del Rosario. Las Camarolas. 30S 380194/4092393. 2. Málaga. Colmenar. Puerto de los Perdigones. $30 \mathrm{~S}$ 382985/4093355. Cal: calizas.

zonas muy expuestas y venteadas. Aunque podrían constituir una etapa dinámica de los acerales de Vinco difformis-Quercetum fagineae aceretosum monspessulani en su variante sobre karst, en realidad representan vegetación permanente en esos hábitats edafoxéricos. termófila y de cauces con fuerte estiaje con Nerium oleander. En el subsector Torcalense, se ha detectado una variante con Ficus carica que representa los hábitats de nacimientos kársticos, con fuerte oscilación en la cantidad de agua, y sobre materiales calizos o calizodolomíticos, caracterizados por la dominancia de Ficus carica, acompañada de Ulmus minor, Sambucus nigra y Vitis sylvestris.

\section{Paeonio coriaceae-Quercetum} rotundifoliae Rivas Martínez 1975 [Tabla 24]

\section{quercetosum rotundifoliae}

var. con Quercus suber sensu Pérez Latorre, P. Navas, D. Navas, Y. Gil \& Cabezudo 1998

quercetosum fagineae Rivas Martínez 1964 em. Rivas Goday \& Rivas Martínez 1971

pistacietosum lentisci Pérez Latorre, Casimiro-Soriguer \& Cabezudo subass. nova [Tabla 24, holotypus hoc loco, inv. $\left.\mathrm{n}^{\mathrm{o}} 4\right]$

Los bosques más extensos en el ámbito de la ZEC están constituidos por los encinares mesomediterráneos béticos y 
Tabla 23

67. Ficario ranunculoidis-Fraxinetum
angustifoliae Rivas-Martínez \& Costa in Rivas-
Martínez, Costa, Castroviejo y Valdés 1980
salicetosum pedicellatae Díez-Garretas, Cuenca \&
Asensi 1986, raza bética con Spartium junceum,
var. con Nerium oleander sensu Pérez Latorre
Casimiro-Soriguer, Gavira \& Cabezudo (2012)
var. con Ficus carica
(Salici-Populetea, Populetalia albae,
Populion albae)

\begin{tabular}{|c|c|c|c|c|}
\hline INVEN & 1 & 2 & 3 & 4 \\
\hline Oric & $\mathrm{N}$ & $\mathrm{N}$ & $\mathrm{N}$ & $\mathrm{N}$ \\
\hline & & 5 & J & \\
\hline Are & 100 & 40 & 200 & 150 \\
\hline & Tar & $\mathrm{Ma}$ & Arc & $\mathrm{Cal}$ \\
\hline lit & 490 & 850 & 1010 & 830 \\
\hline ltu & 6 & 9 & 18 & 18 \\
\hline Cobertura vegetación $(\%)$ & 100 & 100 & 100 & 100 \\
\hline
\end{tabular}

Características y diferenciales de asociación

$\begin{array}{lllll}\text { Fraxinus angustifolia } & 4 & 4 & 5 & 3\end{array}$

Ranunculus ficaria . . ..+

Diferencial de subasociación y raza bética

Salix pedicellata

Spartium junceum

1

$+\quad+i$

\section{Diferenciales de variantes}

$\begin{array}{lcccc}\text { Nerium oleander } & 2 & . & . & . \\ \text { Ficus carica } & \cdot & + & \cdot & 4 \\ \text { Ulmus minor } & + & \cdot & \cdot & + \\ \text { Sambucus nigra } & \cdot & . & \cdot & + \\ \text { Vitis sylvestris } & \cdot & \cdot & \cdot & +\end{array}$

\section{Características de unidades superiores}

Vinca difformis

Arum italicum

$\begin{array}{cccc}2 & 1 & + & . \\ \cdot & + & \cdot & . \\ & & & \\ & & & \\ 1 & 1 & + & + \\ + & 2 & . & 2 \\ 2 & 2 & + & . \\ 2 & 2 & 1 & . \\ . & 2 & + & + \\ . & + & + & . \\ 1 & . & 1 & . \\ 1 & 1 & . & .\end{array}$

basófilos de Quercus rotundifolia, asentados fundamentalmente sobre cambisoles. Presentan distintas variaciones ecológicas y florísticas aun siendo los más frecuentes los encinares puros. En el subsector Antequerano solo aparece la subasociación termófila, mesomediterránea inferior, con Pistacia lentiscus. En la cara sur de la Sierra de San Jorge y sobre vulcanitas ácidas aparecen formaciones mixtas de encinas con Quercus suber aislados o en pequeños grupos, aunque sin auténtico sotobosque silicícola. En las zonas mesomediterráneas medias y superiores y en situaciones de fondos de dolinas o laderas umbrías, el bosque es mixto con Quercus faginea y/o Acer monspessulanum (subasociación quercetosum fagineae). En la amplia bibliografía sobre estos encinares se ha citado una variante, faciación o subserie termófila con Pistacia lentiscus (Rivas Martínez, 1987; Gómez Mercado et al., 2000; Pérez Latorre et al., 2009, entre otros). Realizada consulta en SIVIM (2016) no aparece definido un sintaxon para este tipo de encinar termófilo por lo que proponemos la subasociación pistacietosum lentisci subass.

Otras compañeras. En 1: Bupleurum fruticosum +, Clematis flammula 1, Daphne gnidium + , Osyris alba + , Phillyrea latifolia + , Pistacia lentiscus + , Quercus faginea + . En 2: Brachypodium phoenicoides + , Carex divulsa + , Phillyrea latifolia 2 , Rosa pouzinii 1, Rosa sempervirens 1, Ruscus aculeatus 1. En 3: Apium nodiflorum 1, Chamaemelum fuscatum +, Galium verum +, Geranium lucidum +, Glyceria declinata 1, Hordeum bulbosum 1, Lonicera etrusca + , Lotus pedunculatus +, Nasturtium officinale 1, Prunus insititia + , Rosa canina 1 , Rubia peregrina 1, Veronica anagallis-aquatica + . En 4: Geranium purpureum + , Mentha rotundifolia + , Scrophularia lyrata 3, Polypogon viridis 1.

Localidades. 1. Málaga. Antequera. Arroyo de las Adelfas. 30SUF6419. 2. Málaga. Antequera. La Fresneda. Sierra del Co. Arroyo de las Peñas. 30SUF7590. 3. Málaga. Antequera. Sierra de Camorolos. Arroyo Pilones. 30S 377071/4091820. 4. Málaga. Villanueva del Trabuco. Nacimiento de los 100 Caños. 30S 386125/4098994. Mar: margas. Mac: margocalizas. Arc: arcillas. Cal: calizas. 
Tabla 24

69. Paeonio coriaceae-Quercetum rotundifoliae Rivas Martínez 1975 quercetosum rotundifoliae, var. con Quercus suber sensu Pérez Latorre, P. Navas, D. Navas, Y. Gil \& Cabezudo 1998,

quercetosum fagineae Rivas Martínez 1964 em. Rivas Goday \& Rivas Martínez 1971 pistacietosum lentisci Pérez Latorre, Casimiro-Soriguer \& Cabezudo subass. nova (Quercetea ilicis, Quercetalia ilicis, Quercion broteroi)

\begin{tabular}{|c|c|c|c|c|c|c|c|}
\hline INVENTARIO No & 1 & 2 & 3 & 4 & 5 & 6 & 7 \\
\hline Orientación & $\mathrm{N}$ & $\mathrm{N}$ & $\mathrm{W}$ & W & NW & $\mathrm{E}$ & - \\
\hline Inclinación $\left(^{\circ}\right)$ & 25 & 80 & 30 & 20 & 20 & 25 & - \\
\hline Área $\left(\mathrm{m}^{2}\right)$ & 150 & 100 & 300 & 100 & 200 & 50 & 250 \\
\hline Litología & Dol & Dol & Mac & Are & Cal & Vud & $\mathrm{Cal}$ \\
\hline Altitud (m) & 1140 & 1000 & 650 & 650 & 1130 & 1125 & 1150 \\
\hline Altura vegetación (m.) & 10 & 5 & 6 & 4 & 8 & 14 & 8 \\
\hline Cobertura vegetación $(\%)$ & 100 & 70 & 100 & 90 & 100 & 80 & 90 \\
\hline \multicolumn{8}{|c|}{ Características y diferenciales de asociación } \\
\hline Quercus rotundifolia & 5 & 4 & 4 & 4 & 5 & 2 & 5 \\
\hline $\bar{P}$ Paeonia broteroi & 2 & . & . & . & + & . & 1 \\
\hline Festuca patula & + & + & . & . & . & . & \\
\hline Achnatherum bromoides & . & . & . & . & . & + & 1 \\
\hline \multicolumn{8}{|c|}{ Diferenciales de subasociación quercetosum fagineae } \\
\hline Quercus faginea & . & . & + & . & + & . & + \\
\hline Acer monspessulanum & . & . & . & . & + & . & + \\
\hline Heleborus foetidus & . & . & . & . & 2 & . & 1 \\
\hline Tamus communis & . & . & . & . & + & . & 1 \\
\hline \multicolumn{8}{|l|}{ Diferenciales de variante } \\
\hline Quercus suber & . & . & . & . & . & 4 & . \\
\hline Epipactis microphylla & . & 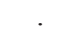 & . & . & . & + & . \\
\hline \multicolumn{8}{|c|}{ Diferenciales de subasociación pistacietosum lentisci } \\
\hline Pistacia lentiscus & . & . & 3 & 3 & . & . & . \\
\hline Smilax aspera & . & . & 1 & 1 & . & . & . \\
\hline Olea europaea var. sylvestris & . & . & . & 1 & . & . & . \\
\hline Rhamnus oleoides & . & . & . & 1 & . & . & . \\
\hline \multicolumn{8}{|c|}{ Características de unidades superiores } \\
\hline Daphne gnidium & + & . & 1 & . & . & 1 & + \\
\hline Rubia peregrina & + & & . & . & + & 1 & + \\
\hline Pistacia terebinthus & . & 1 & 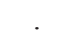 & 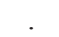 & + & + & . \\
\hline Quercus coccifera & . & & 1 & 1 & . & + & . \\
\hline Rhamnus alaternus & . & 1 & 1 & 1 & . & . & . \\
\hline Ruscus aculeatus & 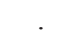 & + & & & . & . & + \\
\hline Asparagus acutifolius & . & . & 1 & . & . & . & + \\
\hline
\end{tabular}

Otras características. En 2: Bupleurum fruticosum +, Phillyrea latifolia 1. En 3: Rhamnus lycioides subsp. laderoi + , Teucrium fruticans + . En 4: Juniperus oxycedrus + , Lonicera implexa 1, Pulicaria odora + .

Compañeras

Crataegus monogyna

Hedera helix subsp. helix

Brachypodium retusum

Brachypodium sylvaticum

Dactylis hispanica

Briófitos

Cistus albidus

Elymus hispanicus

Lonicera etrusca

Ptilostemon hispanicus

Rosa pouzinii

Silene vulgaris

Thymus mastichina

Ulex parviflorus

\begin{tabular}{|c|c|c|c|c|c|}
\hline 2 & 1 & . & & + & 1 \\
\hline+ & 2 & & & + & \\
\hline & . & 2 & 3 & & 1 \\
\hline & . & 1 & $\cdot$ & 1 & . \\
\hline+ & . & . & . & & + \\
\hline • & . & . & & 3 & \\
\hline & . & . & + & . & 2 \\
\hline+ & $\cdot$ & . & $\cdot$ & ¿ & + \\
\hline+ &. & . & $\cdot$ & $\top$ & $\dot{+}$ \\
\hline & . & . & . & + & + \\
\hline+ & . & . & . & . & . \\
\hline+ & . & . & . & + & \\
\hline+ & . & 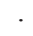 & . & . & 2 \\
\hline
\end{tabular}


nova para el termotipo mesomediterráneo inferior. En el ámbito de estos encinares se han realizado extensas forestaciones con Pinus halepensis, especie por otro lado alóctona en estas Sierras del subsector Torcalense.

\section{Viburno tini-Quercetum fagineae Torres} \& Cano in Cano et al., 2001 [Tabla 25]

Quejigales basófilos mesomediterráneos bajo ombrotipo subhúmedo y de areal subbético que alcanzan el subsector Antequerano (Hispalense sensu Cano et al., 2001) en la ZEC de Camarolos, asentados sobre cambisoles. Se consideran microtopográficos, ya que ocupan zonas puntuales, en laderas de umbría pronunciada, con suelos profundos y fuerte inclinación, sobre sustratos margocalizos. En la actualidad se encuentran en estado dinámico progresivo, con alturas modestas de Quercus faginea, menores de 10 metros. Hacia los suelos menos desarrollados (cambisoles erosionados), en solanas y pendientes más pronunciadas son sustituidos como vegetación climácica por encinares de Paeonio coriaceae-Quercetum rotundifoliae. Su composición florística con abundancia en elementos termófilos como Pistacia lentiscus, Smilax aspera, Bupleurum fruticosum, Rhamnus oleoides o Rhamnus alaternus los diferencia de los quejigales presentes en la ZEC pero en el subsector Torcalense, en el termotipo mesosupramediterráneo, que corresponden a Vinco
difformis-Quercetum fagineae, ricos en especies de Querco-Fagetea y Rhamno-Prunetea (Pérez Latorre et al., 2009).

73. Vinco difformis-Quercetum fagineae Pérez Latorre \& Cabezudo in Pérez Latorre, Caballero, Casimiro-Soriguer, Gavira \& Cabezudo 2009 [Tabla 26] var. de Quercus alpestris quercetosum fagineae var. con Fraxinus angustifolia aceretosum monspessulani Pavón, Hidalgo \& Pérez Latorre 2013 var. con Pistacia terebinthus

Quejigales torcalenses fundamentalmente mesomediterráneos, basófilos, que ocupan una extensión considerable en la ZEC, caracterizados por Quercus faginea subsp. faginea, asentados fundamentalmente sobre luvisoles. Sin embargo, existen enclaves puntuales, que consideramos relictuales, caracterizados por suelos muy húmicos en zonas umbrías y lluviosas, en el piso mesomediterráneo superior de la Sierra de Camarolos, donde el quejigal está dominado por Quercus faginea subsp. alpestris (tabla 26, inv 4), lo que podría considerarse como un fragmento relicto de los quejigares subbéticos de Berberido hispanicaeQuercetum alpestris Rivas Martínez 2011 (Rivas Martínez et al., 2011). Estos quejigales pudieron estar más representados en épocas más frías postglaciares (Blanco et al., 1997). Existe

Otras compañeras. En 1: Celtica gigantea + , Euphorbia nicaeensis,+ Linum jimenezi subsp. willkommii + , Piptatherum paradoxum 1, Rhagadiolus edulis 1, Rosa canina + , Rubus ulmifolius + , Silene mellifera + . En 2: Campanula rotundifolia + , Chaenorrhinum villosum + , Galium lucidum + , Prunus mahaleb 1, Scrophularia scorodonia + , Silene andryalifolia +, Smyrnium olusatrum + , Stachys circinata 1, Anthemis tuberculata + . En 3: Dorycnium pentaphyllum + , Rosmarinus officinalis 1, En 4: Cistus monspeliensis + . En 5: Cerastium boissieri +, Cynosorus echinatus 1, Dianthus hispanicus + , Phlomis herba-venti +, Phlomis lychnitis + . En 6: Brachypodium phoenicoides + , Centaurea castellanoides,+ Genista cinerea,+ Ononis spinosa 1, Phlomis purpurea +. En 7: Aristolochia onga + , Rhamnus infectoria,+ Rosa micrantha + .

Localidades. 1. Málaga. Antequera. Sierra del Co. 30S 375662/4090604. 2. Málaga. Antequera. Sierra de las Cabras. 30SUF6793. 3 y 4. Málaga. Antequera. Cerro de las Minas. 30SUF6596. 5. Villanueva del Trabuco. Sierra del Jobo NE. 30S 384662/4096014. 6. Málaga. Alfarnate. Sierra de San Jorge. 30S 388104/4097479. 7. Málaga. Alfarnate. Sierra Gorda. Cortijo del Jobo. 30S 384878/4095375. Dol: dolomías. Mac: margas y carniolas. Are: areniscas. Cal: calizas. Vud: dolomías con vulcanitas. 
Tabla 25

70. Viburno tini-Quercetum fagineae Torres \& Cano in Cano et al., 2001

(Quercetea ilicis, Quercetalia ilicis, Quercion broteroi)

$\begin{array}{lcc}\text { INVENTARIO N } & & 2 \\ \text { Orientación } & 1 & \mathrm{E} \\ \text { Inclinación }\left(^{\circ}\right) & 30 & 30 \\ \text { Área }\left(\mathrm{m}^{2}\right) & 300 & 400 \\ \text { Litología } & \mathrm{Mac} & \mathrm{Mar} \\ \text { Altitud }(\mathrm{m}) & 650 & 490 \\ \text { Altura vegetación }(\mathrm{m} .) & 6 & 7 \\ \text { Cobertura vegetación }(\%) & 100 & 100\end{array}$

Características y diferenciales de asociación y unidades superiores sensu Torres \& Cano Quercus faginea subsp. faginea Crataegus monogyna

Pistacia lentiscus

Quercus coccifera

Rubia peregrina

Smilax aspera

$\begin{array}{ll}4 & 5 \\ 2 & 1 \\ 1 & + \\ + & + \\ 1 & 1 \\ 1 & 1\end{array}$

Otras características. En 1: Bupleurum fruticosum + , Rhamnus alaternus + , Ruscus aculeatus 1 . En 2: Clematis flammula 1, Colutea hispanica + , Lonicera implexa 1 .

\section{Características de unidades superiores Carex halleriana Osyris alba

1

Otras características. En 1: Phillyrea angustifolia + , Quercus rotundifolia + , Piptatherum paradoxum +. En 2: Asparagus acutifolius +, Daphne gnidium + , Rhamnus oleoides subsp. oleoides + , Rhamnus lycioides subsp. laderoi + , Teucrium fruticans + .

Compañeras

Brachypodium retusum

1

1

Otras compañeras. En 1: Brachypodium sylvaticum + , Carex flacca + . En 2: Melica minuta + , Phlomis purpurea + , Rosa canina 1 , Vinca difformis 1 .

Localidades. 1. Antequera. Cerro de Las Minas. 30SUF6596. 2. Antequera. Arroyo de las Adelfas. 30SUF6495. Mac: margas y carniolas. Mar: margas.

una variante con Fraxinus angustifolia en los suelos más arcillosos y con cierta humedad o encharcamiento temporal, o en el fondo de vaguadas. La subasociación aceretosum monspessulani tiene dos variantes ecológicas: una en que forma un bosque mixto de quejigos y arces sobre suelos profundos (luvisoles) y otra en zonas kársticas, lapiaces, base rocosa de cantiles e incluso repisas cercanas a crestas donde domina por completo Acer monspessulanum, acompañado de Pistacia terebinthus (Pavón et al., 2013). Estos bosques constituyen el único hábitat donde se pueden encontrar de modo esporádico indicadores de los pastizales esciohumícolas de TrifolioGeranietea/Origanion virentis como Origanum virens, Campanula rapunculus, Calamintha sylvatica, Stachys germanica y Vicia tenuifolia.

\section{Otras formaciones vegetales}

a) Reforestaciones con Pinus halepensis. Tanto en el subsector Antequerano como en el Torcalense de la ZEC se han realizado plantaciones de Pinus halepensis. En el caso Antequerano, algunas de ellas se podrían considerar como reintroducciones, ya que se hicieron en suelos gípsicos zonopotencialmente propios de la criptoserie de Pinus halepensis y Anthyllis cytisoides, aunque la mayoría están realizadas en la zonopotencialidad de los encinares de Paeonio coriaceae-Quercetum rotundifoliae y los quejigales de Viburno tini-Quercetum fagineae, por lo que procedería su paulatina erradicación para favorecer el desarrollo de la vegetación climácica de dichas series. En el subsector Torcalense, las plantaciones de $P$. halepensis ocupan la zonopotencialidad climácica de encinares de la serie Paeonio coriaceae-Querceto rotundifoliae $S$ y de quejigales y acerales de la serie Vinco difformis-Querceto fagineae $S$, por lo que también procedería la gestión forestal indicada con anterioridad. Bajo dichos pinares densos se encuentran yesquerales de Brachypodium retusum, que podrían incluirse en Cerastio gibraltarici-Brachypodietum retusi.

b) Olmedas de Ulmus minor. En algunas umbrías de la cara norte de la cordillera, al pie de cantiles calizo-dolomíticos en el subsector Torcalense (Cerro de la Cruz, Sierra de las 
Cabras), se han detectado muy puntualmente, olmedas incluibles en Biaro carratracensisUlmetum minoris Rivas-Martínez \& Molero 2011, sobre suelos de tipo zonal, profundos y húmicos, aunque en cierta medida en hábitats con suelos de humedad más dilatada, por el efecto de umbría y del contacto litológico entre materiales duros y arcillosos. Además de Ulmus minor como dominante, llevan en su composición, entre otras, Acer monspessulanum, Crataegus monogyna, Prunus insititia, Hedera helix, Lonicera etrusca, Rubus ulmifolius, Myrrhoides nodosa, Smyrnium olusatrum, Ranunculus ficaria, Urtica dubia, Geranium lucidum, Anthriscus caucalis y Arum italicum.

\section{Series y geopermaseries de vegetación}

\section{Series climatófilas}

Encinares

\section{Paeonio coriaceae-Querceto rotundifoliae $\boldsymbol{S}$ [Torcalense y Antequerano]}

Serie bética, basófila, mesomediterránea, seco-subhúmeda-húmeda de la encina (Quercus rotundifolia).

Bosques de encinas (Paeonio coriaceaeQuercetum rotundifoliae) que constituyen la mayor masa arbórea de la ZEC.

1a. Faciación típica mesomediterránea quercetoso rotundifoliae $s$ (encinares) [Torcalense]

1a1. El encinar calcícola es sustituido por el coscojar de Crataego monogynae-Quercetum cocciferae tras su desaparición y al degradarse el suelo. Cuando éste se erosiona aún más pero mantiene horizontes margosos se instalan matorrales de Genisto cinereae-Ulicetum parviflorii típicos, mientras que sobre calizas duras, lapiaces y demás zonas karstificadas domina el lastonar de Helictotricho-Festucetum scariosae. Sobre suelos erosionados pero aún arcillosos en superficie se desarrolla un pastizal anual subnitrófilo de la comunidad de Thrincia hispida y Anthemis arvensis, que presenta tendencias hacia Hordeion leporini por fuerte pastoreo; sin embargo, en zonas con pastoreo tradicional de ganado ovino, aparece el majadal de Thrincio hispidae-Poetum bulbosae que evoluciona por sobrepastoreo y sinfenosucesión a cardales de Notobasio syriacae-Scolymetum maculati. En zonas con abandono de cultivos cerealísticos se instala la vegetación pionera de los retamales de Retamo sphaerocarpaeGenistetum speciosae.

1a2. El encinar dolomitícola es más xerófilo y de menor talla y es sustituido también por coscojares (Crataego monogynae-Quercetum cocciferae). La etapa de matorral es el aulagar con espliego de Genisto cinereae-Ulicetum parviflorii lavanduletosum lanatae, buen bioindicador de sustratos dolomíticos, así como lo son los pastizales de litosuelos: el nanopastizal tardoinvernal de Saxifrago tridactylitae-Hornungietum petraeae y el primaveral de Arenarietum arundanae. De modo más fragmentario, en algunas zonas más elevadas y con laderas rocosas dolomíticas muy expuestas y venteadas se desarrolla un espartal de la comunidad de Celtica gigantea con piorno azul (Erinacea anthyllis).

1b. Faciación termófila y xerófila, mesomediterránea inferior, con Pistacia lentiscus [Antequerano]

Estos encinares de Paeonio coriaceaeQuercetum rotundifoliae pistacietosum lenstici se desarrollan bajo ombrotipo secosubhúmedo, en suelos desarrollados a partir fundamentalmente de margas abigarradas con yesos y carniolas y en altitudes por debajo de $750 \mathrm{~m}$. Su primera etapa de sustitución es un coscojar de Crataego monogynae-Quercetum cocciferae con especies termófilas como Pistacia lentiscus o Rhamnus oleoides, ya sobre suelos erosionados. Si el grado de erosión aumenta, el suelo margoso es colonizado por matorrales ricos en genisteas de Genisto 
Tabla 26

73. Vinco difformis-Quercetum fagineae Pérez Latorre \& Cabezudo in Pérez Latorre, Caballero, Casimiro-Soriguer, Gavira \& Cabezudo 2009

var. con Quercus alpestris

quercetosum fagineae, var. con Fraxinus angustifolia sensu Pérez Latorre, Caballero, Casimiro-Soriguer, Gavira \& Cabezudo (2009)

aceretosum monspessulani Pavón, Hidalgo \& Pérez Latorre var. con Pistacia terebinthus

(Querco-Fagetea, Quercetalia pubescentis, Aceri granatensis-Quercion fagineae)

INVENTARIO N ${ }^{\circ}$

Orientación

Inclinación $\left({ }^{\circ}\right)$

Área $\left(\mathrm{m}^{2}\right)$

Litología

Altitud (m)

Altura vegetación (m.)

Cobertura vegetación (\%)

Características y diferenciales de asociación

Quercus faginea subsp. faginea

Lonicera etrusca

Paeonia broteroi

Ranunculus blepharicarpos

Vinca difformis

Diferenciales de subasociación

Acer monspessulanum

Diferenciales de variantes

Quercus faginea subsp. alpestris

Heleborus foetidus

Crataegus granatensis

Daphne laureola

Fraxinus angustifolia

Características de unidades superiores

Hedera helix subsp. helix

Paeonia coriacea

Doronicum plantagineum

Hyacinthoides hispanica

\section{Compañeras}

Crataegus monogyna

Brachypodium sylvaticum

Rosa canina

Rubia peregrina

Rubus ulmifolius

Spartium junceum

Campanula rapunculus

Dactylis hispanica

Elymus hispanicus

Geranium lucidum

Iris foetidissima

Piptatherum paradoxum

Quercus rotundifolia

Rhamnus alaternus

Rhamnus infectoria

Rosa micrantha

Rosa pouzinii

\section{1}

N

45

150

$\mathrm{Cal}$

1150

15

100

2

N

30

400

Car

1150

9

100

3
$\mathrm{~N}$
2
400
$\mathrm{M}$
850
1
100

$\begin{array}{cc}3 & 4 \\ \mathrm{~N} & \mathrm{NE} \\ 20 & 5 \\ 400 & 150 \\ \mathrm{Mac} & \mathrm{Cal} \\ 850 & 1190 \\ 12 & 12 \\ 100 & 100\end{array}$

$\begin{array}{cc}5 & 6 \\ \mathrm{~N} & \mathrm{NW} \\ 30 & 5 \\ 150 & 100 \\ \mathrm{Mac} & \mathrm{Car} \\ 1135 & 990 \\ 15 & 12 \\ 90 & 100\end{array}$
5

$+$

5

5

\section{5}


equisetiformis-Cytisetum fontanesii. En los resaltes rocosos compuestos por carniolas, biotopos muy xéricos, se instalan espartales de Thymo gracilis-Stipetum tenacissimae thymetosum capatati. En márgenes alterados de carriles, en las zonas más bajas, se desarrolla un herbazal anual nitrófilo de Hordeo leporiniGlossopappetum macroti. Esta faciación es la que contacta con la vegetación gipsícola sobre yesos antequeranos de la serie de Pinus halepensis.

En esta zona Antequerana y en el ámbito de esta faciación, son dignos de reseñar los afloramientos de areniscas rojas silíceas que favorecen etapas de sustitución silicícolas, que son únicas en el ámbito de la ZEC. Se presentan jaguarzales de Lavandulo stoechadisGenistetum equisetiformis thymetosum capitati y en zonas incendiadas jarales de la comunidad de Cistus ladanifer subsp. africanus y Ulex parviflorus.

1c. Faciación mesófila quercetoso fagineae $\boldsymbol{s}$ (encinares con quejigos) [Torcalense y Antequerano]

1c1. En el subsector Torcalense estos bosques mixtos se sitúan en las zonas con suelos más profundos y en vaguadas y umbrías. Se puede acompañar de un pastizal de suelos temporalmente húmedos de la comunidad de Brachypodium phoenicoides y Achnatherum bromoides BC. La orla del bosque normalmente la constituyen zarzales con gayumbas de Spartio juncei-Rubetum ulmifolii a veces con apariencia de espinares caducifolios por el claro predominio de Crataegus monogyna.

Las etapas seriales de matorral están caracterizadas por el aulagar de Genisto cinereaeUlicetum parviflorii sobre margocalizas y por su subasociación lavanduletosum lanatae sobre dolomías. El lastonar de Helictotricho filifoliiFestucetum scariosae ocupa extensas zonas en biotopos karstificados. En laderas rocosas dolomíticas elevadas (cercanas a $1200 \mathrm{~m}$.) el matorral torna a un lastonar de la comunidad de Celtica gigantea con piorno azul (Erinacea anthyllis). En los suelos arcillosos con pastoreo ovino se hallan majadales de Thrincio hispidaePoetum bulbosae.

1c2. En el subsector Antequerano, los encinares pueden llevar quejigos en su composición sobre todo en laderas umbrías y con suelos conservados. Las etapas de sustitución son las mismas que para la faciación termófila con Pistacia lentiscus (1b).

1d. Faciación silicícola con Quercus suber (encinares con alcornoques) [Torcalense]

Se trata de una faciación ligada a la existencia de vulcanitas en la zona más oriental de la ZEC (laderas sur de la Sierra del Jobo y de San Jorge) que permiten la existencia de especies silicícolas como el alcornoque, representados por ejemplares de elevada edad

Otras compañeras. En 1: Arum italicum 1, Bellis sylvestris 1, Cerastium boissieri + , Geranium molle 2. En 2: Acinos alpinus + , Anthriscus caucalis + , Cytisus reverchonii,+ Myrrhoides nodosa 2, Smyrnium olusatrum +. En 3: Calamintha sylvatica 1, Jasminum fruticans + , Lonicera implexa 1, Osyris alba + , Phillyrea latifolia 3, Quercus coccifera +, Prunus insititia 1, Ruscus aculeatus 1, En 4: Asparagus acutifolius 1. Briófitos 1, Stellaria media 1, Thapsia villosa 1, Veronica hederifolia 1. En 5: Cynosorus echinatus 1, Origanum virens + , Rhagadiolus edulis 2, Rosa pimpinellifolia + , Vicia tenuifolia + . En 6: Achillea ageratum ,+ Allium roseum +, Carex flacca,+ Daphne gnidium,+ Festuca mediterranea 2, Holcus lanatus,+ Hordeum bulbosum +, Ornithogalum narbonense +, Phlomis purpurea 1, Poa trivialis 1, Scirpus holoschoenus + , Stachys germanica + .

Localidades. 1. Málaga. Antequera. Sierra del Realengo. Al este de Sierra del Co. 30SUF7791. 2. Málaga. Antequera. La Fresneda. Sierra del Enebral. 30SUF7690. 3. Málaga. Antequera. La Fresneda. Sierra del Co. 30SUF7491. 4. Antequera. Umbría del Cerro de la Cruz. 30S 379314/4092724. 5. Málaga. Antequera. Sierra del Co. 30S 375765/4090637. 6. Málaga. Antequera. Sierra del Co. Cabecera arroyo Peñas. 30S 375217/4090947.Cal: calizas. Car: calizas-arcillas. Mac: margocalizas. (inv. 4 de A. V. Pérez Latorre y M. Pavón). 
y biomasa, aunque con presencia de individuos jóvenes. El sotobosque se caracteriza por herbazales escionitrófilos de Elymo hispaniciBrachypodietum sylvatici, mientras que el resto de etapas seriales coindiden con las de la faciación con Quercus faginea (1c1).

Quejigales y acerales

\section{Viburno tini-Querceto fagineae $S$ [Antequerano] \\ Serie subbética y antequerana, basófila, mesomediterránea, subhúmeda del quejigo (Quercus faginea).}

\section{2a. Faciación antequerana}

Los quejigales de Viburno tini-Quercetum fagineae aparecen en el subsector Antequerano, sobre sustratos margocalizos, pero en los biotopos más favorecidos: umbrías acentuadas con suelos más profundos (cambisoles) y zonas mejor conservadas. Las etapas seriales coinciden con las de los encinares con quejigos del mismo subsector (1c2).

\section{Vinco difformis-Querceto fagineae $S$ [Torcalense] \\ Serie torcalense, basófila, meso- supramediterránea, subhúmeda-húmeda del quejigo (Quercus faginea).}

3a. Faciación típica mesomediterránea quercetoso fagineae s (quejigales)

La formación climácica corresponde a bosques marcescentes de Vinco difformisQuercetum fagineae que ocupan sobre todo los suelos profundos y conservados desarrollados sobre calizas, margas y arcillas, generalmente en umbrías. Habitualmente en claros y linderos se acompaña del herbazal esciohumícola graminoide de Elymo hispaniciBrachypodietum sylvatici, que en suelos arcillosos donde permanece más la humedad es sustituido por la comunidad de Brachypodium phoenicoides y Achnatherum bromoides BC.
En zonas con suelo nitrificado por el ganado se puede observar un herbazal escionitrófilo de Myrrhoidi nodosae-Alliarietum petiolatae ranunculetosum blepharicarpi. La orla del bosque corresponde a zarzales con gayumbas (Spartio juncei-Rubetum ulmifolii) que pueden ocupar grandes áreas como etapa progresiva de la serie y tomar el aspecto de espinares de la forma con Crataegus monogyna.

Las etapas de sustitución corresponden a escobonales poco abundantes de Genisto speciosae-Cytisetum reverchonii, sobre todo en zonas más elevadas y con suelos profundos. Los matorrales heliófilos corresponden a aulagares de Genisto cinereae-Ulicetum parviflorii sobre suelos arcillosos y a lastonares de Helictotricho filifolii-Festucetum scariosae donde el suelo se ha perdido o ha habido incendios en el pasado. Finalmente aparece un pastizal graminoide terofítico subnitrófilo y xerófilo de la comunidad de Aegylops neglecta y Avena sterilis en litosuelos margosos con cierto pastoreo.

Esta faciación contacta hacia suelos con mayor grado de hidromorfía con la geopermaserie temporihigrófila de los herbazales verticícolas.

3b. Faciación temporihigrófila con Fraxinus angustifolia (quejigal-fresneda)

Esta faciación del quejigal se enriquece con fresnos en los suelos arcillosos donde la humedad permanece durante más tiempo y en los fondos de vaguadas. Presenta el mismo dinamismo serial que la faciación típica (3a) salvo por la presencia elevada del herbazal esciohumícola de Elymo hispaniciBrachypodietum sylvatici. Esta faciación contacta hacia suelos con mayor grado de hidromorfía con la geopermaserie de los herbazales higrófilos verticícolas.

3c. Faciación supra-mesomediterránea mesófila / karsticícola aceretoso monspessulani $\boldsymbol{s}$ (acerales) 
La vegetación climácica del piso supramediterráneo torcalense sobre suelos zonales corresponde a bosques caducifolios de Acer monspessulanum o aceral-quejigales en los que se acompaña de Quercus faginea en la asociación Vinco difformis-Quercetum fagineae aceretosum monspessulani. También el aceral es la vegetación climácica en sustratos afectados por el modelado kárstico: dolinas, lapiaces, cascajares, etc. (var. con Pistacia terebinthus). Estas formaciones pueden descender al piso mesomediterráneo, pero siempre en situaciones edáficas (suelos profundos) y topográficas (umbrías) que le favorecen. Estos bosques pueden acompañarse de herbazales escionitrófilos de Myrrhoidi nodosae-Alliarietum petiolatae ranunculetosum blepharicarpi en zonas umbrías y conservadas en el piso supramediterráneo. En el piso mesomediterráneo o en zonas pastoreadas el herbazal esciófilo anual corresponde a la comunidad de Geranium lucidum BC. La orla del bosque está constituida por espinares caducifolios de gran talla de Lonicero arboreaeCrataegetum granatensis donde el suelo aún tiene cierto desarrollo y puede incluso presentar la misma vegetación nemoral citada con anterioridad.

Las etapas de sustitución de estas formaciones comienzan por escobonales de Genisto speciosae-Cytisetum reverchonii, donde el suelo aún se conserva; sin embargo y a modo subrupícola en lapiaces y zonas muy venteadas, predomina entonces la comunidad de Cytisus reverchonii y Rhamnus infectoria. En zonas culminales por encima de $1500 \mathrm{~m}$. se encuentran de modo puntual espinares de Pruno mahalebo-Berberidetum hispanicae prunetosum prostratae en zonas karstificadas (lapiaces). El matorral de sustitución corresponde a piornales xeroacánticos de Festuco segimonensis-Erinaceetum anthyllidis en el piso supramediterráneo y a lastonares de Helictotricho filifolii-Festucetum scariosae tanto en el termotipo supra como en el mesomediterráneo, en zonas de escaso suelo (intersticial en lapiaces) o incendiadas hace tiempo.

Los pastizales varían en función del suelo: a/ en crestas y rellanos supramediterráneos venteados se desarrollan pastizales vivaces psicroxerófilos graminoides de la comunidad de Festuca segimonensis y Koeleria filifolia; b/ en suelos arcillosos profundos y secos se instala un herbazal subnitrófilo anual de la comunidad de Thrincia hispida y Anthemis arvensis, que puede proceder dinámicamente del majadal por pastoreo ovino de Thrincio hispidae-Poetum bulbosae o, más escaso, del nanopastizal de Sedo caespitosii-Crassuletum tillaeae poetosum bulbosae en fondos arcillosos húmedos de las dolinas; c/ en cascajares y gleras calizas supramediterráneas se encuentra el pastizal terofítico de Violo demetriaeJonopsidietum prolongoi. Esta faciación contacta hacia suelos con mayor grado de hidromorfía con la geopermaserie de los herbazales temporihigrófilos verticícolas, a través de la comunidad de Holcus lanatus y Avena barbata DC.

\section{Series edafoxerófilas}

Acebuchales

\section{Tamo communis-Oleeto sylvestris $\mathbf{S}$ [Torcalense] \\ Serie verticícola, iberomarroquí-atlántica, termomediterránea subhúmedo-húmeda del acebuche (Olea europaea var. sylvestris)}

4a. Faciación rupestre, antequerana y malacitano-axarquiense (bética) con Pistacia terebinthus.

Los acebuchales subrupícolas solo se encuentran muy puntualmente en la base sudoccidental de la Sierra del Co en todo el ámbito de la ZEC. Prácticamente constituyen vegetación permanente de zonas karstificadas y/o rocosas, en solanas muy térmicas, aunque 
en otras zonas de la Cordillera Antequerana puedan ser sustituidos por coscojares y espinares termófilos (Pérez Latorre et al., 2009). En los claros, sobre sustrato arcilloso, se desarrollan los pastizales geofíticos otoñales de Scillo autumnalis-Ranunculetum bullati. Estos acebuchales contactan directamente con las geopermaseries de vegetación rupícola calcícola.

Cornicabrales-terebintales

\section{Phyllireo latifoliae-Pistacieto terebinthi $\boldsymbol{S}$ [Torcalense]}

Serie karsticícola, bética, mesomediterránea, subhúmedo-húmeda del terebinto (Pistacia terebinthus)

Los cornicabrales-terebintales (Pavón et al., 2013) constituyen vegetación permanente que solo se encuentra en el límite oriental de la ZEC en la zona nordeste de la Sierra de San Jorge y este de la de Gibalto, ya en Granada, sobre calizas en biotopos karstificados y con ombrotipo húmedo. Se encuentran ligados a la zonopotencialidad y al dinamismo sucesional de los quejigales de Vinco difformis-Querceto fagineae $S$.

Pinares

\section{Criptoserie de Pinus halepensis [Antequerano]}

Serie gipsícola, antequerana, mesomediterránea seca del pino carrasco (Pinus halepensis)

En el subsector Antequerano se encuentran biotopos muy particulares, que combinan litologías a base de yesos y margas yesíferas, litosoles, laderas con orientacion sur y grandes inclinaciones superiores a $45^{\circ}$. En estas condiciones hiperxéricas, acentuadas por el ombrotipo seco y el termotipo mesomediterráneo inferior, se desarrolla la vegetación gipsícola, caracterizada fundamentalmente por el albaidal de la comunidad Hippocrepido bourgaei-
Anthyllidetum cytisoidis, que en algunas zonas de yesos masivos con pequeños rellanos arenosos puede acompañarse del pastizal gipsícola de Chaenorrhino reyesi-Campanuletum fastigiatae avellinietosum festucoidis. En la actualidad no hemos detectado en la zona los pinares criptoclimácicos de Pinus halepensis, existentes en otras zonas yesíferas antequeranas como la Hoz de Archidona (Ceballos y Vicioso, 1933; Cabezudo et al., 2013), sin embargo las reforestaciones existosas sobre yesos y algunos pinos aislados en laderas inaccesibles podrían indicar al pinar carrasco como cabecera de la serie también en la zona de estudio.

\section{Series edafohigrófilas}

Fresnedas

7. Ficario ranunculoidis-Fraxineto angustifoliae $\boldsymbol{S}$ [Torcalense y Antequerana]

Serie fluvial iberomarroquí-atlántica del fresno (Fraxinus angustifolia)

7a. Faciación aljíbica y bética salicetoso pedicellatae $s$

7a1. Subfaciación Torcalense

Las fresnedas constituyen el bosque ripario más común en los ríos y arroyos, generalmente de cauces estrechos, permanentes aunque con acusado estiaje, de la zona. En el subsector Torcalense aparecen entre los 800 y 1100 metros, fundamentalmente sobre sustratos arcillosos. Una notable variante de estas fresendas ocurre en esta ZEC y está ligada a los nacimientos kársticos. En estos casos el bosque es mixto y además de fresnos dominan la higuera (Ficus carica) y el olmo (Ulmus minor) e incluso aparecen saúcos (Sambucus nigra) como especies diferenciales. La orla y primera etapa de sustitución de las fresnedas la constituyen los zarzales con gayumbas de Spartio juncei-Rubetum ulmifolii, con gran desarrollo y cobertura. Cuando la vegetación 
arbóreo-arbustiva es eliminada, los cauces son ocupados por juncales de Holoschoenetum vulgaris. Cubierta por la fresneda, pero en remansos que forman suelos permanentemente húmedos, aparecen herbazales helofíticos de Glycerio declinatae-Apietum nodiflori. En las zonas de nacimientos, fuentes y acequias, con márgenes algo nitrificados, es posible hallar la vegetación helofítica de Apietum nodiflori.

7a2. Subfaciación Antequerana termófila con Nerium oleander

Las fresnedas antequeranas también se desarrollan en cauces angostos y sobre materiales arcillosos, pero enriquecidas en especies termófilas como la adelfa (Nerium oleander). Las etapas de sustitución son muy similares, bien zarzales de Spartio juncei-Rubetum ulmifolii en su variante con Rosa sempervirens o juncales de Holoschoenetum vulgaris, que pueden ser más extensos en zonas de fuentes y rezumaderos. También se ha detectado un prado graminoide de elevada talla sobre los suelos arcillosos con mayor periodo de encharcamiento, presidido por Hordeum bulbosum, Elymus repens subsp. repens y Brachypodium phoenicoides. La destrucción de la fresneda y la alteración del cauce puede llevar a la instalación de adelfares de Rubo ulmifolii-Nerietum oleandri.

Adelfares

\section{Rubo ulmifolii-Nerieto oleandri $S$ [Torcalense, Antequerano] \\ Serie riparia ibérica, termo-mesome- diterránea inferior de la adelfa (Nerium oleander)}

En el subsector Torcalense solo se han detectado formaciones con adelfas en el cauce del río Guadalmedina, pero muy fragmentarias y mezcladas con zarzales de Spartio juncei-Rubetum ulmifolii. Algunos tramos incluibles en Rubo ulmifolii-Nerietum oleandri son reconocibles en los arroyos del subsector Antequerano, también orlados y/o sustituidos por la misma comunidad de zarzal y relacionados dinámicamente con las fresnedas de Ficario ranunculoidis-Fraxinetum angustifoliae.

\section{Geopermaseries}

IVa. Casmofíticas y glerícolas, calcícolas [Torcalense]

La vegetación rupícola sobre materiales fundamentalmente calizos y en los termotipos meso y supramediterráneo modula su aparición en función de la exposición. En exposición sur, a veces superando la verticalidad (extraplomos), se desarrolla el Linario anticariae-Centaureetum clementei, generalmente en acantilados de gran superficie y desarrollo vertical. En las zonas más térmicas de la ZEC, en rellanos terrosos de grietas horizontales, aparece la comunidad pteridofítica vivaz del Polypodietum serrati. En orientaciones fundamentalmente norte aparecen tres asociaciones: a/ Linario anticariaeSaxifragetum biternatae, en oquedades y grietas generalmente horizontales muy poco soleadas llegando a 1350 m.; b/ Biscutello sempervirentis-Saxifragetum reuterianae, en grietas más expuestas generalmente verticales, alcanzando 1540 m. y c/ Saxifragetum camposii, probablemente relictual y detectada solo en la ladera norte de la Sierra del Jobo, formando cojines de gran tamaño muy expuestos a 1400 $\mathrm{m}$. en roquedos de formas convexas. En las bocas de cuevas, base de cantiles y grandes oquedades ligeramente nitrificadas se desarrolla el Stachydetum circinatae. Finalmente en las gleras y cascajares de tamaños decimétricos semimóviles aparece la comunidad de Rumex induratus. Ligados a estos biotopos de base de cantiles sombreados y nitrificados, en altitudes bajas y medias se desarrolla una comunidad de Smyrnium olusatrum BC que no llega a desarrollarse como para incluirse en Myrrhoidi nodosae-Alliarietum petiolatae. 
IVb. Casmofíticas y glerícolas, dolomitícolas [Torcalense]

Los afloramientos de dolomías presentan una vegetación rupícola propia y diferenciada de las calizas, aunque alguna asociación pueda cohabitar ambos tipos de litologías. La vegetación dolomitícola casmofítica más característica la constituye Hieracietum baeticitexedensis, propia de umbrías acentuadas y callejones kársticos en los pisos supra y mesomediterráneo llegando hasta $1450 \mathrm{~m}$. En esas altitudes, los acúmulos de grandes bloques sombreados presentan vegetación petridofítica ténera y orófila de la comunidad de Cystopteris dickieana BC. En las oquedades extraplomadas y nitrificadas en el piso mesomediterráneo se desarrolla el Sarcocapnetum baeticae, sustituida por el Linario anticariae-Centaureetum clementei en paredones verticales de gran desarrollo y grandes grietas. Los cascajares y gleras decimétricas fijas y semimóviles son colonizadas por la comunidad de Rumex induratus, mientras que en canteras y taludes dolomíticos no llega a formarse una comunidad vivaz de Andryalo-Crambion filiformis, aunque sí que se han detectado poblaciones de dolomitófitos de la alianza como Chaenorrhinum macropodum subsp. degenii.

IVc. Dulceacuícolas helofíticas e hidrofíticas lagunares [Torcalense]

Los biotopos lagunares constituyen otra de las singularidades de la ZEC, junto con los yesos y los prados higrófilos, entre otras. Se trata generalmente de pequeñas lagunas temporales de aguas dulces sobre sustratos arcillosos, en una franja altitudinal entre los 1000 y 1400 m., en los termotipos meso y supramediterráneo. Entre estos biotopos incluimos también las balsas ganaderas, pues las características ecológicas son similares. Estas lagunas temporales perimiten la existencia de vegetación helofítica e hidrofítica muy escasa en todo el sector biogeográfico y por tanto dignas de la mayor atención conservacionista. Las comunidades vegetales aparecen de modo fragmentario en las distintas localidades, influenciadas por la duración de la lámina de agua y la profundidad de la laguna y su nitrificación por el pastoreo. El borde, con suelos húmedos en primavera, no encharcado pero pastoreado, es colonizado por juncales nitrófilos de la comunidad de Juncus inflexus. En las zonas pisotedas y pastoreados pero con encharcamiento hasta comienzo de verano aparecen cépedes nitrófilos de la comunidad de Carex divisa BC. La vegetación helofítica presenta el juncal de Acrocladio-Eleocharitetum palustris en aguas más permanentes del borde lagunar. La vegetación de batráquidos flotantes pero enraizados presenta la comunidad de Ranunculus peltatus subsp. saniculifolius en aguas someras efímeras, mientras que en aguas más permanentes aunque mesotróficas se desarrolla la comunidad de Ranunculus peltatus subsp. peltatus. La vegetación hidrofítica enraizada y sumergida está constituida por la comunidad de Zannichellia palustris BC. Finalmente la vegetación algal sumergida, está bastante extendida, y dominada por carófitos del Charetum vulgaris.

IVd. Verticícolas temporihigrófilas [Torcalense]

En la zona Torcalense de la ZEC están bastante extendidos los sustratos arcillosos vérticos y con hidromorfía temporal, en áreas bastante lluviosas con ombrotipo húmedo. Estos biotopos están colonizados por praderas higrófilas que prestan un gran singularidad a la Sierra de Camarolos, incluso paisajística, y que se desarrollan en los pisos meso y supramediterráneo. Estos biotopos mantienen la humedad hasta principios del verano y presentan diversos grados de pastoreo, lo que influye bastante en la composición fitocenológica de la vegetación y en su estructura y ecomorfología. 
Los prados más extendidos están ligados al constante pastoreo y corresponden a praderas veraniegas de baja talla de Stachydo officinalisEryngietum caespitiferii, muy importantes a nivel florístico por ser hábitat de especies muy escasas en la ZEC como Narcissus pseudonarcissus subsp. nevadensis. Cuando los biotopos están menos influenciados por el pastoreo se desarrollan prados graminoides de Elymo repentis-Phalaridetum coerulescentis a finales de primavera y comienzos de verano o de la comunidad de Festuca mediterranea BC en zonas basales más térmicas. Incluso se hallan vallicares de Gaudinio fragilis-Agrostietum castellanae festucetosum amplae en suelos donde los regatos de agua son más duraderos. Las cuatro asociaciones pueden ser sustituidas por juncales nitrófilos de la comunidad de Juncus inflexus a causa de aumento de la presión de pastoreo. En los márgenes de estos pastizales, donde el suelo se seca antes, se desarrollan herbazales de la comunidad de Holcus lanatus y Avena barbata DC, a caballo entre Festuco-Brometea erecti y MolinioArrhenatheretea, derivados por pastoreo hacia Thero-Brometalia y que pueden incluso actuar como etapa dinámica de pastizal de los acerales de Vinco difformis-Quercetum fagineae aceretosum monspessulani. Como efecto del proceso de sinfenosucesión, todos estos prados en su facies nitrificada pueden ser sustituidos por cardales de la Eryngio dilatati-Cynaretum baeticae durante el verano.

En las surgencias y fuentes con sustratos arcillosos encharcados y con fuerte pastoreo aparece una comunidad de Agrostis stolonifera y Trifolium fragiferum. En biotopos muy puntuales arcillosos con encharcamiento superficial duradero y escasa pendiente se puede desarrollar un nanojuncal de la comunidad de Juncus bufonius y Centaurium pulchellum. Finalmente en zonas supramediterráneas, a veces dolomíticas, se puede encontrar en mosaico con el piornal de Festuco segimonensisErinaceetum anthyllidis un pastizal higrófilo más temprano que el resto, de la comunidad de Festuca segimonensis y Eryngium caespitiferum que supone una transición hacia la pradera de Stachydo officinalis-Eryngietum caespitiferi con la que el piornal contacta.

\section{IVe. Antropógenas [Torcalense]}

Corresponde a pastizales y herbazales con distinto grado de nitrofilia, ligados a la agricultura y al pastoreo en el territorio de estudio. Los cultivos cerealistas presentan la comunidad meseguera de Ridolphio segetiCapnophylletum peregrini; en los olivares sobre arcillas se desarrolla la comunidad tardo-invernal de Arenaria hispanica. El intenso pastoreo detectado en la ZEC, causa la aparición de cardales entre la vegetación climatófila, siendo los más extendidos el Notobasio syriacae-Scolymetum hispanici propio del verano, sustituido en las zonas con sobrepastoreo y redileo del ganado por el Carduo bourgaeani-Sylibetum mariani, que puede llegar a ocupar las dolinas a finales de primavera. El cardal de Notobasio syriacaeScolymetum maculati también entra como etapa final en la sinfenosucesión en biotopos de suelos arcillosos húmedos, donde se desarrollan previamente algunos de los pastizales higrófilos definidos en el apartado IVd.

\section{Zonopotencialidad vegetal (Paisaje Vegetal)}

En la tabla 27 se relacionan los aspectos ecológicos en los distintos cenotopos con la zonopotencialidad vegetal climácica de la ZEC.

\section{ESQUEMA SINTAXONÓMICO Y ECOFISIONÓMICO}

Las unidades de vegetación identificadas en la ZEC se ordenan en la siguiente clasificación fitosociológica. Se ha seguido el esquema 
propuesto por Rivas Martínez et al. (2002) a nivel de clases y grupos ecofisionómicos. Cada asociación, subasociación, comunidad (o comunidad basal, BC) y variante (resaltadas en negrita) presentan una breve descripción con datos fisionómicos, fitoecológicos y/o corológicos para la zona de estudio. El código del Anexo I de la Directiva 92/43UE de "Hábitats" se proporciona entre paréntesis y en negrita.

\section{Vegetación acuática flotante, sumergida o enraizada}

\section{Ia. Vegetación de aguas dulces}

CHARETEA Fukarek 1961

+ Charetalia Sauer 1937

* Charion fragilis Krausch 1964

1. Charetum vulgaris Corillion 1957 [Vegetación algal carofítica en aguas dulces efímeras, someras, mesotrofizadas] (3140)

POTAMETEA Klika in Klika \& Novák 1941 + Potametalia W. Koch 1926

* Potamion (Koch 1926) Libbert 1931

2. Comunidad de Zannichellia palustris BC [Vegetación sumergida de elodeidos en aguas someras] (3260)

* Ranunculion aquatilis Passarge 1964

3. Comunidad de Ranunculus peltatus subsp. saniculifolius sensu Pérez Raya (1987) [Vegetación de hidrófitos batráquidos en aguas efímeras, someras, mesotrofizadas] (3260)

4. Comunidad de Ranunculus peltatus subsp. peltatus [Comunidad de hidrófitos batráquidos en aguas perennes, mesotrofizadas] (3260)

\section{Vegetación dulceacuícola fontinal, anfibia y turfófila}

\section{IIa. Vegetación pionera efímera}

ISOETO-NANOJUNCETEA Br. - Bl. \& Tüxen ex Westhoff, Djik \& Passchier 1946
+ Nanocyperetalia Klika 1935

* Nanocyperion Koch ex Libbert 1932

5. Comunidad de Juncus bufonius y Centaurium pulchellum sensu Pérez Raya (1987)

[Nanojuncales sobre arcillas hidromorfas] (3130)

IIb. Vegetación lacustre, fontinal y turfófila

MAGNOCARICI-PHRAGMITETEA Klika in Klika \& Novak 1941 nom. inv.

+ Nasturtio-Glyceretalia Pignatti 1954

Glycerio-Sparganion Br. - Bl. \& Sissingh in Boer 1942

Glycerienion fluitantis (Géhu \& Géhu-Frank 1987) Molina 1996

6. Acrocladio cuspidati-Eleocharitetum palustris O. Bolòs \& Vigo 1967 [Vegetación helofítica del borde de lagunas mesotrofizadas]

+ Magnocaricetalia Pignatti 1954

* Magnocaricion elatae Koch 1926

7. Apietum nodiflori Maire 1924 nom. mut. [Vegetación helofítica mesotrófica de aguas corrientes]

8. Glycerio declinatae-Apietum nodiflori J. A. Molina 1996 [Herbazales helofíticos de cauces lentos y nitrificados.]

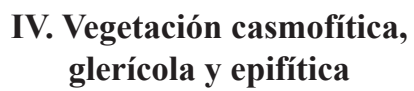

IVa. Vegetación casmofítica

ASPLENIETEA TRICHOMANIS (Br.-Bl. in Meier \& Br.-B1. 1934) Oberdorfer 1977

+ Potentilletalia caulescentis Br.-B1. in Br.-B1. \& Jenny 1926

* Saxifragion camposii Cuatrecasas ex Quézel 1953

9. Saxifragetum camposii Cuatrecasas ex Martínez Parras \& Peinado Lorca 1990 (8210) [Vegetación rupícola supramediterránea calcícola]

10. Hieracietum baetici-texedensis Pérez 


\begin{tabular}{|c|c|c|c|}
\hline \multicolumn{4}{|c|}{ SUBSECTOR ANTEQUERANO } \\
\hline Litología/cenotopo & Termotipo & Ombrotipo & Zonopotencialidad \\
\hline Margas y calizas & mesomediterráneo inferior & seco-subhúmedo & $\begin{array}{l}\text { Encinares (Quercus } \\
\text { rotundifolia) }\end{array}$ \\
\hline Margas y calizas & $\begin{array}{l}\text { mesomediterráneo inferior } \\
\text { y medio }\end{array}$ & subhúmedo & $\begin{array}{c}\text { Quejigares y encinares con } \\
\text { quejigos (Quercus faginea, } \\
\text { Q. rotundifolia) }\end{array}$ \\
\hline Yesos & mesomediterráneo inferior & seco-subhúmedo & $\begin{array}{c}\text { Matorral gipsícola con pinos } \\
\text { (Anthyllis cytisoides, Pinus } \\
\text { halepensis) }\end{array}$ \\
\hline Arroyos & mesomediterráneo inferior & seco-subhúmedo & $\begin{array}{l}\text { Fresnedas (Fraxinus } \\
\text { angustifolia) y adelfares } \\
\text { (Nerium oleander) }\end{array}$ \\
\hline \multicolumn{4}{|c|}{ SUBSECTOR TORCALENSE } \\
\hline Litología/cenotopo & Termotipo & Ombrotipo & Zonopotencialidad \\
\hline Calizas, dolomías, margas & mesomediterráneo & subhúmedo & $\begin{array}{l}\text { Encinares (Quercus } \\
\text { rotundifolia) }\end{array}$ \\
\hline Calizas, dolomías, margas & $\begin{array}{l}\text { mesomediterráneo medio y } \\
\text { superior }\end{array}$ & subhúmedo-húmedo & $\begin{array}{c}\text { Quejigales (Quercus faginea } \\
\text { subsp. faginea y subsp. } \\
\text { alpestris) }\end{array}$ \\
\hline Calizas karstificadas & meso-supramediterráneo & subhúmedo-húmedo & $\begin{array}{c}\text { Acerales }(\text { Acer } \\
\text { monspessulanum }), \text { Espinar } \\
\text { (Crataegus granatensis })\end{array}$ \\
\hline Arroyos & mesomediterráneo & subhúmedo & Fresnedas (Fraxinus angustifolia) \\
\hline Calizas & $\begin{array}{l}\text { mesomediterráneo medio y } \\
\text { superior }\end{array}$ & subhúmedo-húmedo & $\begin{array}{c}\text { Cornicabrales (Pistacia } \\
\text { terebinthus) }\end{array}$ \\
\hline Calizas & mesomediterráneo inferior & subhúmedo & $\begin{array}{c}\text { Acebuchales (Olea europaea } \\
\text { var. sylvestris) }\end{array}$ \\
\hline Calizas & meso-supramediterráneo & subhúmedo-húmedo & $\begin{array}{l}\text { Vegetación rupícola } \\
\text { (Saxifraga biternata, } S \text {. } \\
\text { reuteriana, } S \text {. camposii) }\end{array}$ \\
\hline Dolomías & meso-supramediterráneo & subhúmedo-húmedo & $\begin{array}{c}\text { Vegetación rupícola } \\
\text { (Hieracium texedense, } H \text {. } \\
\text { baeticum) }\end{array}$ \\
\hline Lagunas & meso-supramediterráneo & subhúmedo-húmedo & $\begin{array}{l}\text { Vegetación hidrofítica } \\
\text { (Ranunculus peltatus subsp. } \\
\text { saniculifolius y subsp. } \\
\text { peltatus, Zannichellia } \\
\text { palustris, Chara vulgaris } \\
\text { subsp. crassicaulis) }\end{array}$ \\
\hline Margas y arcillas & meso-supramediterráneo & subhúmedo-húmedo & $\begin{array}{c}\text { Prados higrófilos (Eryngium } \\
\text { caespitiferum, E. aquifolium, } \\
\text { Phalaris caerulescens, } \\
\text { Festuca ampla) }\end{array}$ \\
\hline Nacimientos y fuentes & mesomediterráneo & subhúmedo-húmedo & $\begin{array}{l}\text { Higuerales-olmedas (Ficus } \\
\text { carica, Ulmus minor) }\end{array}$ \\
\hline
\end{tabular}

Tabla 27. Vegetación climácica en la ZEC en función de la zonopotencialidad de los distintos subsectores y cenotopos. Climax vegetation in the ZEC according to zono-potential lithology/coenotope and bioclimatic indexes in the phytogeographical units (subsectors). 
Latorre, Casimiro-Soriguer \& Cabezudo ass. nova [Vegetación rupícola supramesomediterránea dolomitícola] (8210)

+ Androsacetalia vandellii Br. - Bl. in Meier \& Br. - Bl. 1934 nom. corr.

11. Comunidad de Cystopteris dickieana BC [Vegetación pteridofítica ténera umbrófila, de gleras dolomíticas supramediterráneas] (8210) + Asplenietalia petrarchae (glandulosi) Br.-Bl. in Meier \& Br.-Bl. 1934

++ Tinguarrenalia siculae (Daumas, Quèzel \& Santa 1952) Galán de Mera in Pérez Latorre, Galán de Mera, Deil \& Cabezudo 1996

* Campanulion velutinae Martínez Parras \& Peinado 1990

** Campanulenion velutinae

12. Biscutello frutescentis-Saxifragetum reuterianae Socorro \& Marín Calderón 1983 (8210)

- saxifragetosum reuteranae [Vegetación rupícola ombrófila]

- var. con Erodium cheilanthifolium [Variante orófila]

13. Linario anticariae-Saxifragetum biternatae Esteve \& López Guadalupe 1973 [Vegetación rupícola mesófila umbrófila] (8210)

** Centaureenion clementei

14. Linario anticariae-Centaureetum clementei Pérez Latorre \& Cabezudo in Pérez Latorre, Caballero, Casimiro-Soriguer Solanas, Gavira \& Cabezudo 2009 [Vegetación rupícola heliófila, nitrófila] (8210)

PARIETARIETEA Rivas-Martínez in Rivas Goday 1964

+ Parietarietalia judaicae Rivas-Martínez in Rivas Goday 1964

* Parietario-Galion murale Rivas Martínez ex Rivas Goday 1964

15. Stachydetum circinatae Fdez. Casas 1972 [Comunidad de oquedades nitrificadas]

PETROCOPTIDO-SARCOCAPNETEA ENNEAPHYLLAE Rivas-Martínez, Cantó \& Izco in Rivas-Martínez, Díaz, Fernández-
González, Izco, Loidi, Lousã \& Penas 2002

+ Sarcocapnetalia enneaphyllae Fdez. Casas 1972 em. Deil \& Galán de Mera 1997

16. Sarcocapnetum baeticae Pérez Latorre \& Cabezudo in Pérez Latorre, P. Navas, D. Navas, Gil \& Cabezudo 1998 [Vegetación bética de extraplomos] (8210)

IVb. Vegetación casmocomofítica, epifítica y glerícola

ANOMODONTO-POLYPODIETEA RivasMartínez 1975

+ Anomodonto-Polypodietalia O. Bolòs \& Vives in O. Bolòs 1957

* Polypodion serrati Br.-Bl. in Br.-Bl., Roussine \& Nègre 1952

17. Polypodietum serrati Br.-Bl. in Br.-B1., Roussine \& Nègre 1952 [Comunidad pteridofítica umbrófila, vivaz, de repisas terrosas] (8130)

PHAGNALO-RUMICETEA INDURATI (Rivas Goday \& Esteve 1972) Rivas-Martínez, Izco \& Costa 1973

+ Phagnalo-Rumicetalia indurati Rivas Goday \& Esteve 1972

18. Comunidad de Rumex induratus sensu Pérez Latorre, Casimiro-Soriguer Solanas, Gavira \& Cabezudo (2012) [Vegetación de gleras fijas meso-supramediterráneas] (8130)

\section{Vegetación antropógena, de lindero de bosque y megafórbica.}

\section{Va. Vegetación antropógena}

ARTEMISIETEA VULGARIS Lohmeyer, Preising \& Tüxen in Tüxen 1950 ampl. RivasMartínez, Báscones, T.E. Díaz, Fernández González \& Loidi 1991

+ Carthametalia lanati Brullo in Brullo \& Marceno 1985

* Onopordion castellani Br.-B1. \& O. Bolòs 1958 corr. Rivas-Martínez, T.E. Díaz, Fernández- 
González, Izco, Loidi, Lousã \& Penas 2002 19. Notobasio syriacae-Scolymetum maculati Rivas Goday ex Ladero, Socorro, Molero, M. López, Zafra, Marín, Hurtado \& Pérez-Raya 1981 [Cardales de suelos arcillosos, estivales] 20. Eryngio aquifolii-Cynaretum baeticae Pérez Latorre, Casimiro Soriguer \& Cabezudo ass. nova [Cardales de alcaucil blanco de suelos vérticos húmedos, estivales]

* Sylibo-Urticion Sissingh ex Br. - Bl. \& O. Bolós 1958

21. Carduo bourgaeani-Sylibetum mariani Rivas Martínez ex Rivas Martínez, Costa \& Loidi 1992 [Cardales primaverales]

STELLARIETEA MEDIAE Tüxen, Lohmeyer \& Preising ex von Rochow 1951

Stellarienea mediae

+ Centaureetalia cyani Tüxen ex Von Rochow 1951

* Ridolphion segeti Nègre ex Rivas Martínez, Fernández González \& Loidi 1999

22. Ridolphio segeti-Capnophylletum peregrini Guinochet 1978 [Pastizales arvenses de cultivos cerealísticos]

Chenopodio-Stellarienea Rivas Goday 1956

+ Thero-Brometalia (Rivas Goday \& Rivas-Martínez ex Esteve 1973) O. Bolòs 1975

* Taeniathero-Aegylopion geniculatae Rivas-Martínez \& Izco 1977

23. Comunidad de Thrincia hispida y Anthemis arvensis [Pastizal anual sobre litosuelos, subnitrófilo]

24. Comunidad de Aegylops neglecta y Avena sterilis [Pastizal graminoide sobre margas, subnitrófilo]

* Cerintho majoris-Fedion cornucopiae Rivas-Martínez \& Izco ex Peinado, MartínezParras \& Bartolomé 1986

25. Comunidad de Arenaria hispanica [Pastizal tardoinvernal nitrófilo de olivares sobre arcillas] + Sisymbrietalia officinalis J. Tüxen in Lohmeyer \& al. 1962 em. Rivas-Martínez, Báscones, T.E. Díaz, Fernández-González \& Loidi 1991
* Hordeion leporini Br.-Bl. in Br.-Bl., Gajewski, Wraber \& Walas 1936

26. Hordeo leporini-Glossopappetum macroti Peinado, Martínez-Parras \& Bartolomé 1986 [Pastizal anual nitrófilo, primaveral, sobre margocalizas]

CARDAMINO HIRSUTAE-GERANIETEA PURPUREI (Rívas Martinez, FernándezGonzález \& Loidi 1999) Rívas Martinez, Fernández-González \& Loidi 2002

+ Geranio purpurei-Cardaminetalia hirsutae Brullo in Brullo \& Marceno 1985

* Geranio pusilli-Anthriscion caucalidis Rivas Martínez 1978

27. Comunidad de Geranium lucidum BC sensu Pérez Latorre et al., 1998 [Pastizal anual escionitrófilo subrupícola]

\section{Vb. Vegetación de lindero de bosque y megafórbica}

GALIO-URTICETEA Passarge ex Kopecky 1969

+ Galio aparines-Alliarietalia petiolatae Gors \& Muller 1969 em. Rivas Martínez 1987

* Galio-Alliarion petiolatae Oberdorter \& Lohmeyer in Oberdorfer. Gérs, Korneck, Lohmeyer, Mtiller. Philippi \& Seiben 1967

28. Myrrhoidi nodosae-Alliarietum petiolatae Rivas-Martinez \& Mayor ex Fuente 1986

- ranunculetosum blepharicarpi (Pérez Latorre \& Pavón 2009) Pavón, Hidalgo Triana \& Pérez Latorre 2012 [Herbazal escionitrófilo nemoral supramediterráneo]

29. Comunidad de Smyrnium olusatrum BC sensu Pérez Latorre et al., 2009 [Herbazal escionitrófilo subrupícola]

\section{TRIFOLIO-GERANIETEA SANGUINEI} Müller 1962

+ Origanetalia vulgaris Müller 1962

* Origanion virentis Rivas-Martínez \& O. Bolòs in Rivas-Martínez, T.E. Díaz, F. Prieto, Loidi \& Penas 1984 
** Origanienion virentis (Rivas-Martínez \& O. Bolòs in Rivas-Martínez, T.E. Díaz, F. Prieto, Loidi \& Penas 1984) Capelo 1996

30. Elymo hispanici-Brachypodietum sylvatici Gómez-Mercado \& F. Valle 1991 [Herbazal graminoide esciohumícola, supramesomediterráneo, basófilo, de bosques caducifolios béticos]

\section{Vegetación pratense y pascícola}

\section{VIIa. Pastizales terofíticos}

TUBERARIETEA GUTTATAE (Br.-Bl. in Br.-B1., Roussine \& Nègre 1952) Rivas Goday \& Rivas-Martínez 1963 nom. mut. propos.

+ Brachypodietalia distachyi Rivas-Martínez 1978

* Sedo-Ctenopsion gypsophilae Rivas Goday \& Rivas-Martínez ex Izco 1974

31. Chaenorrhino reyesii-Campanuletum fastigiatae Rivas-Martínez \& Izco in Izco 1974 corr. Alcaraz, Ríos, De la Torre, Delgado \& Inocencio 1998 (6220)

- avellinietosum festucoidis Cabezudo, Pérez Latorre \& Casimiro-Soriguer 2013 [Pastizales terofíticos gipsófíticos antequeranos]

* Omphalodion commutatae Rivas Martínez, Izco \& Costa in Izco 1973 corr. Pérez Raya 1988

32. Arenarietum arundanae Pérez Latorre \& Cabezudo in Pérez Latorre, P. \& D. Navas, Gil \& Cabezudo 1998 [Nanopastizal efímero, dolomitícola, en suelos arenosos] (6220)

* Brachypodion distachyi Rivas-Martínez 1978 33. Sedo caespitosii-Crassuletum tillaeae Rivas Goday 1958 (6220)

- poetosum bulbosae Pérez Latorre \& Cabezudo in Pérez Latorre, Caballero, Casimiro-Soriguer, Gavira \& Cabezudo 2008 [Pastizal anual, crasifolio, pastoreado]

34. Violo demetriae-Jonopsidietum prolongoi Asensi, Díez-Garretas \& Esteve 1979 (6220) - jonopsidetosum [Pastizal anual fugaz, de litosuelos calizos]
35. Saxifrago tridactylitae-Hornungietum petraeae Izco 1974 [Pastizal anual tardoinvernal sobre gravas dolomíticas] (6220)

* Ranunculion bullati Pérez Latorre \& Cabezudo in Pérez Latorre, Caballero, Casimiro-Soriguer, Gavira \& Cabezudo 2008

36. Scillo autumnalis-Ranunculetum bullati Pérez Latorre \& Cabezudo in Pérez Latorre, Caballero, Casimiro-Soriguer, Gavira \& Cabezudo 2008 [Pastizal geofítico otoñal] (6220)

VIIb. Pastizales y prados vivaces xerofíticos y mesofíticos

FESTUCO-BROMETEA Br. - Bl. \& Tüxen ex Br. - B1. 1949

+ Brachypodietalia phoenicoides (Br. - B1. 1931) Molinier 1934

37. Comunidad de Brachypodium phoenicoides y Achnatherum bromoides BC [Herbazales graminoides de suelos margosos húmedos hasta final de primavera]

FESTUCO HYSTRICIS-ONONIDETEA STRIATAE Rivas-Martínez, T.E. Díaz, F. Prieto, Loidi \& Penas 2002

+ Festuco hystricis-Poetalia ligulatae Rivas Goday \& Rivas-Martínez 1963

* Sideritido fontquerianae-Arenarion aggregatae Rivas Goday \& Borja 1961 corr. Rivas Martínez, T. E. Díaz, Fernández González, Izco, Loidi, Lousa \& Penas 2002

38. Comunidad de Festuca segimonensis y Koeleria filifolia [Pastizal psicroxerófilo graminoide, supramediterráneo, torcalense]

POETEA BULBOSAE Rivas Goday \& Rivas-Martínez in Rivas-Martínez 1978

+ Poetalia bulbosae Rivas Goday \& Rivas-Martínez in Rivas Goday \& Ladero 1970

* Plantaginion serrariae Galán de Mera, Morales \& Vicente Orellana 2000

39. Thrincio hispidae-Poetum bulbosae Pérez Latorre, Casimiro-Soriguer \& Cabezudo ass. 
nova [Majadales basófilos sobre margocalizas y arcillas, torcalenses, subbéticos y rondeños] (6310)

LYGEO SPARTI-STIPETEATENACISSIMAE Rivas-Martínez 1978

+ Lygeo sparti-Stipetalia tenacissimae Br-Bl. \& O. Bolós 1958 em. Rivas-Martínez 1978

* Thero-Brachypodion Br. - B1. 1925

40. Cerastio gibraltarici-Brachypodietum retusi Díez Garretas \& Asensi in Rivas Martínez et al. 2011 (6220)

- brachypodietosum retusi [Yesquerales xerófilos basófilos]

* Stipion tenacissimae Rivas-Martínez 1978

41. Thymo gracilis-Stipetum tenacissimae Pérez Raya \& Molero 1988 [Espartales]

- thymetosum capitati Pérez Latorre, Casimiro Soriguer \& Cabezudo subass. nova [Espartales termófilos]

42. Comunidad de Celtica gigantea [Berceales de talla elevada sobre calizo-dolomías]

* Festucion scariosae Martínez Parras, Peinado \& Alcaraz 1983

43. Helictotricho filifolii-Festucetum scariosae Martínez Parras, Peinado \& Alcaraz 1983 [Lastonares supra-mesomediterráneos]

VIIc. Vegetación de praderas antropizadas de siega y pastoreo

MOLINIO-ARRHENATHERETEA R. Tx. 1937

44. Comunidad de Holcus lanatus y Avena barbata DC [Prados graminoides de suelos húmedos hasta primavera]

+ Holoschoenetalia Br.-Bl. (1931) 1947

* Molinio-Holoschoenion Br.-Bl. (1931) 1947

45. Holoschoenetum vulgaris $\mathrm{Br}$.-B1. ex Tchou 1948 [Juncales subnitrófilos de junco churrero] (6420)

* Deschampsion mediae Br.-B1. In Br. - Bl., Roussine \& Nègre 1952

46. Stachydo officinalis-Eryngietum caespitiferi Pérez Latorre, Casimiro-Soriguer
\& Cabezudo 2014 corr. hoc loco [Praderas hemicriptofítico - geofíticas de pequeña talla, verticícolas, edafohigrófilas, Torcalenses] - var. con Eryngium aquifolium [Variante mesomediterránea]

47. Comunidad de Festuca segimonensis y Eryngium caespitiferum [Pastizales perennes de baja talla, en suelos temporalmente húmedos, supramediterráneos]

+ Plantaginetalia majoris R. Tx. \& Preising in R. Tx. 1950 em Rivas-Martínez 1987

* Trifolio fragiferi-Cynodontion Br. - B1. \& O. Bolòs 1958

48. Comunidad de Agrostis stolonifera y Trifolium fragiferum

49. Comunidad de Carex divisa BC [Herbazal higrófilo, subnitrófilo, de borde de lagunas]

* Mentho-Juncion inflexi De Foucault 1984

50. Comunidad de Juncus inflexus [Juncales nitrófilos]

+ Phalaridetalia coerulescentis A. Galán, Deil, Haug \& Vicente Orellana 1997

* Gaudinio fragilis-Hordeion bulbosi A. Galán, Deil, Haug \& Vicente Orellana 1997

51. Elymo repentis-Phalaridetum coerulescentis Pérez Latorre, Galán \& Cabezudo in Pérez Latorre, P. Navas, D. Navas, Y. Gil \& Cabezudo 1998 [Herbazal verticícola temporihigrófilo] (6420)

- phaladiretosum coerulescentis

- var. con Eryngium caespitiferum [Variante pastoreada/pisoteada]

- var. con Oenanthe globulosa [Variante con encharcamiento temporal]

52. Comunidad de Festuca mediterranea BC sensu Pérez Latorre, Casimiro-Soriguer Solanas, García Sánchez \& Cabezudo 2014 [Praderas graminoides termófilas de suelos arcillosos temporalmente húmedos] (6420)

+ Agrostidetalia castellanae Rivas Goday in Rivas-Martínez, Costa, Castroviejo \& E. Valdés 1980

* Agrostion castellanae Rivas Goday 1958 corr. Rivas Goday \& Rivas-Martínez 1963

53. Gaudinio fragilis-Agrostietum castellanae 
Rivas Martínez \& Belmonte 1985

- festucetosum amplae Pérez Latorre, CasimiroSoriguer \& Cabezudo subass. nova [Vallicares en suelos arcillosos húmedos] (6420)

\section{Vegetación serial sufruticosa, fruticosa y arbustiva}

VIIIa. Vegetación de brezales y matorrales

CISTO-LAVANDULETEA Br.-B1. in Br.-B1., Molinier \& Wagner 1940

+ Lavanduletalia stoechadis Br.-Bl. in Br.-B1., Molinier \& Wagner 1940

* Calicotomo-Cistion ladaniferi Br. - Bl. (1931) 1940 em. Rivas Martínez 1979

** Genistenion umbellatae Peinado, Alcaraz \& Martínez Parras 1992

54. Lavandulo stoechadis-Genistetum equisetiformis Rivas Goday \& Rivas-Martínez 1969

- thymetosum capitati Martínez Parras, Peinado \& Alcaraz 1986 [Jaguarzal sobre areniscas silíceas]

55. Comunidad de Cistus ladanifer y Ulex parviflorus sensu Pérez Latorre, Caballero, Casimiro-Soriguer, Gavira \& Cabezudo (2008) [Jarales sobre areniscas silíceas en zonas incendiadas-aterrazadas]

CISTO-MICROMERIETEA JULIANAE Oberdorfer 1954

+ Rosmarinetalia officinalis Br.-B1. ex Molinier 1934

* Saturejo micranthae-Thymbrion capitati Rivas-Goday \& Rivas-Martínez 1969

** Saturejo micranthae-Thymbrenion capitati

56. Genisto speciosae-Ulicetum parviflorii Rivas Goday \& Rivas-Martínez ex Pérez Latorre y Cabezudo 2009 nom. inv. propos. (5330)

- ulicetosum parviflorii [Matorrales calcícolas, mesomediterráneos, torcalenses]

- lavanduletosum lanatae Rivas Goday \& Rivas Martínez ex Pérez Latorre, Casimiro-
Soriguer \& Cabezudo 2014 [Matorrales dolomitícolas torcalenses]

- var. con Teucrium webbianum sensu Pérez Latorre, Casimiro-Soriguer. García-Sánchez \& Cabezudo (2014) [Variante orófila]

57. Genisto equisetiformis-Cytisetum fontanesii Rivas Goday \& Rivas-Martínez ex Pérez Latorre, Casimiro-Soriguer \& Cabezudo 2014 [Matorrales sobre margocalizas mesomediterráneos, antequeranos] (5330)

** Fumano hispidulae-Hippocrepidenion bourgaei Pérez Latorre, Casimiro-Soriguer \& Cabezudo suball. nova

58. Hippocrepido bourgaei-Anthyllidetum cytisoidis Pérez Latorre, Casimiro-Soriguer \& Cabezudo ass. nova [Matorrales antequeranos sobre yesos] (5330)

- anthillidetosum cytisoidis

- var. con Thymus capitatus [Variante termófila]

+ Erinacetalia anthyllidis Quézel 1951

* Xeroacantho-Erinaceion anthyllidis (Quézel 1953) O. Bolòs 1967

59. Festuco segimonensis-Erinaceetum anthyllidis Pérez Latorre, Casimiro-Soriguer \& Cabezudo ass. nova [Piornal xeroacántico, supra-mesomediterráneo, torcalense] (4090)

VIIIb. Vegetación serial arbustiva y de margen de bosque

CYTISETEA SCOPARIO-STRIATII Rivas Martínez 1974

+ Cytisetalia scopario-striatii Rivas Martínez 1974

* Retamion sphaerocarpae Rivas-Martínez 1981

60. Retamo sphaerocarpae-Genistetum speciosae Rivas Martínez ex Martínez Parras, Peinado y Alcaraz, 1983 [Retamares basófilos mesomediterráneos]

* Adenocarpion decorticantis (Rivas-Martínez \& F. Valle ex F. Valle 1985) Rivas-Martínez, Fernández-González \& Loidi 1999

61. Genisto speciosae-Cytisetum reverchonii F. Valle 1987 [Escobonales basófilos supra- 
mesomediterráneos]

RHAMNO-PRUNETEA Rivas Goday \& Borja ex Tüxen 1962

+ Prunetalia spinosae Tüxen 1952

* Pruno-Rubion ulmifolii O. Bolòs 1954

** Pruno-Rubenion ulmifolii

62. Spartio juncei-Rubetum ulmifolii Pérez Latorre \& Cabezudo in Pérez Latorre, Caballero, Casimiro-Soriguer, Gavira \& Cabezudo 2008 [Zarzal con gayumbas]

- var. con Rosa sempervirens sensu Pérez Latorre, Caballero, Casimiro-Soriguer, Gavira \& Cabezudo (2008) [Variante termófila]

- var. con Prunus insititia [Variante torcalense mesófila]

- Forma con Crataegus monogyna [Espinares arbustivos abiertos]

* Lonicero arboreae-Berberidion hispanicae O. Bolòs 1954

63. Lonicero arboreae-Crataegetum granatensis O. Bolòs 1954 nom invers. propos. [Espinares caducifolios microfanerofíticos supramediterráneos]

64. Pruno mahalebo-Berberidetum hispanicae Asensi \& Rivas-Martínez 1979

- prunetosum postratae Pérez Latorre \& Cabezudo in Pérez Latorre, P. Navas, D. Navas, Y. Gil \& Cabezudo 1998 [Espinares arbustivos nanofanerofíticos y postrados, supramediterráneos]

65. Comunidad de Cytisus reverchonii y Rhamnus infectoria [Espinares postrados de lapiaces kársticos venteados]

\section{Vegetación potencial forestal (bosques), preforestal (arbustedas), semidesértica y desértica}

IXa. Arbustedas y bosques palustres, quionófilos o colonizadores riparios

NERIO-TAMARICETEA Br.-Bl. \& O. Bolòs 1958

+ Tamaricetalia africanae Br.-Bl. \& O. Bolòs
1958 em. Izco, Fernández-González \& Molina 1984

* Rubo ulmifolii-Nerion oleandri O. Bolòs 1985 66. Rubo ulmifolii-Nerietum oleandri $\mathrm{O}$. Bolòs 1956 [Adelfares] (92D0)

SALICI-POPULETEA (Rivas-Martínez \& Cantó ex Rivas-Martínez et al. 1991) Rivas-Martínez \& Cantó 2002

+ Populetalia albae Br.-Bl. ex Tchou 1948

* Populion albae Br.-Bl. ex Tchou 1948

** Fraxino angustifoliae-Ulmenion minoris Rivas Martínez 1975

67. Ficario ranunculoidis-Fraxinetum angustifoliae Rivas-Martínez \& Costa in Rivas-Martínez, Costa, Castroviejo y Valdés 1980 (91B0)

- salicetosum pedicellatae Díez-Garretas, Cuenca \& Asensi 1986, raza bética con Spartium junceum [Fresnedas con sauces pedicelados, raza de la provincia Bética]

- var. con Nerium oleander sensu Pérez Latorre Casimiro-Soriguer, Gavira \& Cabezudo 2012 [Variante termófila]

- var. con Ficus carica [Variante de surgencias kársticas]

68. Biaro carratracensis-Ulmetum minoris Rivas-Martínez \& Molero 2011 [Olmedas] (91B0)

IXb. Vegetación climatófila y edafófila potencial mediterránea y eurosiberiana

QUERCETEA ILICIS Br.-B1. 1947

+ Quercetalia ilicis Br.-Bl. ex Molinier 1934 em. Rivas-Martínez 1975

* Quercion broteroi Br.-B1., P. Silva \& Rozeira 1956 corr. Ladero 1974 em. Rivas-Martínez 1975

** Paeonio broteroi-Quercenion rotundifoliae Rivas Martínez in Rivas Martínez, Costa e Izco 1986

69. Paeonio coriaceae-Quercetum rotundifoliae Rivas Martínez 1975 (9340)

- quercetosum rotundifoliae [Encinares 
mesomediterráneos basófilos]

- var. con Quercus suber sensu Pérez Latorre, P. Navas, D. Navas, Y. Gil \& Cabezudo 1998 [Variante con alcornoques sobre vulcanitas]

- quercetosum fagineae Rivas Martínez 1964 em. Rivas Goday \& Rivas Martínez 1971 [Encinares con quejigos]

- pistacietosum lentisci Pérez Latorre, Casimiro-Soriguer \& Cabezudo subass. nova [Encinares termófilos]

70. Viburno tini-Quercetum fagineae Torres \& Cano in Cano et al., 2001 [Quejigares termófilos sobre margocalizas] (9240)

* Querco-Oleion sylvestris Barbero, Quèzel \& Rivas Martínez 1981

71. Tamo communis-Oleetum sylvestris Benabid ex Pérez Latorre, Galán de Mera, Deil \& Cabezudo 1996 (9320)

- var. con Pistacia terebinthus sensu Pérez Latorre, Caballero, Casimiro-Soriguer, Gavira \& Cabezudo (2009) [Acebuchales subrupícolas] + Pistacio lentisci-Rhamnetalia alaterni Rivas-Martínez 1975

* Rhamno lycioidis-Quercion cocciferae Rivas Goday ex Rivas Martínez 1975

72. Crataego monogynae-Quercetum cocciferae Martínez Parras, Peinado \& Alcaraz 1985

- quercetosum cocciferae [Coscojares mesomediterráneos basófilos]

- var. con Pistacia lentiscus sensu Pérez Latorre Casimiro-Soriguer, Gavira \& Cabezudo 2012 [Variante termófila]

QUERCO-FAGETEA Br.-Bl. \& Vlieger in Vlieger 1937

+ Quercetalia pubescentis Klika 1933

* Aceri granatensis-Quercion fagineae (Rivas Goday, Rigual \& Rivas Martínez in Rivas Goday et al. 1960) Rivas Martínez 1987

73. Vinco difformis-Quercetum fagineae Pérez Latorre \& Cabezudo in Pérez Latorre, Caballero, Casimiro-Soriguer, Gavira \& Cabezudo 2009 (9240)

- var. con Quercus alpestris [Variante relicta con quejigo de montaña]

- quercetosum fagineae [Quejigales mesomediterráneos]

- var. con Fraxinus angustifolia sensu Pérez Latorre, Caballero, Casimiro-Soriguer, Gavira \& Cabezudo (2009) [Variante verticícolohigrófila con fresnos]

- aceretosum monspessulani Pavón, Hidalgo \& Pérez Latorre 2013 [Variante mesófila con arces]

- var. con Pistacia terebinthus [Variante karsticícola con arces y cornicabras]

AGRADECIMIENTOS. Agradecemos a los Drs. S. Talavera, J. A. Devesa, A. Pujadas, C. Romero Zarco y P. Garcia Murillo y a la Lda. G. Martínez por su ayuda en la identificación de material dudoso. A los Agentes de Medio Ambiente de la Junta de Andalucía de Antequera y Alfarnate por facilitarnos el tránsito por la ZEC. Al gestor de la finca La Fresneda y al propietario de la finca El Malagueño por permitirnos el aceso a sus propiedades.

\section{ANEXO I}

\section{PTERIDOFITOS}

\section{ASPLENIACEAE}

*Asplenium petrarchae subsp. petrarchae (ANTHOS)

Asplenium ruta-muraria subsp. ruta-muraria

Asplenium trichomanes subsp. pachyrachis

Asplenium trichomanes subsp. quadrivalens

Ceterach officinarum subsp. officinarum

ATHYRIACEAE

Cystopteris dickieana

Cystopteris fragilis subsp. fragilis

EQUISETACEAE

Equisetum ramosissimum

HEMIONITIDACEAE

Cosentinia vellea

POLYPODIACEAE

Polypodium cambricum

GIMNOSPERMAS

CUPRESSACEAE

Juniperus oxycedrus subsp. oxycedrus 
\#Pinus halepensis

ANGIOSPERMAS

ACERACEAE

Acer monspessulanum

AMARYLLIDACEAE

Lapiedra martinezii

Narcissus albicans

Narcissus assoanus

Narcissus elegans

Narcissus pseudonarcissus subsp. nevadensis

Narcissus papyraceus

ANACARDIACEAE

Pistacia lentiscus

Pistacia terebinthus

APOCYNACEAE

\#Nerium oleander

Vinca difformis

ARACEAE

Arisarum simorrhinum

Arum italicum

Biarum arundanum

Biarum carratracense

ARALIACEAE

Hedera helix subsp. helix

Hedera helix subsp. rhizomatifera

ARISTOLOCHIACEAE

Aristolochia baetica

Aristolochia paucinervis

BERBERIDACEAE

Berberis hispanica

BORAGINACEAE

*Alkanna tinctoria (MA)

Cynoglossum cheirifolium subsp. cheirifolium

Cynoglossum cheirifolium subsp. heterocarpum

Cynoglossum clandestinum

Echium boissieri

Echium flavum

\#Echium plantagineum

*Lithodora fruticosa (ANTHOS)

Myosotis ramosissima subsp. globularis

Myosotis ramosissima subsp. ramosissima

Neatostema apulum

Nonea vesicaria

Omphalodes commutata

Omphalodes linifolia

CAMPANULACEAE

Campanula cabezudoi

*Campanula erinus (SEV, MA)
Campanula fastigiata

Campanula mollis

Campanula rapunculus

Campanula rotundifolia subsp. hispanica

Legousia falcata

Legousia hybrida

Legousia scabra

CAPRIFOLIACEAE

Lonicera arborea

Lonicera etrusca

Lonicera implexa

Lonicera periclymenum subsp. hispanica

Sambucus nigra

CARYOPHYLLACEAE

Arenaria armerina subsp. armerina

Arenaria arundana

Arenaria hispanica

Arenaria leptoclados

Arenaria serpyllifolia

Cerastium gibraltaricum var. lanuginosum

Cerastium glomeratum

\#Cerastium pumilum

Cerastium semidecandrum

Dianthus anticarius

Dianthus brachyanthus

Dianthus broteri

Dianthus gaditanus

Dianthus hispanicus

Herniaria cinerea

Herniaria glabra

Minuartia hybrida subsp. hybrida

Minuartia mediterranea

Moehringia pentandra

Paronychia argentea

Petrorhagia nanteuilii

Petrorhagia prolifera

Polycarpon tetraphyllum

Silene andryalifolia

Silene colorata

Silene cretica

Silene inaperta subsp. inaperta

Silene latifolia

Silene mellifera

Silene nocturna

Silene secundiflora

Silene tridentata

Silene vulgaris subsp. commutata

Silene vulgaris subsp. vulgaris

Stellaria media

Stellaria pallida 
Velezia rigida

\section{CHENOPODIACEAE}

Chenopodium vulvaria

CISTACEAE

\#Cistus albidus

Cistus ladanifer subsp. africanus

Cistus monspeliensis

\#Cistus salviifolius

Fumana ericifolia

Fumana hispidula

Fumana thymifolia

Helianthemum aegyptiacum

Helianthemum angustatum

Helianthemum apenninum subsp. apenninum

Helianthemum apenninum subsp. cavanillesianum

Helianthemum apenninum subsp. stoechadifolium

Helianthemum apenninum subsp. suffruticosum

\#Helianthemum asperum

Helianthemum cinereum subsp. cinereum

Helianthemum cinereum subsp. rotundifolium

Helianthemum hirtum

Helianthemum ledifolium

Helianthemum marifolium subsp. andalusicum

Helianthemum marifolium subsp. marifolium

Helianthemum nummularium

Helianthemum salicifolium

Helianthemum sanguineum

Helianthemum syriacum

Tuberaria guttata

COMPOSITAE

Achillea ageratum

Anacyclus clavatus

Andryala integrifolia

Andryala ragusina var. ragusina

Anthemis arvensis

Anthemis cotula

Anthemis pedunculata

Asteriscus aquaticus

Atractylis cancellata

\#Bellis microcephala

Bellis perennis

Bellis sylvestris

Bombycilaena discolor

*Calendula arvensis (SEV)

Calendula suffruticosa subsp. suffruticosa

Carduncellus caeruleus

Carduus platypus subsp. granatensis

Carduus pycnocephalus

Carduus tenuiflorus

Carlina gummifera
Carlina hispanica

Carlina racemosa

Carthamus creticus

Carthamus lanatus

Catananche caerulea

Centaurea aspera subsp. aspera

Centaurea calcitrapa

Centaurea castellanoides subsp. arundana

Centaurea clementei

Centaurea diluta

Centaurea graminifolia

Centaurea melitensis

Centaurea ornata

Centaurea prolongoi

Centaurea pullata subsp. pullata

Centaurea sulphurea

Chamaemelum fuscatum

Cichorium intybus

Cirsium echinatum

Crepis albida

Crepis foetida subsp. foetida

Crepis pulchra

Crepis vesicaria subsp. taraxacifolia

Crupina crupinastrum

*Crupina vulgaris (ANTHOS)

Cynara baetica subsp. baetica

Cynara cardunculus subsp. flavescens

Cynara humilis

*Dittrichia viscosa subsp. viscosa (COA)

\#Doronicum plantagineum

Echinops strigosus

Filago pygmaea subsp. pygmaea

Filago pyramidata

Filago ramosissima

Galactites tomentosa

Geropogon hybridus

Glossopappus macrotus

Hedypnois rhagadioloides

Helichrysum italicum subsp. serotinum

\#Helminthotheca echioides

Hieracium amplexicaule

Hieracium baeticum

Hieracium texedense

Hyoseris radiata

Hypochaeris achyrophorus

Hypochaeris radicata

Inula montana

Jasonia tuberosa

Klasea flavescens subsp. leucantha

Klasea pinnatifida 
*Lactuca tenerrima (SEV)

Lactuca viminea subsp. chondrilliflora

Lactuca virosa subsp. virosa

\#Logfia gallica

Mantisalca salmantica

Micropus supinus

Notobasis syriaca

Onopordum illyricum subsp. illyricum

Onopordum macracanthum

Pallenis spinosa var. aurea

Pallenis spinosa var. spinosa

Phagnalon rupestre

Phagnalon saxatile

Phagnalon sordidum

Ptilostemon hispanicus

Pulicaria odora

Reichardia intermedia

Rhagadiolus edulis

Rhagadiolus stellatus

Rhaponticum coniferum

Santolina chamaecyparissus

Santolina rosmarinifolia subsp. canescens

Scolymus hispanicus

*Scolymus maculatus (ANTHOS)

Scorzonera angustifolia var. angustifolia

Scorzonera hispanica var. crispatula

Scorzonera laciniata

Senecio minutus

Senecio vulgaris

\#Silybum marianum

Sonchus asper subsp. asper

Sonchus tenerrimus

Staehelina dubia

Taraxacum laevigatum

Taraxacum obovatum

Thrincia hispida

Thrincia tingitana

Thrincia tuberosa

Tolpis umbellata

Tragopogon porrifolius

Tragopogon pratensis

Urospermum picroides

Xanthium spinosum

Xeranthemum cylindraceum

Xeranthemum inapertum

CONVOLVULACEAE

Convolvulus arvensis

\#Convolvulus lanuginosus

Convolvulus lineatus

Convolvulus meonanthus
\#Convolvulus tricolor

\#Cuscuta epithymum

*Cuscuta planiflora (SEV)

CRASSULACEAE

Pistorinia hispanica

Sedum acre

Sedum album

Sedum amplexicaule subsp. amplexicaule

Sedum caespitosum

Sedum dasyphyllum

Sedum gypsicola

Sedum mucizonia

*Sedum sediforme (SEV, ANTHOS)

Umbilicus gaditanus

CRUCIFERAE

Alliaria petiolata

Alyssum alyssoides

Alyssum simplex

Arabis auriculata

Arabis planisiliqua

Arabis serpyllifolia

Arabis verna

Biscutella auriculata

Biscutella frutescens

Biscutella variegata

Camelina microcarpa

Capsella bursa-pastoris

Cardamine hirsuta

Clypeola jonthlaspi subsp. jonthlaspi

Clypeola jonthlaspi subsp. microcarpa

Coincya monensis subsp. cheiranthos

Coronopus squamatus

Crambe filiformis

Diplotaxis viminea

Draba hispanica hispanica

Erophila verna

*Erucastrum virgatum subsp. baeticum (ANTHOS)

Hesperis laciniata

Hormathophylla longicaulis

Hormathophylla spinosa

Hornungia petraea subsp. petraea

*Iberis carnosa subsp. granatensis (EMMA)

Iberis nazarita

Iberis saxatilis subsp. cinerea

Ionopsidium prolongoi

Lepidium calycotrichum subsp. anticarium

*Lepidium heterophyllum (COA)

Lepidium hirtum

Lobularia maritima subsp. maritima

Moricandia moricandioides subsp. giennensis 
Raphanus raphanistrum subsp. raphanistrum Rapistrum rugosum subsp. rugosum Rorippa nasturtium-aquaticum Sinapis alba subsp. alba Sinapis arvensis Sisymbrella aspera subsp. aspera Sisymbrium crassifolium Sisymbrium officinale Thlaspi arvense Thlaspi perfoliatum

\section{CUCURBITACEAE}

Bryonia dioica

\section{CYPERACEAE}

Carex cuprina

Carex distachya

Carex divisa

Carex divulsa subsp. divulsa

Carex divulsa subsp. leersii

Carex flacca

Carex halleriana

Carex hispida

Cyperus longus

Eleocharis palustris subsp. palustris

\#Scirpoides holoschoenus

\section{DIOSCOREACEAE}

Tamus communis

DIPSACACEAE

Cephalaria leucantha

Dipsacus fullonum

Lomelosia divaricata

Lomelosia stellata

Scabiosa atropurpurea

Scabiosa sicula

Scabiosa turolensis subsp. grosii

Scabiosa turolensis subsp. turolensis

EUPHORBIACEAE

Euphorbia characias subsp. characias Euphorbia clementei subsp. clementei Euphorbia exigua subsp. exigua \#Euphorbia hirsuta

Euphorbia nicaeensis subsp. nicaeensis

Euphorbia segetalis

Euphorbia serrata

Euphorbia squamigera

Mercurialis tomentosa

FAGACEAE

Quercus coccifera

Quercus faginea subsp. alpestris

Quercus faginea subsp. faginea

Quercus rotundifolia
Quercus suber

\section{GENTIANACEAE}

Blackstonia perfoliata

Centaurium majus subsp. majus

Centaurium pulchellum

Centaurium tenuiflorum subsp. tenuiflorum

GERANIACEAE

Erodium aethiopicum subsp. aethiopicum

Erodium brachycarpum

Erodium cheilanthifolium

Erodium cicutarium

Erodium malacoides subsp. malacoides

Erodium primulaceum

Erodium recoderii

Geranium columbinum

Geranium lucidum

Geranium malviflorum

Geranium molle

Geranium purpureum

\#Geranium rotundifolium

GRAMINEAE

Achnatherum bromoides

Aegilops geniculata

Aegilops neglecta

Aegilops triuncialis

Aegilops ventricosa

Agrostis castellana var. olivetorum

Agrostis stolonifera

Aira cupaniana

Aira uniaristata

Alopecurus arundinaceus

*Arrhenatherum album (ANTHOS)

Arrhenatherum elatius subsp. baeticum

Avellinia festucoides

* Avena barbata subsp. barbata (LEB)

Avena sterilis subsp. ludoviciana

Avena sterilis subsp. sterilis

Avenula bromoides subsp. bromoides

Avenula bromoides subsp. pauneroi

Avenula gervaisii subsp. arundana

Avenula gervaisii subsp. gervaisii

Brachypodium phoenicoides

Brachypodium retusum subsp. retusum

Brachypodium sylvaticum subsp. sylvaticum

Briza minor

Bromus diandrus

Bromus erectus

Bromus hordeaceus

Bromus intermedius

Bromus lanceolatus 
Bromus madritensis subsp. madritensis

Bromus rubens subsp. rubens

Bromus sterilis

Catapodium rigidum subsp. rigidum

Celtica gigantea subsp. gigantea

Cynodon dactylon

Cynosurus echinatus

Cynosurus effusus

Dactylis glomerata subsp. hispanica

Echinaria capitata

Elymus hispanicus

Elymus repens subsp. repens

Festuca ampla

Festuca baetica

Festuca capillifolia

Festuca elegans

Festuca fenas

Festuca iberica

Festuca mediterranea

Festuca patula

Festuca plicata

Festuca scariosa

Festuca segimonensis

Gastridium phleoides

Gastridium ventricosum

Gaudinia fragilis

Glyceria declinata

Helictotrichon sarracenorum

Holcus lanatus

Hordeum bulbosum

Hordeum geniculatum

Hordeum murinum subsp. leporinum

Hordeum murinum subsp. murinum

Koeleria filifolia

Koeleria vallesiana

Lagurus ovatus

Lolium perenne

Lolium rigidum

Macrochloa tenacissima

Melica bocquetii

Melica humilis

Melica magnolii

Melica minuta

Micropyrum tenellum var. tenellum

Milium vernale subsp. montianum

Narduroides salzmannii

Neoschischkinia reuteri

Phalaris brachystachys

Phalaris coerulescens

Phalaris paradoxa
Phleum bertolonii

\#Phragmites australis subsp. australis

Piptatherum coerulescens

*Piptatherum miliaceum (ANTHOS)

Piptatherum paradoxum

*Piptatherum thomasii (SEV)

Poa bulbosa

Poa flaccidula

Poa infirma

Poa pratensis

Poa trivialis

Polypogon maritimus subsp. maritimus

\#Polypogon monspelliensis

Polypogon viridis

Rostraria cristata

Trachynia distachya

Vulpia bromoides

Vulpia ciliata subsp. ciliata

Vulpia muralis

Vulpia myuros

Vulpia unilateralis

GUTTIFERAE

Hypericum perforatum subsp. angustifolium

Hypericum perforatum subsp. perforatum

Hypericum tomentosum

IRIDACEAE

Chamaeiris foetidissima

Crocus serotinus subsp. salzmannii

\#Gladiolus communis

Gladiolus italicus

Romulea ramiflora

\#Xiphion planifolium

Xiphion serotinum

Xiphion vulgare

JUNCACEAE

Juncus acutiflorus

Juncus articulatus subsp. articulatus

Juncus bufonius

Juncus fontanesii subsp. fontanesii

Juncus inflexus subsp. inflexus

Juncus sphaerocarpus

\#Luzula forsteri

LABIATAE

Acinos alpinus subsp. meridionalis

Ajuga iva

Ballota hirsuta

Cleonia lusitanica

Clinopodium vulgare

Lamium amplexicaule

Lavandula lanata 
Lavandula stoechas

Marrubium supinum

Marrubium vulgare

Mentha aquatica

Mentha pulegium

Mentha suaveolens

Micromeria graeca subsp. graeca

Nepeta tuberosa

Origanum virens

Phlomis herba-venti

Phlomis lychnitis

Phlomis purpurea

Prunella hyssopifolia

Prunella laciniata

Prunella vulgaris

Rosmarinus officinalis

Salvia verbenaca

*Sideritis hirsuta

Stachys circinata

Stachys germanica

Stachys ocymastrum

Stachys officinalis

\#Teucrium capitatum

Teucrium fruticans

Teucrium gnaphalodes

Teucrium lusitanicum subsp. lusitanicum

Teucrium pseudochamaepitys

Teucrium scordium subsp. scordium

Teucrium similatum

Teucrium webbianum

Thymbra capitata

Thymus $x$ arundanus

Thymus baeticus

Thymus mastichina subsp. mastichina

Thymus zygis subsp. gracilis

\section{LEGUMINOSAE}

*Anagyris foetida (BC, COA)

Anthyllis cytisoides

Anthyllis vulneraria subsp. arundana

Anthyllis vulneraria subsp. gandogeri

Anthyllis vulneraria subsp. maura

*Anthyllis vulneraria subsp. reuteri (GDA)

Argyrolobium zanonii subsp. zanonii

Astragalus echinatus

Astragalus glaux

Astragalus hamosus

Astragalus monspessulanus subsp. gypsophilus

Astragalus sesameus

Colutea hispanica

Cytisus arboreus subsp. catalaunicus
Cytisus fontanesii subsp. fontanesii

Cytisus grandiflorus subsp. grandiflorus

Cytisus scoparius subsp. reverchonii

Dorycnium pentaphyllum

\#Dorycnium rectum

Erinacea anthyllis subsp. anthyllis

Genista cinerea

Genista umbellata subsp. equisetiformis

Hedysarum boveanum subsp. europaeum

Hedysarum coronarium

Hedysarum glomeratum

Hedysarum spinosissimum

Hippocrepis bourgaei

Hippocrepis ciliata

Hippocrepis rupestris

Lathyrus cicera

Lathyrus latifolius

Lotus corniculatus subsp. carpetanus

Lotus corniculatus subsp. delortii

Lotus pedunculatus

Medicago arabica

Medicago doliata

Medicago littoralis

Medicago lupulina

Medicago minima

Medicago orbicularis

Medicago polymorpha

Melilotus sulcatus

Onobrychis matritensis

Ononis aragonensis

Ononis laxiflora

Ononis mitissima

*Ononis natrix (MA)

Ononis pusilla subsp. pusilla

Ononis speciosa

Ononis spinosa subsp. australis

Ononis viscosa subsp. porrigens

Pisum sativum subsp. elatius

\#Psoralea bituminosa

\#Retama sphaerocarpa

Scorpiurus muricatus

Scorpiurus sulcatus

Spartium junceum

Tetragonolobus conjugatus subsp. requienii

Tetragonolobus purpureus

\#Trifolium angustifolium

\#Trifolium arvense

Trifolium campestre

Trifolium fragiferum

Trifolium glomeratum 
Trifolium lappaceum

Trifolium leucanthum

Trifolium ligusticum

Trifolium pratense subsp. pratense

Trifolium repens subsp. repens

Trifolium resupinatum

\#Trifolium scabrum

Trifolium squamosum

Trifolium stellatum

Trifolium striatum subsp. striatum

Trifolium subterraneum subsp. subterraneum

Trifolium suffocatum

Trifolium tomentosum

Tripodion tetraphyllum

Ulex parviflorus subsp. parviflorus

Vicia cordata

Vicia onobrychioides

*Vicia parviflora (SEV)

Vicia pubescens

Vicia tenuifolia

Vicia vicioides

LILIACEAE

Allium ampeloprasum

Allium neapolitanum

Allium nigrum

Allium pallens subsp. pallens

Allium roseum

Allium sphaerocephalon subsp. sphaerocephalon

Allium stearnii

Asparagus acutifolius

Asparagus albus

Asparagus horridus

Asparagus officinalis

Asphodelus cerasiferus

Asphodelus macrocarpus subsp. rubescens

Colchicum lusitanum

Fritillaria lusitanica subsp. lusitanica

Gagea lacaitae

Hyacinthoides hispanica

Merendera androcymbioides

Merendera montana

Muscari atlanticum

Muscari baeticum

Muscari comosum

Muscari matritensis

Ornithogalum bourgaeanum

Ornithogalum narbonense

Ornithogalum pyrenaicum

Polygonatum odoratum

Ruscus aculeatus
Scilla autumnalis

Scilla peruviana

Tulipa sylvestris subsp. australis

Urginea maritima

LINACEAE

Linum austriacum subsp. collinum

Linum bienne

Linum jimenezii subsp. willkommii

Linum narbonense

Linum setaceum

Linum tenue

Linum trigynum

LYTHRACEAE

Lythrum junceum

Lythrum tribracteatum

MALVACEAE

Malva cretica subsp. althaeoides

Malva hispanica

Malva sylvestris

MORACEAE

\#Ficus carica

OLEACEAE

Fraxinus angustifolia

Jasminum fruticans

\#Olea europaea var. sylvestris

Phillyrea angustifolia

Phillyrea latifolia

ONAGRACEAE

Epilobium brachycarpum

ORCHIDACEAE

Aceras anthropophorum

Anacamptis pyramidalis

Epipactis microphylla

Himantoglossum hircinum

Ophrys apifera

Ophrys fusca

Ophrys lutea

Ophrys scolopax

Ophrys speculum

Ophrys tenthredinifera

Orchis collina

Orchis coriophora

Orchis langei

\#Orchis laxiflora

Orchis mascula

Orchis morio

Orchis papilionacea

Orchis ustulata

Serapias lingua

Serapias parviflora 


\author{
OROBANCHACEAE \\ Orobanche amethystea \\ Orobanche clausonis \\ Orobanche crenata \\ Orobanche gracilis subsp. deludens \\ Orobanche gracilis subsp. gracilis \\ Orobanche haenseleri \\ Orobanche hederae \\ Orobanche minor \\ PAEONIACEAE \\ Paeonia broteri \\ Paeonia coriacea
}

PAPAVERACEAE

*Fumaria capreolata (COA)

Fumaria macrosepala subsp. macrosepala

Fumaria officinalis var. officinalis

Fumaria petteri subsp. calcarata

Fumaria rupestris subsp. rupestris

\#Papaver rhoeas

Roemeria argemone

Sarcocapnos baetica

PLANTAGINACEAE

\#Plantago afra

Plantago albicans

Plantago bellardii

*Plantago lagopus (ANTHOS)

Plantago lanceolata

Plantago serraria

PLUMBAGINACEAE

Armeria villosa subsp. longiaristata

Plumbago europaea

POLYGALACEAE

Polygala monspeliaca

Polygala rupestris

POLYGONACEAE

Polygonum aviculare

Rumex angiocarpus

\#Rumex bucephalophorus

Rumex conglomeratus

Rumex crispus

Rumex induratus

Rumex intermedius

Rumex pulcher subsp. woodsii

PRIMULACEAE

Anagallis arvensis

\#Asterolinon linum-stellatum

Samolus valerandi

RANUNCULACEAE

Clematis flammula

Clematis vitalba
Delphinium emarginatum subsp. nevadense

Delphinium gracile

Delphinium staphisagria

Helleborus foetidus

Nigella damascena

Ranunculus arvensis

\#Ranunculus bulbosus subsp. aleae

Ranunculus bullatus

Ranunculus ficaria subsp. ficaria

Ranunculus macrophyllus

Ranunculus paludosus

Ranunculus parviflorus

Ranunculus peltatus subsp. peltatus

Ranunculus peltatus subsp. saniculifolius

Ranunculus pseudomillefoliatus

Ranunculus spicatus subsp. blepharicarpos

Ranunculus trilobus

RESEDACEAE

Reseda alba subsp. alba

Reseda lutea subsp. lutea

Reseda phyteuma

RHAMNACEAE

Rhamnus alaternus subsp. alaternus

Rhamnus infectoria

Rhamnus lycioides subsp. laderoi

Rhamnus oleoides subsp. oleoides

Rhamnus pumila

ROSACEAE

Amelanchier ovalis

Aphanes cornucopioides

Crataegus granatensis

Crataegus monogyna

Geum sylvaticum

Potentilla reptans

Prunus insititia

Prunus mahaleb

Prunus prostrata

Prunus spinosa

Rosa canina

Rosa micrantha

\#Rosa pimpinellifolia

Rosa pouzinii

Rosa sempervirens

Rubus ulmifolius

\#Sanguisorba hybrida

Sanguisorba verrucosa

Sorbus aria

RUBIACEAE

Asperula aristata subsp. scabra

Asperula arvensis 
Asperula hirsuta

\#Crucianella angustifolia

Galium aparine subsp. aparine

Galium lucidum subsp. lucidum

Galium minutulum

Galium mollugo subsp. erectum

Galium murale

Galium parisiense subsp. parisiense

Galium tricornutum

Galium verrucosum subsp. verrucosum

Galium verticillatum

Galium verum subsp. verum

Putoria calabrica

Rubia peregrina

Sherardia arvensis

\#Valantia hispida

RUTACEAE

Dictamnus albus

Ruta angustifolia

Ruta montana

SALICACEAE

Salix atrocinerea

Salix pedicellata

\section{SANTALACEAE}

Osyris alba

Thesium humifusum

SAXIFRAGACEAE

Saxifraga biternata

Saxifraga camposii subsp. camposii

Saxifraga dichotoma

Saxifraga reuteriana

Saxifraga tridactylites

\section{SCROPHULARIACEAE}

Anarrhinum laxiflorum

Antirrhinum graniticum

Chaenorhinum macropodum subsp. degenii

\#Chaenorhinum reyesii

Chaenorhinum rubrifolium subsp. rubrifolium

Chaenorhinum villosum subsp. granatense

Chaenorhinum villosum subsp. villosum

Erinus alpinus

Kickxia lanigera

Linaria amethystea

Linaria hirta

Linaria oblongifolia subsp. haenseleri

Linaria oblongifolia subsp. oblongifolia

Linaria verticillata subsp. anticaria

Parentucellia latifolia

Parentucellia viscosa

Scrophularia lyrata
Scrophularia sambucifolia

Scrophularia scorodonia

Scrophularia viciosoi

Verbascum giganteum subsp. giganteum

Verbascum rotundifolium subsp. haenseleri

Veronica anagallis-aquatica

Veronica arvensis

Veronica catenata

Veronica cymbalaria

Veronica hederifolia

Veronica polita

Smilacaceae

\#Smilax aspera

SOLANACEAE

Lycium europaeum

THELIGONACEAE

*Theligonum cynocrambe (SEV)

THYMELAEACEAE

\#Daphne gnidium

Daphne laureola

Thymelaea argentata

Thymelaea hirsuta

Thymelaea pubescens subsp. elliptica

ULMACEAE

Ulmus minor

\section{UMBELLIFERAE}

Ammi majus

Ammoides pusilla

Anthriscus caucalis

Apium nodiflorum

Bifora testiculata

Bunium macuca subsp. macuca

Bupleurum baldense

Bupleurum fruticosum

Bupleurum gibraltaricum

Bupleurum lancifolium

Bupleurum rigidum subsp. rigidum

Bupleurum spinosum

\#Capnophyllum peregrinum

Conopodium arvense

Conopodium thalictrifolium

Daucus carota subsp. carota

Daucus muricatus

Eryngium aquifolium

Eryngium aquifolium $x$ E. caespitiferum

Eryngium caespitiferum

Eryngium campestre

Ferulago granatensis

Foeniculum sanguineum

Foeniculum vulgare 
Kudmannia silicula

Lagoecia cuminoides

Margotia gummifera

Myrrhoides nodosa

Oenanthe globulosa

Oenanthe lachenalii

Opopanax chironium

Orlaya daucoides

Pimpinella tragium subsp. lithophila

Ridolfia segetum

Scandix australis

Scandix pecten-veneris

Scandix stellata

Smyrnium olusatrum

Smyrnium perfoliatum

Thapsia villosa

Tordylium maximum

Torilis arvensis

Torilis elongata

Torilis japonica

Torilis leptophylla

Torilis nodosa

\section{URTICACEAE}

Parietaria judaica

Urtica dubia

Urtica membranacea

Urtica urens

\section{VALERIANACEAE}

*Fedia cornucopiae (SALA)

Valeriana tuberosa

Valerianella coronata

*Valerianella locusta (MA)

VERBENACEAE

Verbena officinalis

Verbena supina

VIOLACEAE

Viola demetria

VITACEAE

Vitis sylvestris

\section{ZANNICHELLIACEAE}

Zannichellia palustris

\section{BIBLIOGRAFÍA}

AEDO, C. -2013- Narcissus L. En Castroviejo S. (Coord.) Flora Iberica: Plantas vasculares de la Península Ibérica e Islas Baleares. Pags., 340-397. Vol XX: Liliaceae-Agavaceae. Real Jardín Botánico. CSIC. Madrid.
APARICIO MARTÍNEZ, A. \& SILVESTRE DOMINGO, S. -1987- Flora del Parque Natural de la Sierra de Grazalema. Junta de Andalucía, Agencia de Medio Ambiente, Monografías del Medio Ambiente, Sevilla.

ASENSI A., B. DÍEZ GARRETAS y J. M. NIETO -2005- Torcal de Antequera-Desfiladero de Los Gaitanes. Guía Geobotánica. XX Jornadas de Fitosociología. Málaga. 87 pp.

ASENSI, A. \& J. M. NIETO CALDERA -1981Vegetación acuática, halófila y halonitrófila de la provincia de Málaga. Trabajos y Monografías del Departamento de Botánica de Málaga 2: 105-122.

BALSERA MEDINA, J. -1989- Mapa de suelos de Andalucía. CSIC-IARA. Madrid.

BAÑARES, Á., G. BLANCA, J. GÜEMES, J.C. MORENO \& S. ORTIZ (Eds.) -2004- Atlas y Libro Rojo de la Flora Vascular Amenazada de España. Dirección General de Conservación de la Naturaleza. Madrid.

BAÑARES, A., G. BLANCA, J. GÜEMES, J.C. MORENO \& S. ORTIZ (Eds.) -2010-. Atlas y Libro Rojo de la Flora Vascular Amenazada de España (Adenda 2010). Dirección General de Medio Natural y Política Forestal (Ministerio de Medio Ambiente, y Medio Rural y Marino)-Sociedad Española de Biología de la Conservación de Plantas. Madrid.

BECERRA PARRA, M., A. RIVAS RANGEL \& J. PEREÑA ORTIZ -2007- Sobre el estado de conservación de Scrophularia viciosoi A. Ortega \& Devesa (Scrophulariaceae) Acta Bot. Malacitana 32: 282-284

BLANCA G., B. CABEZUDO, J.E. HERNÁNDEZBERMEJO, C.M. HERRERA, J. MOLERO MESA, J. MUÑOZ \& B. VALDÉS -1999, 2000- Libro rojo de la flora silvestre amenazada de Andalucía. (2 vols.) Consejería de Medio Ambiente, Junta de Andalucía, Sevilla.

BLANCA, G. \& M. CUETO -2009- Hieracium L. En: G. BLANCA, B. CABEZUDO, M. CUETO, C. FERNANDEZ LOPEZ \& C. MORALES TORRES (eds.), Flora vascular de Andalucía Oriental. Vol.4. Consejería de Medio Ambiente. Junta de Andalucía. Sevilla.

BLANCA, G., B. CABEZUDO, M. CUETO, C. MORALES TORRES \& C. SALAZAR (eds.) -2011- Flora Vascular de Andalucía Oriental ( $2^{a}$ edición corregida y aumentada). Consejería 
de Medio Ambiente. Junta de Andalucía. Sevilla.

BLANCO CASTRO et al. -1997- Los bosques ibéricos. Una interpretación geobotánica. Ed. Planeta. Barcelona.

BOLÒS, O. -1954- De Vegetatione notulae I. Collect. Bot. 4(2): 253-286.

BRAUN-BLANQUET, J. -1979-. Fitosociología. Ed. Blume. Madrid.

CABEZUDO, B, J.A. DEVESA, R. TORMO, F. VAZQUEZ \& J.M. NIETO-CALDERA -1990Catálogo de las gramíneas malacitanas. Acta Bot. Malacitana 15: 91-123

CABEZUDO, B. \& S. TALAVERA (Coords.) -2005Lista Roja de la Flora Vascular de Andalucía. Consejería de Medio Ambiente. Junta de Andalucía. Sevilla.

CABEZUDO, B., A. V. PÉREZ LATORRE, D. NAVAS FERNÁNDEZ, O. GAVIRA y G. CABALLERO -2005- Contribución al conocimiento de la flora del Parque Natural de las Sierras Tejeda, Almijara y Alhama (MálagaGranada, España). Acta Bot. Malacitana 30: 55-110

CABEZUdo, B., A. V. PÉREZ LATORRE, P. NAVAS FERNÁNDEZ, Y. GIL JIMÉNEZ \& D. NAVAS FERNÁNDEZ -1998- Parque Natural de Sierra de las Nieves. Cartografía y evaluación de la flora y vegetación. Memoria de investigación. Departamento de Biología Vegetal. Universidad de Málaga. 367 pp.

CABEZUDO, B., A.V. PÉREZ LATORRE \& F. CASIMIRO-SORIGUER SOLANAS -2013Vegetación gipsícola del sector Antequerano (provincia Bética, Andalucía). Acta Bot. Malacitana 38: 193-217.

CABEZUDO, B., J. MOLERO MESA y A. V. PÉREZ LATORRE. -1998- Vegetación de Andalucía. En: Carmen Rodríguez Hiraldo (coord.). La Flora (tomo 3). Naturaleza de Andalucía (obra completa). Ediciones Giralda. Sevilla.

CABEZUDO, B., Y. GIL, D. NAVAS, P. NAVAS, Y A. V. PÉREZ LATORRE -2004- Scrophularia viciosoi A. Ortega \& Devesa in: Bañares Baudet, A. et al. (eds.) Atlas y Libro Rojo de la Flora Vascular Amenazada de España. Dirección General para la Biodiversidad, Publicaciones del O.A.P.N. Madrid.

CANO, E., C. PINTO-GOMES, F. VALLE, J. A. TORRES, A. GARCÍA FUENTES, C.
SALAZAR, M. MELENDO y S. MENDES -2001- Primera aproximación al conocimiento de los quejigares del sur de la Península Ibérica (Portugal y España). Quercetea 3: 175-182.

CANO, E., J. A. TORRES, A. CANO-ORTIZ \& R. J. MONTILLA -2005- Una nueva asociación de matorral para la alianza Lavandulo-Genistion boissieri en el sector Subbético. Lagascalia 25: 125-133.

CASIMIRO-SORIGUER SOLANAS, F., PÉREZ LATORRE, A.V., HIDALGO TRIANA, N., GARCÍA SÁNCHEZ, J., PAVÓN, M. \& CABEZUDO, B. -2013-Algunas plantas interesantes de Andalucía Oriental II. (MálagaGranada). Acta Bot. Malacitana 38: 202-207.

CASTROVIEJO, S. et al. (coord.) -1986-2015Flora iberica. Real Jardín Botánico. CSIC. Madrid.

CAVANILles, A. J. -1801- Anales de Ciencias Naturales, 3: 32.

CEBALLOS Y FERNANDEZ DE CORDOBA, L. \& C. VICIOSO -1932- Notas sobre Flora malagueña. Boletín de la Real Sociedad Española de Historia Natural 32 (8): 379-391.

CEBALLOS, L. \& C. VICIOSO -1933-Estudio sobre la vegetación y flora forestal de la provincia de Málaga. Inst. Forestal de Invest. y Exp. Madrid.

DE LEÓN LLAMAZARES, A. -1989Caracterización agroclimática de la provincia de Málaga. M. A. P. A.

DEVESA J. A., P. CATALÁN, J. MÜller, C. CEBOLLA \& E. ORTÚNEZ -2013- Checklist de Festuca L. (Poaceae) en la Península Ibérica. Lagascalia 33: 183-274.

DIERSCHKE, H. -1993-Grundlagen und Methoden der Planzensoziologie. Ulmer. Stuttgart.

FERNÁNDEZ CASAS, F. J. -2010- Narcissorum Notulae, XXI. Fontqueria 56(14): 125-126 [seorsim: 1-2]

FOCAULT, B. -1981-Réflexions su l'apprauvrissement des syntaxons aux limites chorologiques des unités phytosociologiques supérieurs et quelques unes de leurs consequences. Lazaroa 3: 75-100.

FONT QUER, P. \& C. PAU -1931- De flora occidentale adnotationes. Cavallinesia 4: 30

GALÁN DE MERA, A., R. MORALES ALONSO \& J.A. VICENTE ORELLANA -2000- Pasture communities linked to ovine stock. A synthesis 
of the Poetea bulbosae class in the western Mediterranean Region. Phytocoenologia 30 (2): 223-267.

GALÁN DE MERA, A., A. V. PÉREZ LATORRE y J. A. VICENTE ORELLANA-2003- Relaciones fitogeográficas entre el suroccidente de la Península Ibérica y el noroeste de África. Una propuesta de sectorización. Lagascalia 23: 27-52.

GBIF. (Global Biodiversity Information Facility) -2015, 2016- Herbarios y bases de datos consultadas: Anthos, IBB-CSIC-ICUB, BC, COA, EMMA, GDA, LEB, MA, MGC, SALA y SEV. http://www.gbif.org/dataset/. http://doi. org/10.15468/2gfyxk

GEHÚ, J. M. y S. RIVAS-MARTÍNEZ -1981Notions fondamentales de Phytosociologie. Syntaxonomie. Berichte der Internationalen Symposien der Internationalen Vereinigung für Vegetationskunde.

GÓMEZ MERCADO F. 2011- Vegetación y Flora de la Sierra de Cazorla. Guineana. Vol. 17: 1-481. Universidad del País Vasco.

GÓMEZ MERCADO, F., J. F. MOTA, J. PEÑAS, J. CABELLO y F. VALLE -2000- Vegetación del Parque Natural Sierra Subbética (Córdoba), en: J. M. Moreira (ed.). Reconocimiento Biofísico de Espacios Naturales Protegidos: Parque Natural de Las Sierras Subbéticas, pp. 197-288. Consejería de Medio Ambiente, Junta de Andalucía.

GUERRA, J. -1982- Catálogo de la flora vascular de la Sierra del Torcal de Antequera (Málaga). Inst. Est. Almerienses. Homenaje almeriense al botánico Rufino Sagredo: 105-120.

GUERRA, J., E. SALVO, J. M. NIETO y B. CABEZUDO -1988- Espacios de interés natural de la provincia de Málaga: II. Parque natural del Torcal de Antequera. Jábega 60: 75-80.

HIDALGO TRIANA, N. \& A. V. PÉREZ LATORRE -2013- Vegetación y flora de la Sierra de Cártama (Valle del Guadalhorce, Málaga, España). Acta Bot. Malacitana 38: 119-149.

IGME -1978- Mapa Geológico de España. Hoja de Colmenar. 17-43. CSG. Madrid.

IGME -1991- Mapa Geológico de España. Hoja de Archidona. 17-42. Gráficas Loureiro. Madrid.

JURY, J.L. (2002). Eryngium L. En: B. Vadés, M.Rejdali, A. Achhal El Kadmiri, J.L. Jury, J.M.Montserrat (eds.) Catalogue des plantes vasculaires du Nord du Maroc. Vol. I. CSIC. Madrid.

LOSA QUINTANA, J.M. \& F. PEREZ RAYA -1986-. Las comunidades rupícolas del sector Malacitano-Almijarense en Sierra Nevada (Granada, España). Bol. Real. Soc. Esp. Hist. Nat. 81: 51-59

MARTINEZ-PARRAS J. M. \& M. PEINADO LORCA -1990- Ensayo sobre la vegetacion rupicola basofila de la clase asplenietea trichomanis en la provincia corologica Bética. Acta Bot. Malacitana 15: 193-202

MARTÍNEZ-PARRAS, J.M., M. PEINADO \& F. ALCARAZ -1984- Estudio de la serie mesomediterránea basófila de la encina (PaeonioQuerceto rotundifoliae S). Lazaroa 5: 119-129.

MATEO SANZ G. -2007- Los géneros Hieracium y Pilosella en el ámbito de Flora Iberica. Borrador on-line en Flora Iberica.es

MORENO, J.C. (Coordinador) -2010- Lista Roja de la Flora Vascular Española. Web del Ministerio de Medio Ambiente y Medio Rural y Marino. Madrid

MOTA POVEDA, J.F., P. SÁNCHEZ GÓMEZ y J.S. GUIRADO ROMERO (Eds.) -2011- Diversidad vegetal de las yeseras ibéricas. El reto de los archipiélagos edáficos para la biología de la conservación. ADIF-Mediterráneo Asesores Consultores. Almería.

NIETO CALDERA, J. M., A. V. PÉREZ LATORRE y B. CABEZUDO -1991-. Biogeografía y series de vegetación de la provincia de Málaga (España). Acta Bot. Malacitana 16(2): 417-436.

NIETO FELINER G. -2000- Taxonomic notes on Eryngium (Apiaceae) from the West Mediterraneam. Anales del Jardín Botánico de Madrid. 58(2): 367-371

NIETO FELINER, G. -2003- Eryngium L. En: S Castroviejo (coord.) Flora Iberica. Vol. X. Araliaceae-Umbelliferae. Real Jardín Botánico, CSIC. Madrid

NIETO J. M., B. CABEZUDO, A. V. PÉREZ LATORRE, D. NAVAS, P. NAVAS y Y. GIL -1998- Apuntes para el estudio del paisaje vegetal de la provincia de Málaga. In Rebollo M., F. Serrano, J. M. Nieto y B. Cabezudo (Eds.). Itinerarios por Espacios Naturales de la provincia de Málaga. Servicio de publicaciones. Universidad de Málaga.

PAVÓN NÚÑEZ, M., N. HIDALGO TRIANA \& 
A. V. PÉREZ LATORRE -2013- Aportaciones al conocimiento de las comunidades de Pistacia terebinthus L. y de Acer monspessulanum L. en el sur de la Península Ibérica. Lagascalia 33: 299-311.

PAVÓN NÚÑEZ, M., A. V. PÉREZ LATORRE $\&$ N. HIDALGO TRIANA -2015-Novedades fitosociológicas y florísticas en el Parque Natural de Tejeda-Almijara y Alhama (Málaga-Granada, España). Acta Bot. Malacitana 40: 199-205.

PÉREZ LATORRE, A. V. -2010- Vegetación terrestre de la provincia de Málaga. Jábega 101: 28-44.

PÉREZ LATORRE A. V., P. NAVAS, D. NAVAS, Y. GIL \& B. CABEZUDO -1998- Datos sobre la Flora y Vegetación de la Serranía de Ronda (Málaga, España). Acta Bot. Malacitana 23:149-191.

PÉREZ LATORRE, A. V. \& B. CABEZUDO -2002-

La flora y el paisaje vegetal de la provincia de Málaga: importancia y conservación. Jábega 90: 25-39.

PÉREZ LATORREA. V., D. NAVAS FERNÁNDEZ, O. GAVIRA, G. CABALLERO \& B. CABEZUDO -2004- Vegetación del P. N. de las Sierras Tejeda, Almijara y Alhama. Acta Bot. Malacitana 29: 117-190.

PÉREZ LATORRE A. V., G. CABALLERO, F. CASIMIRO-SORIGUER SOLANAS, O. GAVIRA y B. CABEZUDO -2008- Vegetación del sector Malacitano-Axarquiense (comarca de la Axarquía, Montes de Málaga). Acta Bot. Malacitana 33: 215- 270.

PÉREZ LATORRE A. V., F. CASIMIROSORIGUER SOLANAS, O.GAVIRA \& B. CABEZUDO -2012- Vegetación de la Reserva de la Biosfera Sierra de las Nieves: Río Grande y Sierras Prieta y Blanquilla (Málaga, España). Acta Bot. Malacitana 37: 103 -140.

PÉREZ LATORRE A. V., G. CABALLERO, F. CASIMIRO-SORIGUER SOLANAS, O. GAVIRA \& B. CABEZUDO -2009- Vegetación de la Cordillera Antequerana Oriental (subsector Torcalense). Málaga-Granada (España). Acta Bot. Malacitana 34: 144-173.

PÉREZ LATORRE, A. V., A. GALÁN DE MERA y

B. CABEZUDO -2005- Notas sobre la vegetación de Andalucía. VI. Acta Bot. Malacitana 30: 231-234.

PÉREZ LATORRE, A. V., A. GALÁN DE MERA, P. NAVAS, D. NAVAS, Y. GIL \& B. CABEZUDO
-1999- Datos sobre la flora y la vegetación del Parque Natural de los Alcornocales (Cádiz-Málaga, España). Acta Bot. Malacitana 24: 133-184.

PÉREZ LATORRE, A. V., F. CASIMIRO SORIGUER-SOLANAS \& B. CABEZUDO -2015- Flora y vegetación de la Sierra de Alcaparaín (Málaga, España). Acta Bot. Malacitana 40: 107-156.

PÉREZ LATORRE, A.V., F. CASIMIROSORIGUER \& B. CABEZUDO -2004-Praderas higrófilas de Deschampsion mediae en el subsector Torcalense (sector Antequerano, Málaga, España). Acta Bot. Malacitana 39: 270-274.

PÉREZ LATORRE, A.V., F. CASIMIROSORIGUER SOLANAS, J. GARCÍA SÁNCHEZ \& B. CABEZUDO -2014- Flora y vegetación del Paraje Natural Desfiladero de los Gaitanes y su entorno (Málaga, España). Acta Bot. Malacitana 39: 129.

PÉREZ-LATORRE, A. V., M. PAVÓN-NÚÑEZ \& N. HIDALGO-TRIANA -2015- Vegetación higrófila de alta montaña con Sesleria argentea (Savi) Savi (Poaceae) en el sur de la península ibérica: Sierra Tejeda (Granada, Málaga). Anales de Biología 37: 11-24.

PÉREZ RAYA, F. \& J. MOLERO MESA -1988- El orden Lygeo spartii-Stipetalia tenacissimae en el sector Malacitano-Almijarense de Sierra Nevada (Granada, España). Ars Pharm. 29(2-3): 245-256.

PÉREZ RAYA, F. A. -1987- La vegetación en el sector Malacitano-Almijarense de Sierra Nevada. Universidad de Granada. Granada. $350 \mathrm{pp}$.

PÉREZ RAYA, F., J. M. LÓPEZ NIETO, J. MOLERO MESA y F. VALLE -1990- Vegetación de Sierra Nevada. Ayuntamiento de Granada y Universidad de Granada.

QUINTANAR, A. \& S. CASTROVIEJO -2013Taxonomic revisión of Koeleria (Poaceae) in the Western Mediterranean Basin and Macaronesia. Sistematic Botany 38: 1029-1061.

RAMÍREZ LÓPEZ, J. -2007- Narcissus elegans (Haworth) Spach (Amaryllidaceae), cita nueva para España continental. Acta Bot. Malacitana. 32: 262

RIVAS MARTÍNEZ, S. \& D. BELMONTE -1985Sobre el orden Agrostietalia castellanae. Lazaroa 
8: 417-419.

RIVAS MARTINEZ, S. -1987- Memoria y mapa de las series de vegetación de España (1: 400.000). ICONA. Madrid.

RIVAS MARTÍNEZ, S. -2007- Mapa de series, geoseries y geopermaseries de vegetación de España. Memoria del Mapa de Vegetación Potencial de España. Parte II. Itinera Geobot. 17: $1-436$.

RIVAS MARTÍNEZ, S. -2011- Mapa de series, geoseries y geopermaseries de vegetación de España. Memoria del Mapa de Vegetación Potencial de España. Parte II. Itinera Geobot. 18(1): 5-424.

RIVAS MARTÍNEZ, S., T.E. DÍAZ, F. FERNÁNDEZ GONZÁLEZ, J. IZCO, J. LOIDI y A. PENAS -2002-Vascular plant communities of Spain and Portugal. Itinera Geobot. 15(1, 2): 5-432.

ROMERO GARCIA A.T., G. BLANCA LOPEZ \& C. MORALES TORRES -1988- Revisión del genero Agrostis L. (Poaceae) en la Península Ibérica. Ruizia vol.7. Monografias del Real Jardín Botánico. CSIC. Madrid

ROMERO ZARCO, C. -1984- revisión del genero Helictotrichon Besser ex Schultes (Gramineae) en la Península Ibérica.I. Estudio taxonómico. Anales Jardin Botánico de Madrid 41(1):97-124 ROMERO ZARCO, C. -2015- Las gramíneas de la Península Ibérica e Islas Baleares. Colección Monografias de Botánica Ibérica, 15. Jolube Consultor Botanico y Editor. Jaca

SCHUHWERK, F. -1990- Relikte und Endemiten in Pflanzengesellschaften Bayerns- eine vorlaufige Ubersicht. Ber. Bayer. Bot. Ges. 61: 303-323.

SILVESTRE, S. -1987- Eryngium L. En: B. Valdés, S. Talavera \& E. Fernandez-Galiano (eds.) Flora Vascular de Andalucía Occidental. E. Ketres. Barcelona

SIVIM -2016- http://www.sivim.info/sivi/
EscriuSelectServlet?v8.

STÜBING G., J.B. PERIS, R. FIGUEROLA \& F. ESTESO -1993- Plant communities of the rice-fields of Valencia (Spain): A numerical approach. Fol. Bot. Misc. 9: 115-125.

TALAVERA, S. -1993- Arabis. In Castroviejo S. et al. (eds.). Flora Iberica. Vol IV. CruciferaeMonotropaceae. Real Jardín Botánico. CSIC. Madrid.

TALAVERA, S., M. TALAVERA \& C. SÁNCHEZ -2015- Los géneros Thrincia Roth y Leontodon L. (Compositae) en Flora Iberica. Acta Bot. Malacitana 40: 344-364

TRIANO, E. -2010- Nueva Flora del Subbético Cordobés. (Autoed. en CD).

VALDÉS, B., M. REJDALI, A. ACHHAL, J. L., JURY y J. M. MONSERRAT (Eds.) -2002Catalogue des Plantes Vasculaires du Nord du Maroc, incluant des clés d'identification. Biblioteca de Ciencias. CSIC. Madrid.

VALDÉS, B., S. TALAVERA y E. F. GALIANO (eds.) -1987- Flora vascular de Andalucia Occidental. Ed. Ketres. Barcelona.

VALLE, F. \& J. LORITE -2005- Datos botánicos aplicados a la Gestión del Medio Natural Andaluz IV. Anexo Cartográfico y Series de Vegetación Edafohigrófilas. Consejería de Medio Ambiente. Junta de Andalucía. Sevilla.

VILLAR L., J.A. SESÉ \& J.V. FERRÁNDEZ -1997/2001- Flora del Pirineo Aragonés vol. I y II. Instituto de Estudios Atoaragoneses \& Consejo de Protección de la Naturaleza de Aragón. Huesca

WEBER, H. E., J. MORAVEC \& J. P. THEURILLAT -2000- International Code of Phytosociological Nomenclature. J. Veg. Sci. 11: 739-768.

YUS RAMOS, R., M. A. TORRES y F. BOTELLA -2007- Por la Dorsal Bética. CEDER Axarquía. Diputación de Málaga, 299 pp. 